\title{
Distributed propulsion and ultra-high by-pass rotor study at aircraft level
}

A. T. Isikveren askin.isikveren@safran.fr

A. Seitz and J. Bijewitz

Bauhaus Luftfahrt e.V.

Ottobrunn

Germany

\section{A. Mirzoyan and A. Isyanov}

Central Institute of Aviation Motors (CIAM)

Moscow

Russia

\section{R. Grenon, O. Atinault and J.-L. Godard \\ ONERA - The French Aerospace Lab \\ Meudon \\ France}

\section{S. Stückl}

Airbus Group Innovations

Ottobrunn

Germany

\section{ABSTRACT}

This technical article discusses design and integration associated with distributed propulsion as a means of providing motive power with significantly reduced emissions and external noise for future aircraft concepts. The technical work reflects activities performed within a European Commission funded Framework 7 project entitled Distributed Propulsion and Ultra-high By-Pass Rotor Study at Aircraft Level, or, DisPURSAL. In this instance, the approach of distributed propulsion includes a Distributed Multiple-Fans Concept driven by a limited number of engine cores as well as one unique solution that integrates the fuselage with a single propulsor (dubbed Propulsive-Fuselage Concept) - both targeting entry-in-service year 2035+. Compared to a state-of-the-art, year 2000 reference aircraft, designs with tighter coupling between airframe aerodynamics and motive power system performance for medium-to-long-range operations indicated potentially a $40-45 \%$ reduction in $\mathrm{CO}_{2}$-emissions. An evolutionary, year 2035, conventional morphology gas-turbine aircraft was predicted to be $-33 \%$ in $\mathrm{CO}_{2}$-emissions.

†Now at Safran Tech, Châteaufort, France. 


\section{NOMENCLATURE}

\section{Symbols}

\begin{tabular}{|c|c|}
\hline $\mathrm{AOC}$ & Additional Operating Cost, USD \\
\hline BPR & Bypass Ratio (-) \\
\hline$c$ & wing chord length at given wing station, $\mathrm{m}$ \\
\hline$C D$ & drag coefficient $(-)$ \\
\hline$C L$ & lift coefficient (-) \\
\hline CNL & Cumulative Noise Level, EPNdB \\
\hline $\mathrm{COC}$ & Cash Operating Cost, USD \\
\hline$D$ & engine fan diameter, $\mathrm{m}$ \\
\hline$D_{\text {ing }}$ or $D_{\text {ingested }}$ & ingested drag, $\mathrm{kN}$ \\
\hline DC60 & circumferential distortion parametre assuming $60^{\circ}$ sector (-) \\
\hline DMC & Direct Maintenance Cost, USD \\
\hline $\begin{array}{l}D_{P} / F_{\text {oo }} \\
F P R \text { or } \mathrm{p}_{13} / \mathrm{p}_{2} \\
k\end{array}$ & $\begin{array}{l}\text { level of } \mathrm{NO}_{x} \text {-emissions, } \mathrm{g} / \mathrm{kN} \\
\text { Fan Pressure Ratio (-) } \\
\text { coefficient of proportionality (-) }\end{array}$ \\
\hline$L / D$ & Lift-to-Drag ratio (-) \\
\hline M & Mach number (-) \\
\hline MEW & Manufacturer's Empty Weight, kg \\
\hline MLW & Maximum Landing Weight, $\mathrm{kg}$ \\
\hline MTOW & Maximum Take-off Weight, kg \\
\hline $\mathrm{MV}_{\mathrm{CO} 2}$ & Metric Value of $\mathrm{CO}_{2}$-emissions, $\mathrm{kg}$ \\
\hline $\mathrm{MZFW}$ & Maximum Zero-Fuel Weight, kg \\
\hline OEW & Operating Empty Weight, kg \\
\hline PSC & Power Saving Coefficient (-) \\
\hline$S_{M f a n}$ & fan surge margin $(-)$ \\
\hline$S_{W}^{\text {Nitan }}$ & reference wing area, $\mathrm{m}^{2}$ \\
\hline$S_{\text {wet }}$ & wetted area, $\mathrm{m}^{2}$ \\
\hline$S_{\text {wet,ing }}$ & ingested wetted area, $\mathrm{m}^{2}$ \\
\hline $\mathrm{T}$ & net thrust after adjustment for ingested drag, $\mathrm{kN}$ \\
\hline TOFL & Take-off Field Length, m \\
\hline TSFC & Thrust Specific Fuel Consumption, g/kN.s \\
\hline$V_{R E F}$ & approach reference speed, KCAS \\
\hline$W_{\text {fuel }}$ & block fuel, $\mathrm{kg}$ \\
\hline$W_{\text {fuel,o }}$ & initial or baseline block fuel, $\mathrm{kg}$ \\
\hline$W_{2 R S t d}$ & fan mass flow, $\mathrm{kg} / \mathrm{s}$ \\
\hline & ingested drag ratio $(-)$ \\
\hline$\pi_{o o}$ & Overall Pressure Ratio (-) \\
\hline
\end{tabular}

\section{Abbreviations and Acronyms}

ACARE

ACN

A/Cond.

AEA

AIP

APU

ATA

ATLeRs

ATM

BLI

b.r.

CAD

CAEP
Advisory Council for Aviation Research and Innovation in Europe Aircraft Classification Number

Air Conditioning system

All Electric Aircraft, Association of European Airlines

Aerodynamic Interface Plane

Auxiliary Power Unit

Air Transport Association

Aircraft Top-Level Requirements

Air Traffic Management

Boundary Layer Ingestion

brakes release

Computer-Aided Design

Committee on Aviation Environmental Protection 


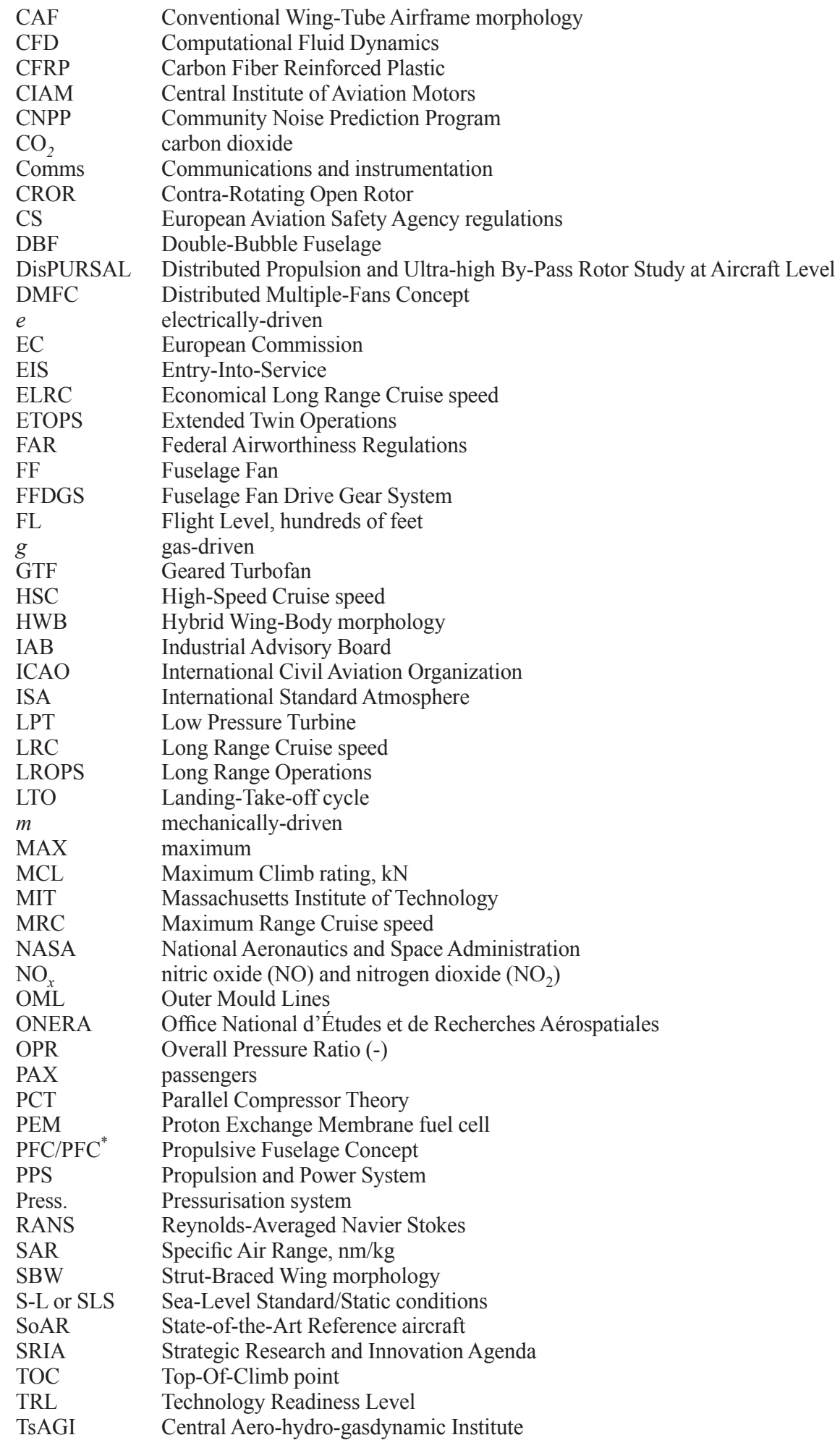


USD US Dollars

USG US Gallons

WaF Wake-Filling

0/1/2/3D Zero/one/two/three-dimensional

2035R/2035R* year 2035 Reference aircraft

\subsection{INTRODUCTION}

One of the ambitious goals outlined in Flightpath 2050 by the European Commission (EC) for year 2050 is a $75 \%$ reduction in $\mathrm{CO}_{2}$-emissions per passenger kilometre (PAX.km) relative to the capabilities of aircraft in the year $2000^{(1)}$. In addition, $90 \% \mathrm{NO}_{x}$-emissions and $65 \%$ noise reductions are also espoused. Targets for $\mathrm{CO}_{2}$-emissions as defined in AGAPE $2020^{(2)}$ were categorised into Airframe, Propulsion and Power System (PPS), Air Traffic Management (ATM) and Airline Operations. As elucidated in Table 1 the Strategic Research and Innovation Agenda (SRIA) goals ${ }^{(3)}$ formulated by the Advisory Council for Aviation Research and Innovation in Europe (ACARE) have been re-calibrated to reflect the AGAPE 2020 report and a new medium-term goal for Entry-Into-Service (EIS) year 2035 has been declared, which is a significant point for aircraft fleet renewal. Further elaboration of these chronologically assigned $\mathrm{CO}_{2}$-emissions targets are offered by way of breakdowns that recommend aircraft energy level targets relative to a year 2000 datum.

Table 1

Chronologically assigned $\mathrm{CO}_{2}$-emissions and $\mathrm{NO}_{2}$-emissions reduction goals as recommended by ACARE in the SRIA document ${ }^{(3)}$

\begin{tabular}{|c|c|c|c|c|c|c|}
\hline $\begin{array}{l}\text { Goals and } \\
\text { Key contributions }\end{array}$ & $\begin{array}{c}2000 \\
\text { (Reference) }\end{array}$ & $\begin{array}{l}2020 \\
\text { (Vision) }\end{array}$ & $\begin{array}{c}2020 \\
\text { (AGAPE) }\end{array}$ & $\begin{array}{l}2020 \\
\text { (SRIA) }\end{array}$ & $\begin{array}{l}2035 \\
\text { (SRIA) }\end{array}$ & $\begin{array}{l}2050 \\
\text { (SRIA) }\end{array}$ \\
\hline $\begin{array}{l}\mathrm{CO}_{2} \text { objective vs } 2000 \\
\text { ("HLG") }\end{array}$ & & $-50 \% *$ & & & & $-75 \% *$ \\
\hline $\begin{array}{l}\mathrm{CO}_{2} \text { vs } 2000(\mathrm{~kg} / \mathrm{pass} \\
\mathrm{km})^{*}\end{array}$ & & $-50 \%$ & $-38 \%$ & $-43 \%$ & $-60 \%$ & $-75 \%$ \\
\hline $\begin{array}{l}\text { Airframe energy need } \\
\text { (Efficiency) }\end{array}$ & 1 & 0.75 & 0.85 & 0.8 & 0.7 & 0,32 \\
\hline $\begin{array}{l}\text { Propulsion \& Power } \\
\text { energy need (Efficiency) }\end{array}$ & 1 & 0.8 & 0.8 & 0.8 & 0.7 & \\
\hline ATM and Infrastructure & 1 & 0,88 & 0.95 & 0.93 & 0.88 & 0.88 \\
\hline $\begin{array}{l}\text { Non Infrastructure- } \\
\text { related Airlines Ops }\end{array}$ & 1 & 0.96 & 0.96 & 0.96 & 0.93 & 0,88 \\
\hline
\end{tabular}

- comparison with same transport capability aircraft and on a same mission in term on range and payload

* ACARE 2020 and ACARE 2050 High Level Goals for airframe, engine, systems and ATM/Operations

\begin{tabular}{|c|c|c|c|}
\hline & at 2020 & 2035 at & at 2050 \\
\hline NO objective vs 2000 ("HLG") & $-80 \% *$ & $-84 \%$ & $-90 \% *$ \\
\hline LTO NO $\times$ (margin to CAEP6) & $-60 \%$ & $-65 \%$ & $-75 \%$ \\
\hline Cruise $\mathrm{No}_{x}$ vs 2000 (kg/pass km)* & $-80 \%$ & $-84 \%$ & $-90 \%$ \\
\hline
\end{tabular}

- comparison with same transport capacity aircraft on a same mission in terms of range and payload

* ACARE 2020 and ACARE 2050 High Level Goals for aircraft/engine/ATM 
The SRIA document ${ }^{(3)}$ also offers an elaboration of external noise targets according to temporal waypoints until EIS 2050. By EIS 2035/2050 a reduction of 55\%/65\% (equivalent to $-11 \cdot 0 /-15 \cdot 0 \mathrm{~dB}$ ) in cumulative external noise (departure and arrival) relative to the capabilities of typical aircraft in-service during year 2000 is advocated.

\subsection{Strategy formulation using pre-design trade-studies}

As a preliminary step, in an effort to understand what combinations of improvement in Thrust Specific Fuel Consumption (TSFC), Zero-Lift Drag and MEW (Manufacturer's Empty Weight) are required to deliver SRIA $\mathrm{CO}_{2}$-emissions goals Isikveren and $\mathrm{Schmidt}^{(4)}$ undertook an advanced trade-study exercise, the results of which is presented in Fig. 1. A simplified prediction algorithm suited for the pre-design stage of transport aircraft sizing was utilised in order to gauge the relative merits of improved propulsion and/or aerodynamic and/or structural/systems efficiencies. The chosen prediction method was based upon fractional change analytical constructs ${ }^{(5)}$ with the underlying premise the designer/analyst begins with a seed condition or baseline aircraft. The nomograph in Fig. 1 represents outcomes expected from a combination of Airframe (drag and MEW) and PPS with corresponding expected targets espoused by AGAPE 2020, SRIA 2020, Vision $2020^{(6)}$, SRIA 2035 and SRIA 2050. All functional sensitivities include the effect of cascade re-sizing, i.e. for a given payload and range, thrust and corresponding nacelle, wing area and empennage have been re-sized, and, appropriate changes in MEW due to diminishing loads (for structures) have been accounted.

As a guide to showing how close various combinations of technologies currently being investigated by the aeronautical community are to SRIA 2035/2050 targets, two scenarios are emphasised in Fig. 1 above. For year 2035, a very aggressive combination of $-25 \%$ TSFC, $-22 \%$ zero-lift drag

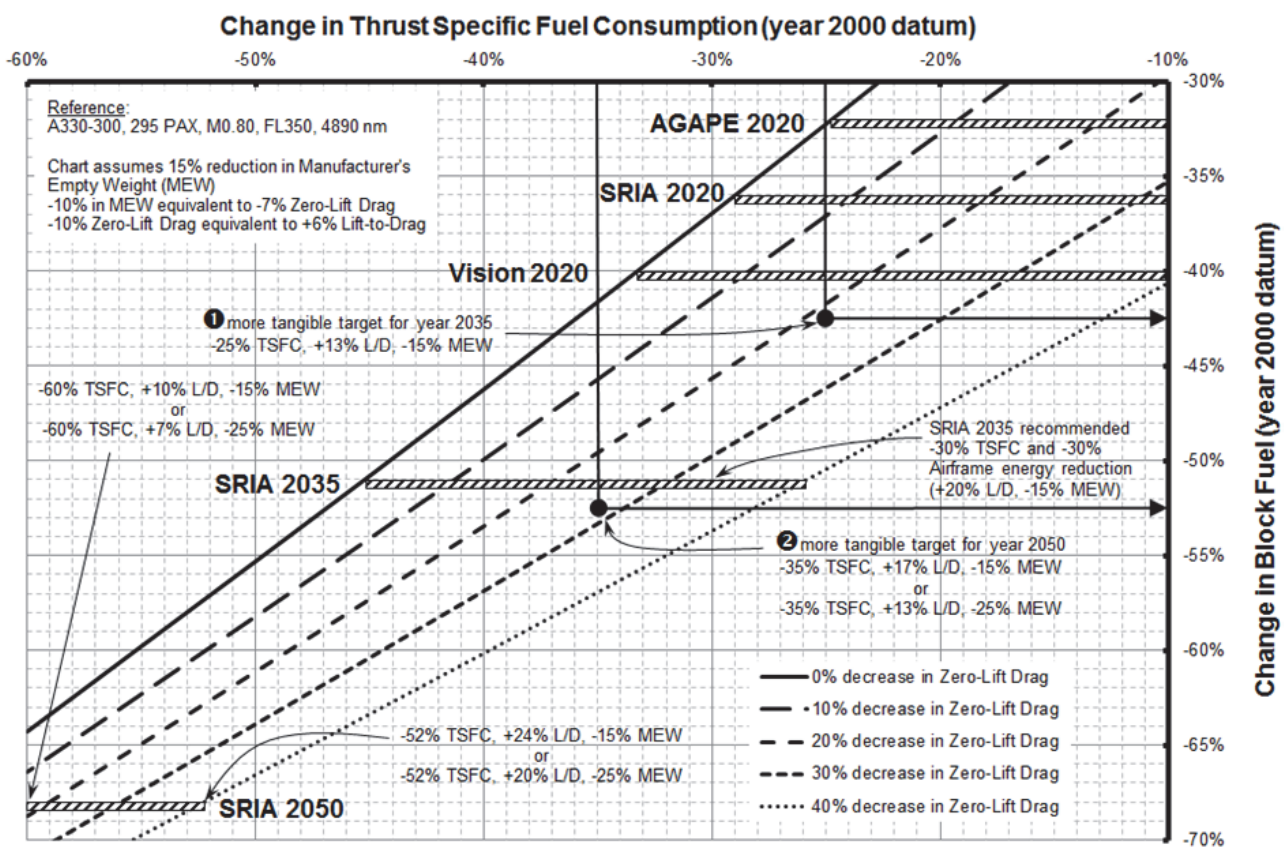

Figure 1. Nomograph illustrating the block fuel reduction outcomes from various combinations of TSFC, Zero-Lift Drag and $\mathrm{MEW}^{(4)}$. 
(equivalent to $+13 \% L / D$ ) and $-15 \%$ MEW produces approximately $-43 \%$ block fuel (see $\mathbf{1}$ in Fig. 1, above). This is a shortfall of $8 \%$ in comparison to the SRIA 2035 target of $-51 \%$ in block fuel. The SRIA 2050 document does not partition between contributions from Airframe and PPS, and, hitherto published studies indicate growing evidence that the improvement due to Airframe will not account for more than around $25 \%$ reduction in block fuel ${ }^{(7-9)}$. Taking this into account, a shortfall of $15 \%$ compared to the block fuel target for SRIA 2050 was observed when adopting (2) in Fig. 1 above, which is a combination of $-35 \%$ TSFC, $-22 \%$ zero-lift drag (equivalent to $+13 \%$ $L / D$ ) and $-25 \%$ MEW producing approximately a 53\% block fuel reduction.

By considering an innovative PPS integration approach and coupling this to the utilisation of alternative architectures, a possibility in delivering $\mathbf{1}$ in Fig. 1 above, even closing further the 8\% gap compared to SRIA 2035 is surmised to occur. Regarding new design degrees-of-freedom, the PPS could be fully or partially embedded within the airframe in an effort to exploit the benefits of Boundary Layer Ingestion (BLI) and/or Wake-Filling, (WaF), thus giving scope to reducing power requirements through a beneficial trade-off between improvements in zero-lift drag and propulsive efficiency versus power plant transmission and energy conversion efficiencies. Such novel approaches necessitate a departure from the conventional, disparate, weakly-coupled airframe-propulsion combination and requires treatment of the design problem in a truly holistic sense with emphasis placed upon maximising synergy from the outset. Figure 2 shows the potential benefit of distributed propulsion using BLI in terms of a so-called Power Saving Coefficient, PSC, which indicates the relative decrease of necessary propulsion power when using BLI. The figure below shows results obtained with different preliminary methods ${ }^{(10-12)}$, and, illustrates the type of integration solution that could produce a given PSC outcome.

\subsection{Published concept study - MIT D8 configuration}

One recent and salient example of examining the potential benefits of BLI and WaF is the Massachusetts Institute of Technology (MIT) future transport aircraft platform dubbed 'D8 ${ }^{\text {(13), }}$ as depicted in Fig. 3. The focus of the work was primarily on aerodynamic characteristics of an aircraft morphology utilising a wide horizontal 'double-bubble' fuselage with beneficial pitching moment and lift carry-over characteristics, wing unsweeping reflecting a reduced design cruise speed, and aft fuselage installed engines that promote BLI and WaF facilitated by application of a twin 'pi-tail' configuration.

In a joint effort between MIT and NASA, Uranga et al ${ }^{(13)}$ presented results of a design optimisation study culminating in the so-called 'D8.2' version. Starting with a B737-800 baseline aircraft and applying the same [relevant] design heuristics and axioms together with operational rules, successive modifications to the platform were incorporated and the outcome of each successive step was plotted - as depicted in Fig. 4. Although the D8.2 configuration is purported to generate $37 \%$ lower block fuel compared to the original B737-800 MAX PAX range, two design attributes collectively producing a $-27 \%$ block fuel result are considered to be the most significant: (1) adoption of slower en route speed schedules; and, (2) the incorporation of BLI and WaF. Through adoption of a very flexible, high aspect ratio wing, manipulation of the aircraft wing loading combined with wing structural weight reduction resulting from a $10 \%$ slower aerodynamic design cruise speed condition, i.e. from baseline M0 80 to M0 72 , yielded $-12 \%$ block fuel. The second and more significant improvement was obtained from implementation of BLI and WaF realised through flush-mounted ducted engines on top of the aft fuselage region. The engines were completely immersed ingesting approximately $40 \%$ of the fuselage boundary layer profile. What is of greatest relevance is the fact that Uranga et $a l^{(13)}$ claim compared to the baseline B737-800 the propulsion-only benefit is $7 \%$, and the residual $8 \%$ of the $15 \%$ total block fuel reduction due 


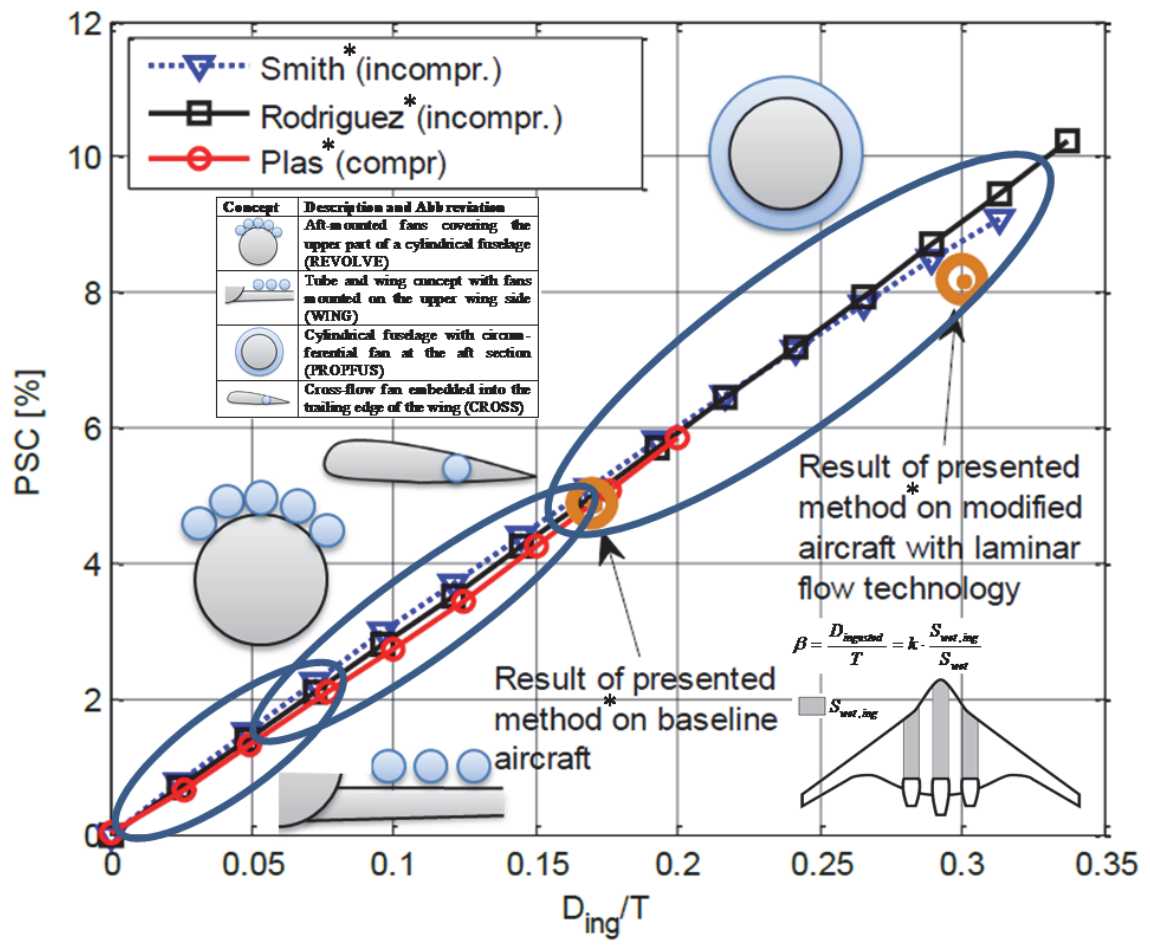

Figure 2. Potential benefits and possible integration morphologies that exploit Boundary Layer Ingestion; *see Steiner et a/(12).

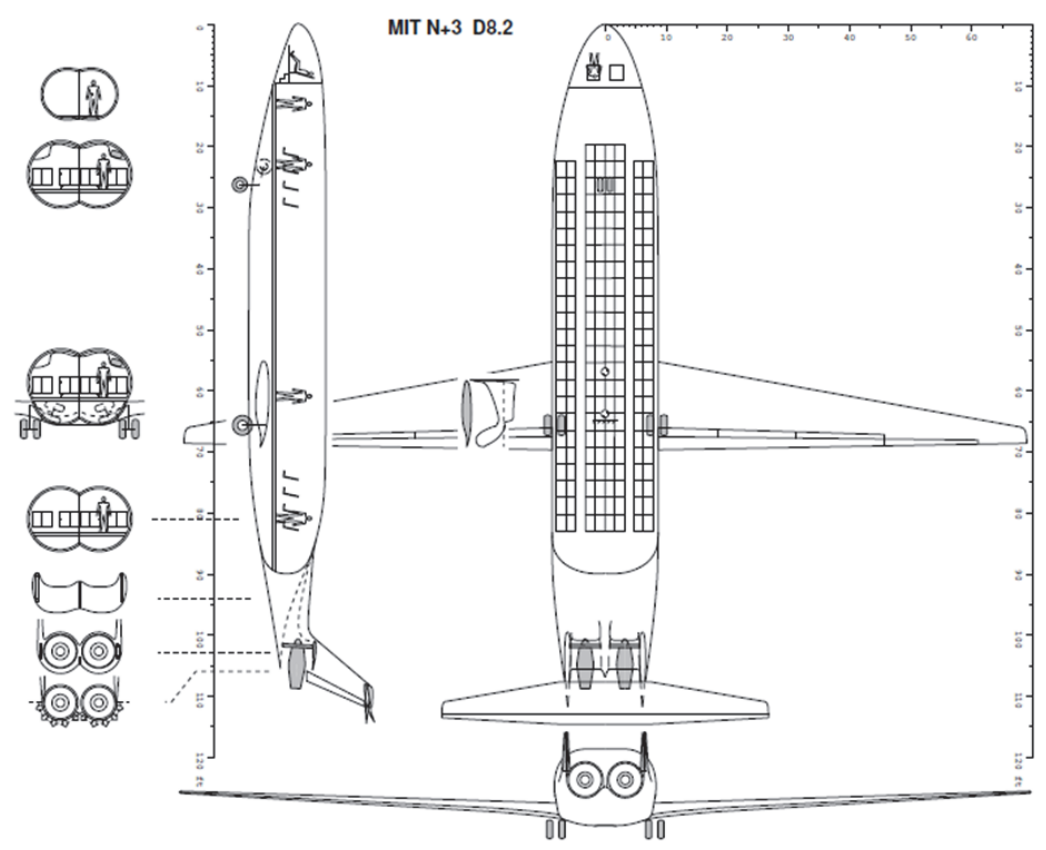

Figure 3. General arrangement of the MIT-NASA D8.2 transport aircraft concept ${ }^{(13)}$. 


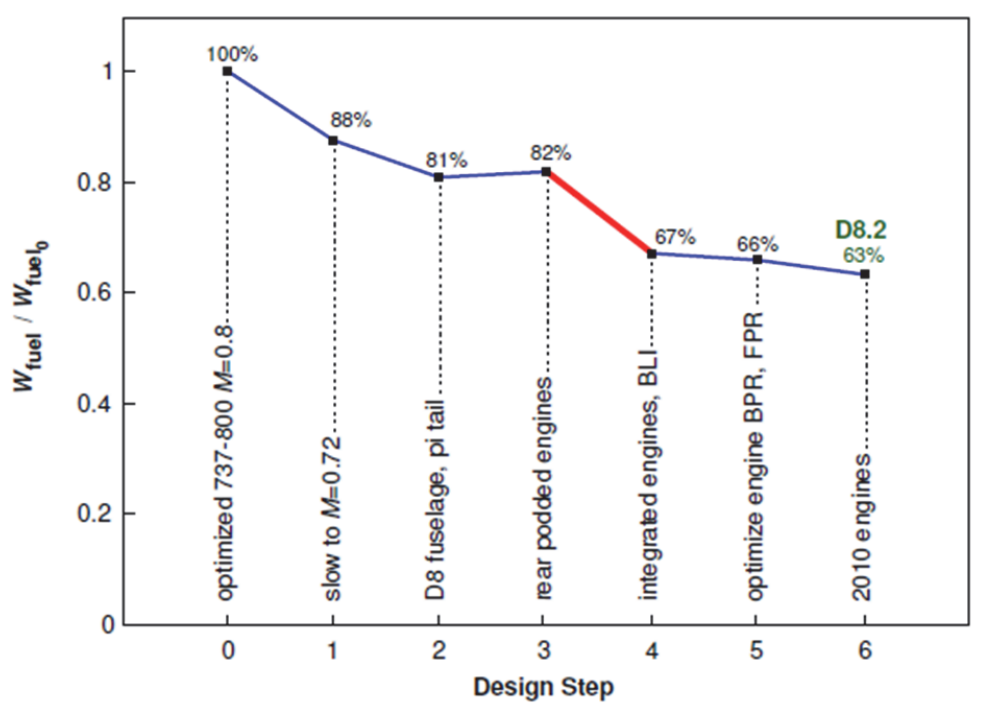

Figure 4. Fractional variation in fuel burn with respect to successive design modifications that constitutes the D8.2 transport aircraft concept ${ }^{(13)}$.

to BLI and WaF was attributable to lower nacelle drag and weight, reduced vertical tail sizing through lower engine-out yaw moments, and cascading gross weight effect.

\subsection{The DisPURSAL project}

The EC recognised the potential benefits afforded by distributed propulsion solutions by granting approval for a Level-0 Framework 7 project entitled Distributed Propulsion and Ultra-high By-Pass Rotor Study at Aircraft Level, or, DisPURSAL ${ }^{(14)}$. Coordinated by Bauhaus Luftfahrt e.V., this 2-year project, which commenced in February 2013, involved partners from the Central Institute for Aviation Motors (CIAM, Russia), Office National d'Études et de Recherches Aérospatiales (ONERA, France) and Airbus Group Innovations (Germany). Moreover, the project benefited from expert advice given by an Industrial Advisory Board (IAB) comprising representatives from Airbus Group Corporate Technical Office (Germany), MTU Aero Engines (Germany), Deutsches Zentrum für Luft- und Raumfahrt (DLR, Germany) and ONERA.

Once a survey and down-selection of the most promising airframe-propulsion concepts was completed, in order to explore the true efficiency potentials of distributed propulsion the following work plan was to be followed:

1. Numerical Experimentation - gain an understanding of aero-propulsive-structuralmechanistic attributes associated with the down-selected concepts

2. Alternative Power-train Architectures - fashion the architectural layout and conceptual design of the most promising novel drive-train approaches

3. Multi-disciplinary Design Optimisation - seek and establish optimised solutions with regards to the integrated propulsive device, power-train and airframe

4. Aircraft-level Benchmarking - perform an assessment using SRIA 2035 goals as the measure, and compare the relative benefits against reference aircraft

5. Technology Roadmap - draft a research and development roadmap targeting entry-intoservice year 2035 that emphasises the maturation of said primary and 'annexed' technologies 
Targeting an EIS of 2035 this project investigated aircraft concepts employing distributed propulsion with focus placed upon a Distributed Multiple-Fans Concept (DMFC) driven by a limited number of engine cores as well as one novel solution that integrates the fuselage with a single propulsor (dubbed the Propulsive-Fuselage Concept, or, PFC). Aspects that were addressed included aircraft design and optimisation, airframe-propulsion integration, power-train system design and advanced flow field simulation.

This technical article presents a sufficiently detailed review of goals, methods, outcomes and future outlook produced by Consortium members of the recently completed DisPURSAL Project. It is an extension of the paper published by Isikveren et $a l^{(15)}$, which expounded findings at a time reflecting the midway point the Project.

\subsection{AIRCRAFT TOP-LEVEL REQUIREMENTS AND REFERENCE AIRCRAFT}

This section is devoted to defining the technical requirements that needed to be fulfilled by all year 2035 reference and advanced aircraft concepts associated with the DisPURSAL Project. Furthermore, in order to ensure each aircraft concept serves as an appropriate baseline for a hypothetical family product line a special set of design axioms and sizing heuristics are also presented. Benchmarking of both the DMFC and PFC distributed propulsion designs was performed against two reference aircraft: the first, comprising major-systems and airframes reflecting in-service year 2000, dubbed State-of-the-Art Reference aircraft (SoAR); and, the second, an evolutionary extrapolation of the contemporary state-of-the-art for target EIS of 2035, called the 2035R. A succinct design description of the SoAR and 2035R aircraft for purposes of evaluation and benchmarking are discussed in Section 2.2.

\subsection{Aircraft top-level requirements}

Declaration of the application scenario and Aircraft Top Level Requirements (ATLeRs) formed the basis for investigations of an advanced reference aircraft reflecting technology freeze-year

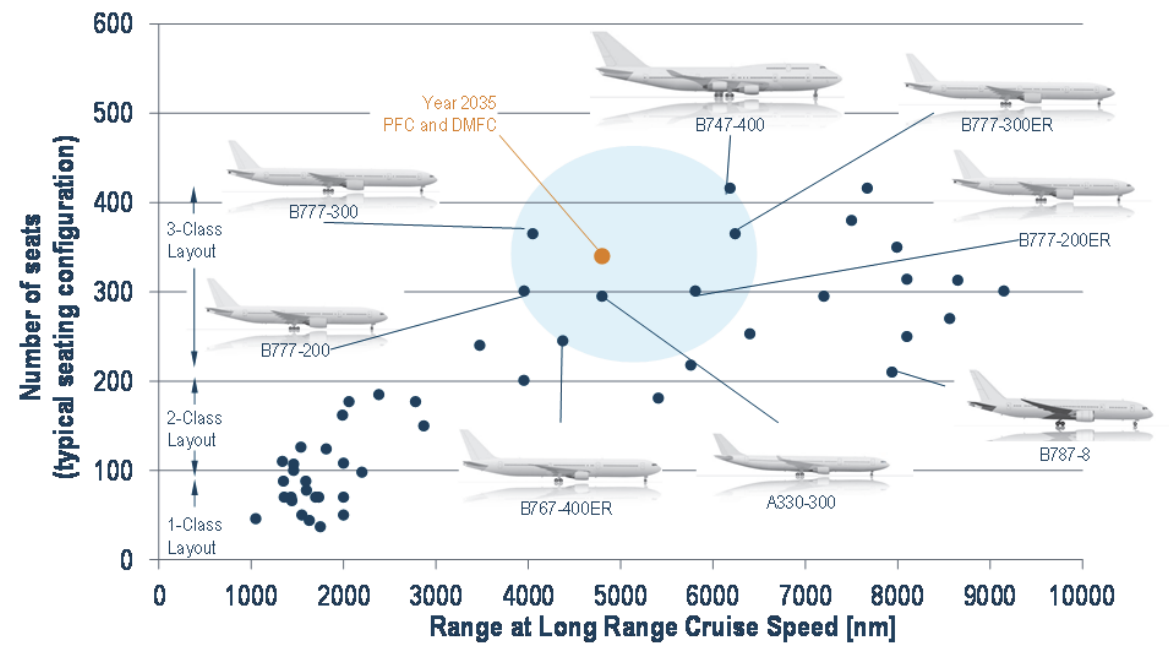

Figure 5. Targeted market segment of entry-into-service year 2035 advanced transport study ${ }^{(15)}$. 
2030 and the two distributed propulsion concepts. Based upon analysis of published data given in Ref. 16 it was found medium-to-long stage lengths have the greatest impact to overall air transport system level cumulative fuel consumption. Using forecasts up to and including year $2035^{(17)}$, it was deduced $95 \%$ of the flights within this broad market segment can be performed with a cabin capacity of 320 to 340 PAX. Accordingly, a design range of $4,800 \mathrm{~nm}(8,890 \mathrm{~km})$ with payload of $340 \mathrm{PAX}$ in a 2-class arrangement was selected (see Fig. 5).

One aspect that cannot be influenced by aircraft integrators or airlines are the passengers. In terms of payload, the average body weight of the passenger is a significant aspect the aviation industry has to deal with. In order to address this issue Schmidt et al ${ }^{(18)}$ undertook investigations of trends in passenger anthropometry. It is stressed that any aircraft efficiency improvement initiatives by some measure need to not only meet targets in relation to a year 2000 datum, but also need to go further in order to off-set the penalising aspects of changing attitudes regarding passenger anthropometry, cabin comfort and more demanding expectations when it comes to amenities. This important consideration was also incorporated when undertaking aircraft dimensioning and weights prediction in relation to cabin outfitting/allowance for the 2035R, DMFC and PFC designs.

The complete array of ATLeRs entries tallied 18 line-items and each are itemised within Table 2. All aircraft concepts were designed in keeping with CS-25 and FAR 25 airworthiness regulations. For purposes of ensuring compliance with contemporary standards of Configuration, Maintenance and Procedures (CMP) including establishment of systems reliability and redundancy best practice a complete aircraft systems design adhering to $240 \mathrm{~min}$. Extended Twin Operations (ETOPS) or Long Range Operations (LROPS) was adopted. Sizing of structures and systems of the 2035R, DMFC and PFC was performed according to a product family strategy allowing for margin of future potential stretch and shrink derivatives of the baseline aircraft (see Table 3). Thus, the propulsion system, for example, needed to be sized for the stretch version with the baseline and shrink versions employing successive $10 \%$ thrust derates. In this manner, all assessment and comparison activities between the year 2000 datum, suitably projected conventional year 2035

\section{Table 2}

\section{Aircraft Top-Level Requirements for all reference aircraft and distributed propulsion concepts}

\begin{tabular}{|c|c|}
\hline & 2035R and 2035DP (DisPURSAL design) \\
\hline Range and $\mathrm{PAX}$ & $4800 \mathrm{~nm}, 340 \mathrm{PAX}$ in 2-class \\
\hline TOFL (MTOW, S-L, ISA) & $2300 \mathrm{~m}$ \\
\hline $2^{\text {nd }}$ Climb Segment & $340 \mathrm{Pax}, 102 \mathrm{~kg}$ per $\mathrm{PAX}, \mathrm{DEN}, \mathrm{ISA}+20^{\circ} \mathrm{C}$ \\
\hline Time-to-Climb $\left(1,500 \mathrm{ft}\right.$ to ICA, ISA $\left.+10^{\circ} \mathrm{C}\right)$ & $\leq 25$ mins \\
\hline Initial Cruise Altitude $\left(\mathrm{ISA}+10^{\circ} \mathrm{C}\right)$ & To be optimised \\
\hline Design Cruise Mach Number & $\geq 0.75$ \\
\hline Maximum Cruise Altitude & FL410 \\
\hline Approach Speed (MLW, S-L, ISA) & 140 KCAS \\
\hline Landing Field Length (MLW, ISA) & $2000 \mathrm{~m}$ \\
\hline One Engine Inoperative Altitude (Dritt Down) & FL170 \\
\hline Airport Compatibility Limits & ICAO Code $E(52 m<x<65 m)$ \\
\hline $\mathrm{ACN}$ (flexible, B) & 67 \\
\hline $\operatorname{coc}$ & At least $20 \%$ reduction per $\mathrm{PAX} . \mathrm{nm}$; based on $\mathrm{A} 330-300$ \\
\hline External Noise \& Emission Target (Reference 2000) & $\mathrm{CO}_{2}-60 \% ; \mathrm{NOx}-84 \%$; Noise $-55 \%$ (interpolated SRIA 2035) \\
\hline ETOPS /LROPS capability & 240 mins \\
\hline Technology Freeze-EIS & $2030-2035$ \\
\hline Design Service Goal & 50000 cycles \\
\hline
\end{tabular}




\section{Table 3 \\ Aircraft build strategies for year 2035 reference aircraft and distributed propulsion concepts}

\begin{tabular}{|c|c|c|c|c|}
\hline \multirow[t]{2}{*}{ Component } & \multicolumn{3}{|c|}{ Family Member } & \multirow{2}{*}{$\begin{array}{l}\text { Remarks } \\
0 \text { - common assemblies or forgings } \\
X \text { - common part-numbers or hardware }\end{array}$} \\
\hline & $\begin{array}{l}296 \text { PAX } \\
\text { Shrink }\end{array}$ & $\begin{array}{l}340 \text { PAX } \\
\text { Baseline }\end{array}$ & $\begin{array}{l}391 \text { PAX } \\
\text { Stretch }\end{array}$ & \\
\hline \multicolumn{5}{|l|}{ STRUCTURE } \\
\hline Fuselage & 0 & 0 & 0 & Common assemblies \\
\hline Wing & 0 & $x$ & $x$ & Common assemblies; common part-numbers for baseline and stretch \\
\hline Empennage & $\mathrm{x}$ & $\mathrm{x}$ & $x$ & Common part-numbers; dimensioned for shrink, loads of stretch version \\
\hline Nose LGear & $x$ & $\mathrm{x}$ & $x$ & Common part-numbers \\
\hline Main LGear & 0 & $\mathrm{x}$ & $x$ & Common forgings; common part-numbers for baseline and stretch \\
\hline Pylons & $x$ & $x$ & $x$ & Common part-numbers; loads of stretch version \\
\hline \multicolumn{5}{|l|}{ SYSTEMS } \\
\hline AVCond. \& Press. & $x$ & $x$ & $x$ & Common hardware; sizing for stretch version \\
\hline Cabin Systems & 0 & 0 & 0 & Common hardware; variation according to shrink-baseline-stretch accommodation \\
\hline Comms/Avionics & $x$ & $\mathrm{x}$ & $x$ & Common hardware \\
\hline Electrical & $\mathrm{x}$ & $x$ & $\mathrm{x}$ & Common hardware; sized for stretch version \\
\hline Landing Gear & $x$ & $x$ & $x$ & Common part-numbers for rolling-stock and brakes; space provision for stretch \\
\hline Flight Controls & $x$ & $x$ & $x$ & Common hardware; sized for stretch version \\
\hline Powerplant & $\mathrm{x}$ & $\mathrm{x}$ & $\mathrm{x}$ & Common part-numbers; shrink and baseline employ successive $10 \%$ thrust derate \\
\hline
\end{tabular}

and distributed propulsion aircraft concepts were based upon a common premise, even taking into account contemporary product development practice.

\subsection{Year 2000 and 2035 reference aircraft}

Selection of the SoAR reference aircraft was based upon the targeted application scenario and ATLeRs presented in Section 2.1. For purposes of gauging the relative merits of the DMFC and PFC to that of SRIA 2035 targets, an appropriate transport aircraft reflecting an in-service year 2000 standard needed to be defined and analysed. As this air transport task is, today, typically serviced by a wide-body medium-to-long-range twin-engine aircraft, an Airbus A330-300 equipped with Rolls-Royce Trent 772B engines was chosen as the SoAR aircraft. Hence, a parametric model of the aircraft including the corresponding propulsion system was fashioned.

In order to appropriately capture the benefits of the distributed propulsion concepts and to establish a suitable basis for consistent benchmarking, a reference aircraft reflecting the advanced technology level corresponding to an EIS 2035 application scenario was derived from the SoAR. The 2035R design range and payload were set in accordance with the ATLeRs given previously. Besides adjustments of the fuselage design relative to the SoAR in order to provide the required accommodation and future comfort standards, a set of aerodynamic, weights reduction and PPS related technologies appropriate for the targeted EIS were also implemented. Technology ideas were generated taking stock of the sensitivities displayed in Fig. 1; thereafter, a formalised downselection was conducted in accordance with the methodology detailed in Section 3.1.

An advanced flexible wing featuring 12.6 aspect ratio, sized to match the International Civil Aviation Organization (ICAO) Annex 14 Code E airport compatibility limit ${ }^{(19)}$, in conjunction with utilisation of Shock Contour Bumps ${ }^{(20)}$ on the wing upper surface and Riblets ${ }^{(21,22)}$ on the fuselage surface yielded a lift-to-drag $(L / D)$ improvement of $8 \cdot 6 \%$ (at $C_{L}=0 \cdot 55$, M0 80, FL350) over the SoAR. With regards to structural design, advanced technologies such as omni-directional ply orientation of carbon fibers ${ }^{(23)}$, judicious use of advanced materials and structural topological 
$\operatorname{design}^{(24,25)}$, and advanced bonding techniques ${ }^{(26)}$ were assumed to motivate a reduction of $15 \%$ in structural weight relative to the SoAR. The aircraft is powered by advanced Geared Turbofan (GTF) power plants with Bypass Ratio (BPR) of 18·0. Cycle properties, turbo component efficiencies and duct pressure losses were adjusted to reflect the targeted technology standard. In view of an aircraft systems architecture complying with the All-Electric Aircraft (AEA) paradigm, PPS design was based upon a zero customer off-take scenario with regards to cabin bleed air and electrical power extraction. This is to be facilitated by a Proton Exchange Membrane (PEM) fuel cell-based Auxiliary Power Unit (APU) utilising an advanced electrical architecture akin to that presented by Pornet et $\mathrm{al}^{(27)}$. This resulted in a TSFC improvement at typical cruise of $21 \cdot 5 \%$ over the Trent 772B installed on the SoAR. In terms of mission performance, the 2035 reference aircraft was predicted to deliver a $32 \%$ block fuel benefit compared the SoAR carrying a payload of 340 PAX at $102 \mathrm{~kg}$ per PAX completing 4,800nm $(8,890 \mathrm{~km})$ at cruise speed of M0 80 .

\subsection{MULTI-DISCIPLINARY DESIGN OF DISTRIBUTED PROPULSION AIRCRAFT SYSTEMS}

A coherent, standardised and robust set-up in conjunction with adherence to strict procedural controls was needed to ensure successful multi-disciplinary interfacing, sizing and optimisation. Details about numerical methods employed for the aero-airframe-propulsion experimental work and a brief overview of multi-disciplinary interfacing are discussed here.

\subsection{Down-selection framework and results}

During the down-selection exercise concept clouds comprising six candidate designs for both DMFC and PFC sets were qualitatively rated against a total of 29 criteria which were grouped into six main categories with a technical, operational and certification related focus:

- Systems Integration;

- Aerodynamics;

- Weights;

- Noise;

- Operability and Certifiability; and,

- Costs

Each main category included a set of four to seven specific sub-categories. The weightings of the main and sub-categories were tailored to reflect the emphasis placed upon fuel burn and cost reduction. Thus, those of the main categories having a major impact on fuel burn ('Systems Integration', 'Aerodynamics' and 'Weights') as well as the cost-influencing category ('Costs') were each weighted with $0 \cdot 20$. The two remaining main categories ('Noise' and 'Operability and Certifiability') were each weighted with $0 \cdot 10$. The rating was attained by evaluation of each individual concept against what was intuitively deemed the best design candidate from within the pool of six. In addition, technical maturity was assessed by evaluating each concept with respect to the likelihood of success and the effort to bring the technology to target Technology Readiness Level (TRL) 6 by technology freeze in year 2030. Following the procedure described by Mistree $e t$ $a l^{(28)}$, robustness of the concept rating was gauged by systematically varying the criteria weighting in each main category. This was achieved by means of artificial amplification in such a way one category was rated with 0.30 and the remaining weightings were equally distributed amongst the other categories. 

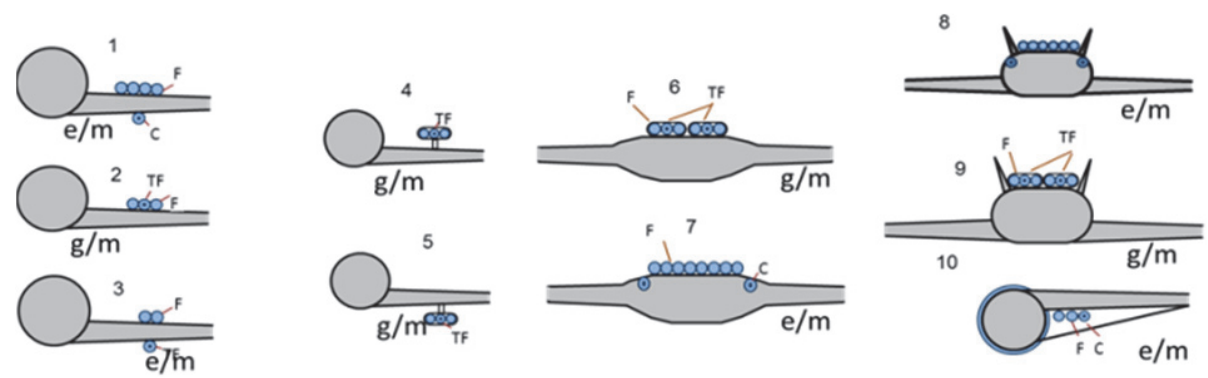

$1 \mathrm{e} / \mathrm{m}-\mathrm{CAF}+$ fans upper-wing, cores under-wing

$2 \mathrm{~g} / \mathrm{m}-\mathrm{CAF}+$ fans, turbofans upper-wing

$3 \mathrm{e} / \mathrm{m}-\mathrm{CAF}+$ fans upper-wing, turbofans under-wing

$4 \mathrm{~g} / \mathrm{m}-\mathrm{CAF}+$ pylon-mounted fans, turbofans upper-wing

$5 \mathrm{~g} / \mathrm{m}-\mathrm{CAF}+$ pylon-mounted fans, turbofans under-wing

$6 \mathrm{~g} / \mathrm{m}-\mathrm{HWB}+$ fans, turbofans upper-body

$7 \mathrm{e} / \mathrm{m}-\mathrm{HWB}+$ fans upper-body, cores embedded within body $\quad 8 \mathrm{e} / \mathrm{m}-\mathrm{DBF}+$ fans upper-fuselage, embedded within fuselage

$9 \mathrm{~g} / \mathrm{m} \backslash-\mathrm{DBF}+$ fans, turbofans upper-fuselage

$10 \mathrm{e} / \mathrm{m}-\mathrm{SBW}$ with distributed multiple fans

Figure 6. Distributed multiple-fans Concept cloud; g-gas-driven, $\mathrm{m}$ - mechanically-driven, e - electrically-driven; C - core, F - fan, TF - turbofan ${ }^{(15) .}$

\subsubsection{Down-selected distributed multiple-fans concept design}

Four basic aircraft configurations for DMFC application were identified: Conventional Wing-Tube Airframe (CAF); Double-Bubble Fuselage (DBF); Hybrid Wing Body (HWB); and, Strut-braced Wing (SBW). Some particulars include:

- The DBF is a modified CAF with conjunction of two traditional fuselages to create an unconventional lifting body

- The HWB has a flattened and reflexed aerofoil shaped body. A low effective wing loading and beneficial trim effect means a complex high-lift system is not required. The outboard wing supports slats and all trailing-edge devices are made up of simple hinged flaps that double as elevons. The distributed propulsion system is mounted atop of the main body, thereby ingesting large portions of the boundary layer

From the basic architectural alternatives itemised above, 20 initial integrated concepts featuring a multiple fans design were derived. Pre-selected concepts are graphically summarised in Fig. 6.

A graphical summary of rating results is visualised in Fig. 7. In order to allow convenient comparison of the rated concepts, the presentation of rating results shown in the diagram were normalised against the best ranked concept. For purposes of clarity the remaining concepts were scaled accordingly. The bars labeled 'Intuition' show the initial results from the concept rating procedure. Additionally, the average value of each robustness scenario is presented.

\subsubsection{Down-selected propulsive fuselage concept design}

Based upon an extensive literature survey, several conceptual morphologies considered indicative of a PFC concept were identified. The derived pool of architectural categories included:

General Aircraft Architectures: PFC based on conventional tube-and-wing design, box-wing configuration and twin-fuselage design 


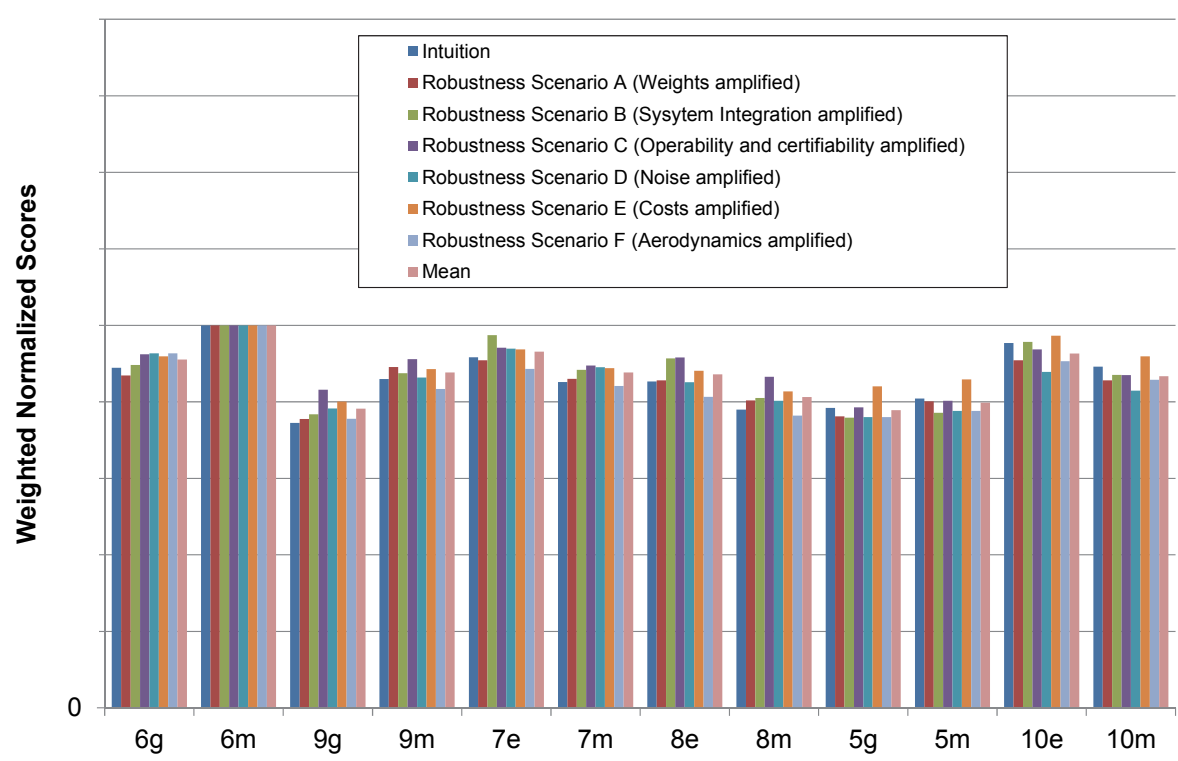

Figure 7. Results of robustness analysis for distributed multiple-fans concept selection; normalised scores for different scenarios ${ }^{(15)}$

Propulsor Options: Single and multi-stage ducted fan, as well as unducted single and ContraRotating Open Rotor (CROR) configurations

Drive-train Concepts: Mechanical power transmission, hydro-mechanical transmission using gas turbine exhaust and a power turbine to drive the Fuselage Fan (FF), as well as electro-mechanical power transmission

Internal Gas-turbine Arrangement: Engines installed in front and aft of the FF plane

Redundancy Implementation: FF in conjunction with under-wing podded power plants, doublebubble configuration and twin-fuselage layout each using two independently driven FFs

As a result of the down-selection process, the most promising candidate for the implementation of a PFC concept was identified: a concept featuring a single rotating FF driven by a gas-turbine installed in the fuselage aft cone ('Concept 1' in Fig. 8). It was also assessed to be a concept with the highest potential to meet the target technical maturity level compared to the other rated alternatives. In order to adequately address system redundancy stipulated by transport category certification requirements, the configuration additionally comprises two under-wing podded ultra-high BPR turbofans.

\subsection{Aero-airframe and aero-propulsion numerical methods}

When embarking upon aircraft and systems integration activities that draw upon maximising the benefits of any distributed propulsion approach, it becomes unavoidable in declaring not only new conventions for aerodynamics/propulsion book-keeping, but also, bespoke problem formulation strategies for numerical experimentation as well as the adoption of special purpose collaborative multi-disciplinary analysis and optimisation work-flow needs to take place. Here, a succinct review of these topics and the implications resulting from departures in relation to the familiar conventional design and analysis processes is presented. 


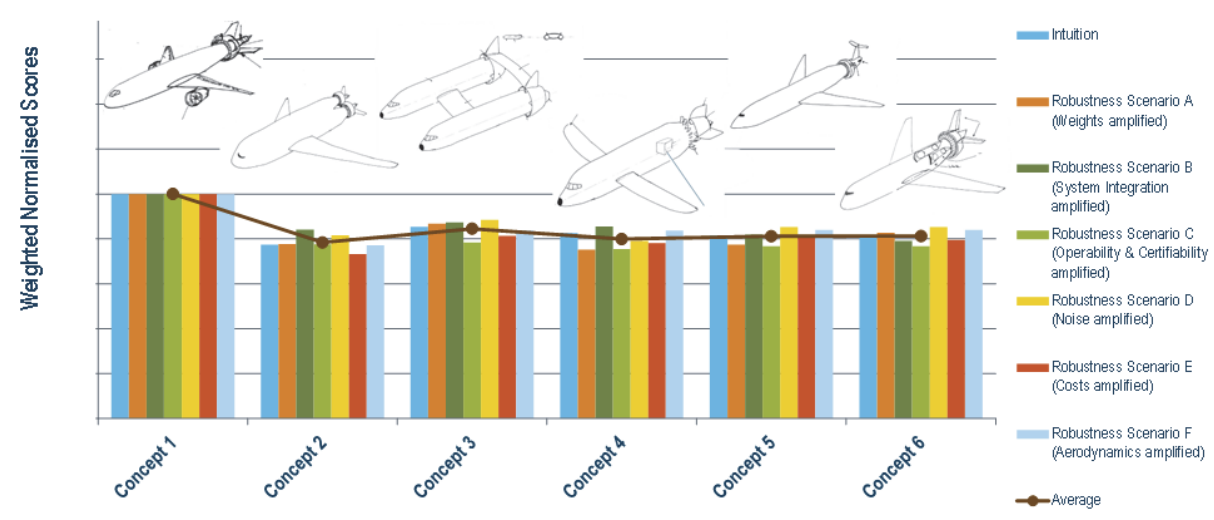

Concepts - AIC Level - EIS 2035

Figure 8. Results of robustness analysis for pxropulsive fuselage concept selection; normalised scores for different scenarios ${ }^{(15)}$.

\subsubsection{Aerodynamics/propulsion book-keeping}

Different from vortex-induced drag, viscous and form drag, particularly the low-momentum boundary layer flow caused by skin friction on wetted area, are manifested as a momentum deficit in the aircraft wake. Through the application of momentum and energy conservation laws it may be easily shown that locally filling this momentum deficit using a momentum delta produced by the propulsion system yields a reduction in propulsive power required for aircraft operation. Consistent treatment of conventionally installed, i.e. podded, and, highly integrated propulsion systems such as the ones adopted for the DMFC and PFC requires a unified standard for definition of the efficiency chain through the entire power plant system, including the notion of appropriate interfacing to the airframe.

A unified book-keeping scheme of system-level efficiency figures and corresponding control volumes applicable to both conventionally podded, as well as, highly integrated BLI propulsion systems was introduced Seitz and Gologan ${ }^{(29)}$. Accordingly, the interface for thrust/drag bookkeeping between the propulsion system and the airframe is geared to the propulsion system stream-tube of air flow (Fig. 9, above). Therefore, aerodynamic effects in the stream-tube ahead of the inlet frontal face are incorporated in the power plant sizing and performance analysis. Nacelle external aerodynamics are considered to contribute to the overall aircraft characteristics, thereby,

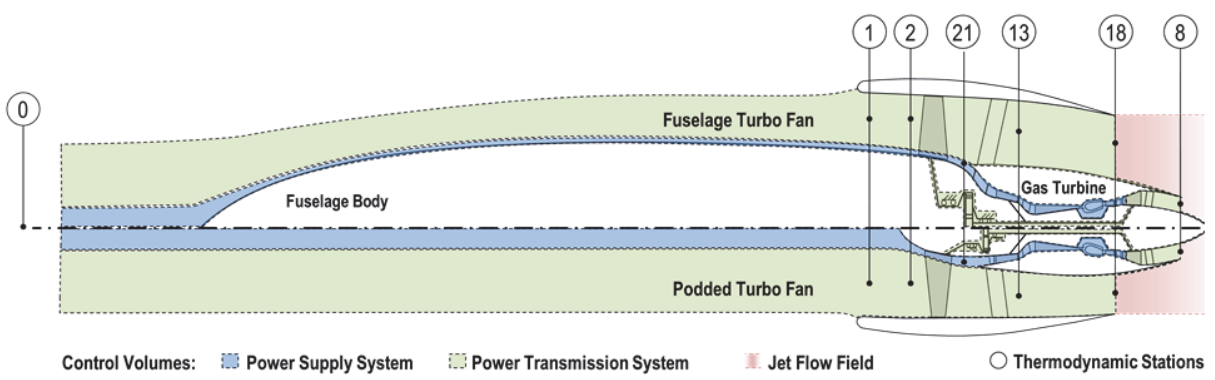

Figure 9. Unified propulsion system definition based on standardised control volumes ${ }^{(29)}$. 
feeding back to the total net thrust required to operate the aircraft. Once the total net required thrust is known, the net thrust requirement for each individual power plant may be derived. Assuming a certain amount of aircraft drag captured inside the propulsion stream-tube (ingested by the propulsive device), the actual net thrust requirement of the aircraft would be reduced accordingly.

\subsubsection{Aero-airframe numerical methods}

The aerodynamic assessment of the airframe-propulsion was planned for cruise conditions and an important aspect was to correctly represent the phenomenon of BLI by the engine intake and the modification of the flow going through the engine fan. Due to this, the ONERA elsA software ${ }^{(30)}$, being a high fidelity method solving the RANS equations, was selected. This software can treat a large variety of configurations and flow conditions. It can handle multi-block structured meshes and includes patched grid and overset capabilities, as well as state of the art numerical methods and advanced physical models. Several types of turbulence models can be used, and in the frame of the DisPURSAL Project, the Spalart-Allmaras approach was used in fully turbulent conditions. Experience has shown this methodology displays an appropriate level of conformity with physical experimental results produced for similar engineering problems ${ }^{(31)}$.

Due to limited time and budget afforded by the DisPURSAL Project, configurations comprising a fuselage/body together with associated nacelle were 2D-representational (Fig. 10(a)) and 2D-axisymmetric (Fig. 10(b)) for the DMFC and PFC respectively. An extrapolation of the aerodynamic performance coefficients was further performed to quantify the effects on a fully 3D configuration.

It should be noted that only the engine fan was simulated, and not the engine core flow; the objective being mainly to evaluate the effect of BLI on the fan. It was not possible to calculate a real rotating fan in the frame of the project due to complexity and computational expense, and so

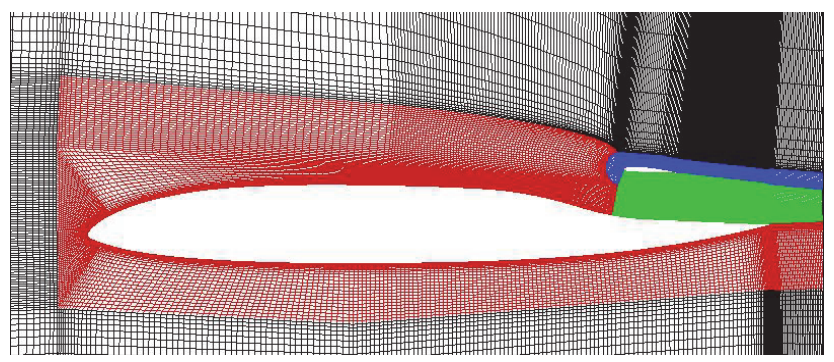

(a)

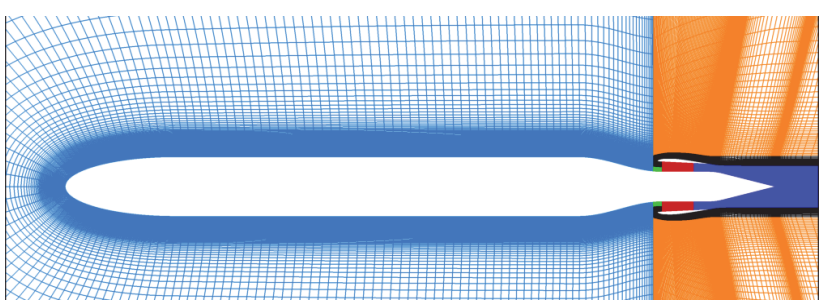

(b)

Figure 10. Aerodynamic meshes for (a) 2D-representational and (b) 2D-axisymmetric configurations for the DMFC and PFC respectively ${ }^{(15)}$. 
the influence of the fan on the flow, including the modification of its characteristics when crossing it had been simulated suitably via specific numerical boundary conditions. Two types of actuator disk conditions were used for 2D-representational and 2D-axisymmetric configurations: the first one applies an increase of pressure through the fan while conserving the flow velocity; the second one is more advanced and based upon a fan characteristics deck which need to be provided by the user. It applies a total pressure and temperature drop as well as an azimuthal deviation of the flow. This latter condition was applied in two planes at different streamwise positions using a CROR fan representation in order to emulate the given fan/stator arrangement. In order to build characteristics information to represent realistic fans, preliminary computations were performed with a code based on Glauert theory for propellers and extended to ducted fans, thus giving for a simplified fan blade skeleton and a given rotation speed flow characteristics necessary for the actuator disk boundary conditions.

Aerodynamic performance analysis was based on mass-flow through the engine, the power delivered by the fan to the flow and the net thrust of the engine, from which a propulsive efficiency can be deduced. These different parametres were obtained through integral operators comprising variables of local mass-flow, enthalpy and dynalpy over a selected surface in the field, in accordance with an approach developed for the RAPRO Project ${ }^{(31)}$.

\subsubsection{Aero-propulsion numerical methods}

All engine performance simulation was conducted using the gas turbine performance program GasTurb $^{\circledR(32,33)}$ combined with special purpose in-house development methods. The GasTurb® baseline engine was considered as a two-spool, geared, unmixed flow turbofan. Important cycle characteristics covering temperature and pressure levels, turbo component efficiencies and duct pressure losses were adjusted to reflect an appropriate technology status corresponding to EIS year 2035, which also corresponded to the propulsion system chosen for the 2035R aircraft.

One of the challenges associated with highly integrated propulsion systems as analysed in the DisPURSAL Project is rooted in the ingestion of a low-momentum boundary layer into the propulsive device and the corresponding influence on engine performance. The momentum deficit formed by fuselage/body skin friction in front of the power plant intake manifests as a total pressure loss relative to the total pressure of the undisturbed free stream at flight velocity. Hence, ram pressure recovery for BLI affected power plants is typically reduced compared to the value of an engine exposed to the free stream only. For both the DMFC and PFC investigations, the method for the mapping of stream-tube losses, i.e. intake additive drag, nozzle discharge and exhaust shear flow, conformed to the convention presented in Section 3.2.1. As air entering propulsive device inlets necessitated the prediction of appropriate ram recovery factors for purposes of adjusting power plant performance analysis, in the first instance, constant degradation factors were applied to fan efficiency as described by Seitz et $a l^{(34)}$. A subsequent refinement in predicting penalising aspects to pressure recovery were derived from the multi-disciplinary numerical aero-experimental activities, as described in Section 3.2.2. As a further consequence of such tightly-coupled propulsion-airframe arrangements, the fan polytropic efficiency was expected to be reduced due to the inevitable distortion of the inflow field of a boundary layer ingesting power plant. Worst-case, nominal and best-case values of fan polytropic efficiency were taken to be $-5 \%,-2 \%$ and $0 \%$ respectively.

A matching procedure to incorporate physical effects derived from the aero-numerical analysis was undertaken such that consistency between the GasTurb® models and CFD results were secured. Regression models were derived for important working parametres such as the intake pressure ratio, and a review of such methods can be found in publications produced by Bijewitz et $a l^{(35)}$, Seitz et $a l^{(34)}$ and Seitz and Gologan ${ }^{(29)}$. Since the $0 D$ GasTurb ${ }^{\circledR}$ plus in-house engine performance 


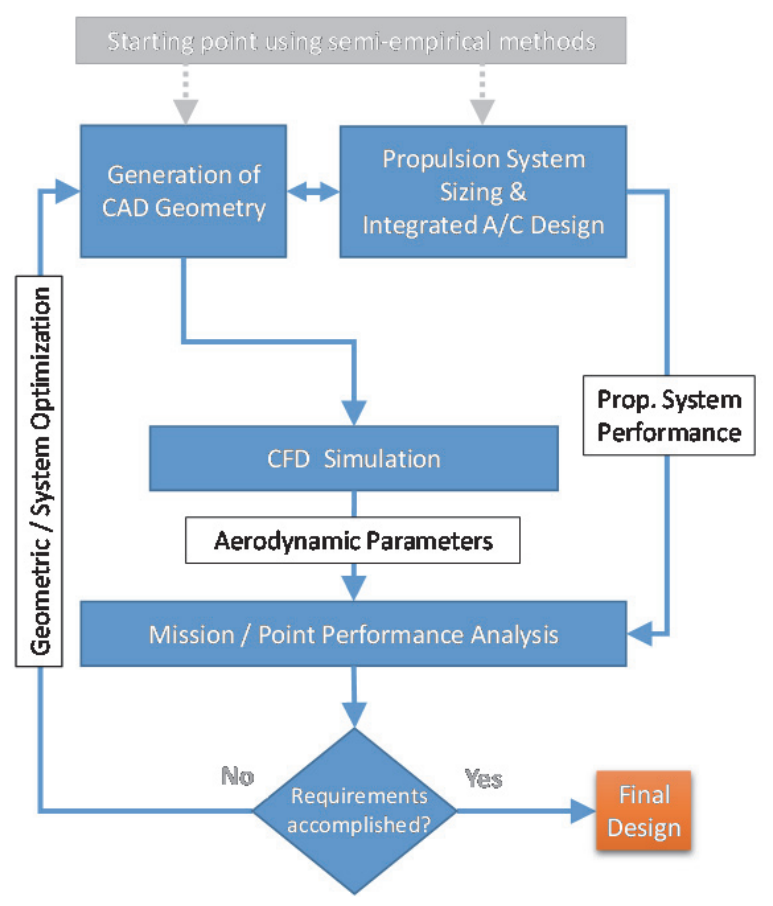

Figure 11. Workflow scheme of the multi-disciplinary design process $^{(15)}$.

software used in the DisPURSAL Project did not have a built-in functionality to account for the impact of inlet flow radial distortions on fan efficiency and surge margin, the Parallel Compressor Theory (PCT) method ${ }^{(32)}$ mainly concerned with circumferential distortion was incorporated. A brief review of the fundaments associated with the PCT method is offered in Section 4.2.

\subsection{Multi-disciplinary interfacing procedures}

As a starting point for multi-disciplinary analysis, first baselines of the DMFC and PFC were developed in a preliminary design study. General aircraft characteristics including principal dimensions, high-speed drag polars, weights, propulsion system characteristics, and flight performance were determined during a pre-conceptual design process based upon a set of initial assumptions and utilisation of mostly semi-empirical methods such as those offered by Seitz and Gologan $^{(29)}$. On this initial basis, detailed shapes defining the Outer Mould Lines (OML) of the aircraft including the integrated FF were created using the CAD platform Catia V5 ${ }^{\mathrm{TM}}$.

Using preliminary results regarding propulsion system characteristics and defining an initial fixed set of the key design parametres fan diameter and fan pressure ratio, numerical flow simulations were conducted on these CAD shapes to investigate airframe-propulsion interaction effects and the overall propulsive efficiency. Potentially occurring flow imperfections like unfavorable shock contours or flow separations, as it appeared in the flow simulation results, were addressed during this stage in an iterative manner by invoking geometric modifications to the rear fuselage and duct contours. Final results of the flow simulation were then used to verify and subsequently calibrate the methods and assumptions used in the overall aircraft design and sizing of the baseline configuration. An illustration of the applied workflow is given in Fig. 11. 


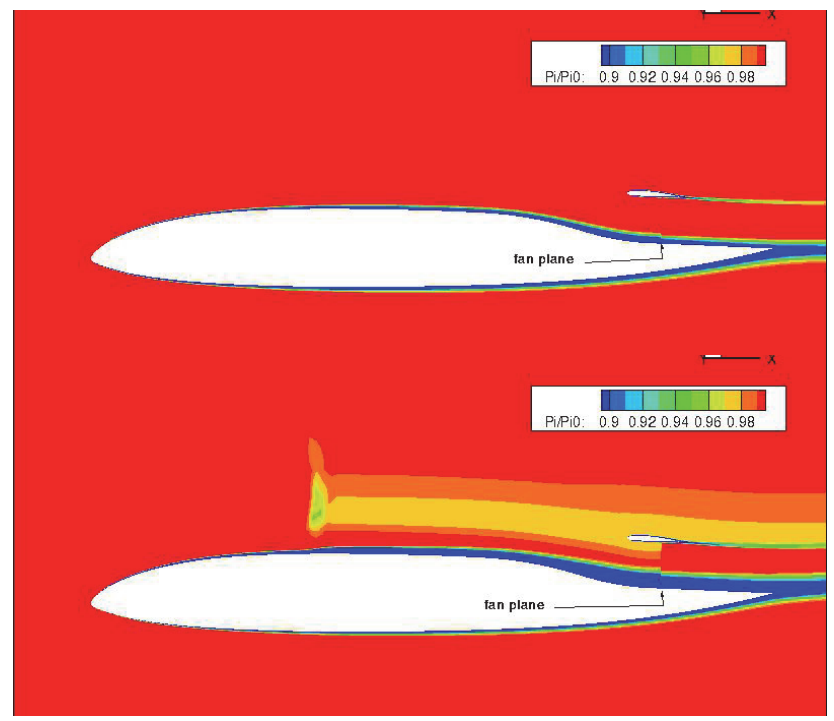

Figure 12. Evolution of total pressure for incidence $0^{\circ}$ (top) and $5^{\circ}$ (bottom) $)^{(15)}$.

After investigation of the baseline configuration, the calibrated sizing model was used to evaluate the impact of variations in key design parametres associated with the propulsion assembly. Subsequently, promising combinations of, for instance, fan diameter and fan pressure ratio were chosen for further investigation and validation in numerical flow simulations. In the frame of a design space exploration, the optimised baseline CAD geometry was modified to generate adapted geometries that match the geometric characteristics of the respective design point. Applying the workflow scheme as described above, the multi-disciplinary analysis procedure was repeated for each point in the design space.

\subsection{DISTRIBUTED MULTIPLE-FANS PRE-CONCEPT DESIGN}

This section is devoted to presenting some of the salient results/insights associated with aero-airframe numerical experimentation, as well as the outcomes, findings and technical insights of the completed multi-disciplinary design effort that constituted the DMFC design.

\subsection{Aero-Airframe Numerical Experimentation}

It was decided from the outset to perform $2 \mathrm{D}$ computations in a selected spanwise section of the HWB. After analysis of the baseline HWB shape, it was deemed prudent to avoid the most inboard fan towards the centre-line due to the upstream presence of the cockpit with its unconventional shape. For sake of simplification to the analysis without compromising overall engineering insight, the core fan was also discarded in order to avoid simulation of the engine primary jet. In the end, the investigated configuration was a $2 \mathrm{D}$ wing aerofoil with a nacelle aerofoil, corresponding to a sectional cut of the 3D HWB configuration at a spanwise position corresponding to a most outboard fan axis (see Fig. 10(a) in Section 3.2.2). The aircraft cruise condition corresponded to M0 80, 


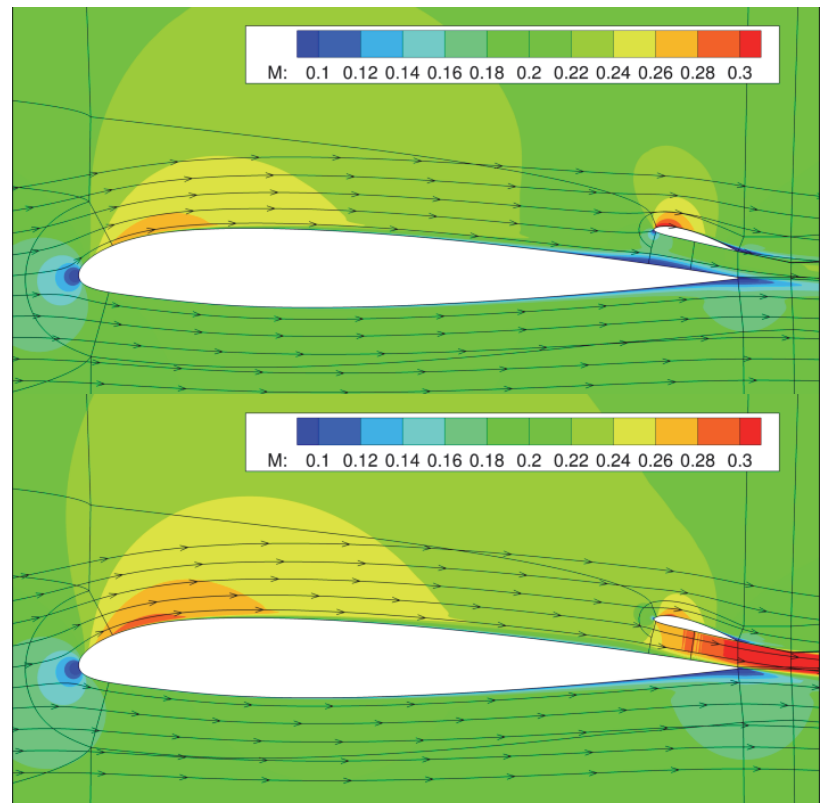

Figure 13. Mach number distributions for low (top) and high (bottom) Fan Pressure Ratios ${ }^{(15)}$.

an altitude FL350, and ISA conditions. It should be noticed that 2D computations were done at a different incidences to simulate a similar local lift coefficient to the one present in this wing section for the 3D shape. In this technical article, sensitivity studies for different driving geometries or aerodynamic parametres performed on the 2D-representational DMFC shape are only presented.

Figure 12 shows the effect of a variation in incidence angle, leading to a variation in boundary layer thickness: the total pressure contours illustrate the relative importance of this thickness (local total pressure/freestream total pressure $<0.99$ approximately) compared to the engine diameter $(D)$, and also a pressure loss due to a shock wave on the upper side of the wing. All these phenomena contributed to the thrust/drag balance which is quite difficult to establish in these conditions especially for a closely-coupled engine/airframe configuration.

As illustrated in Fig. 13 above, a variation in engine thrust or Fan Pressure Ratio (FPR) was observed to have a significant effect on the Mach number distributions around the configuration, and as a consequence, on the lift. Another consequence of an FPR increase were higher velocities upstream and inside the engine intake, leading to a reduction in the boundary layer thickness ingested by the intake.

The engine fan diameter, $D$, is also an important driving parametre, as shown in Fig. 14, for a comparably balanced thrust/drag aerodynamic condition. An increase in $D$, for a similar value of thrust, corresponds to lower velocities within the intake because the engine mass-flow is higher. As a consequence, the velocities or Mach number on the upper side of the airframe are lower, leading to a reduction in the body lift.

To conclude the aero-numerical experimentation, a preliminary investigation showed the influence of a distributed propulsion architecture associated with airframe BLI on the flow and on the aerodynamic performance coefficients, with a potential beneficial effect on lift, in addition to the expected effect on thrust and drag. A comparison to previous 3D computations performed within the EC FP6 NACRe Project ${ }^{(36,37)}$ allowed the determination of approximate values of inlet efficiency and distortion coefficients in the fan plane with BLI conditions. These values were then 


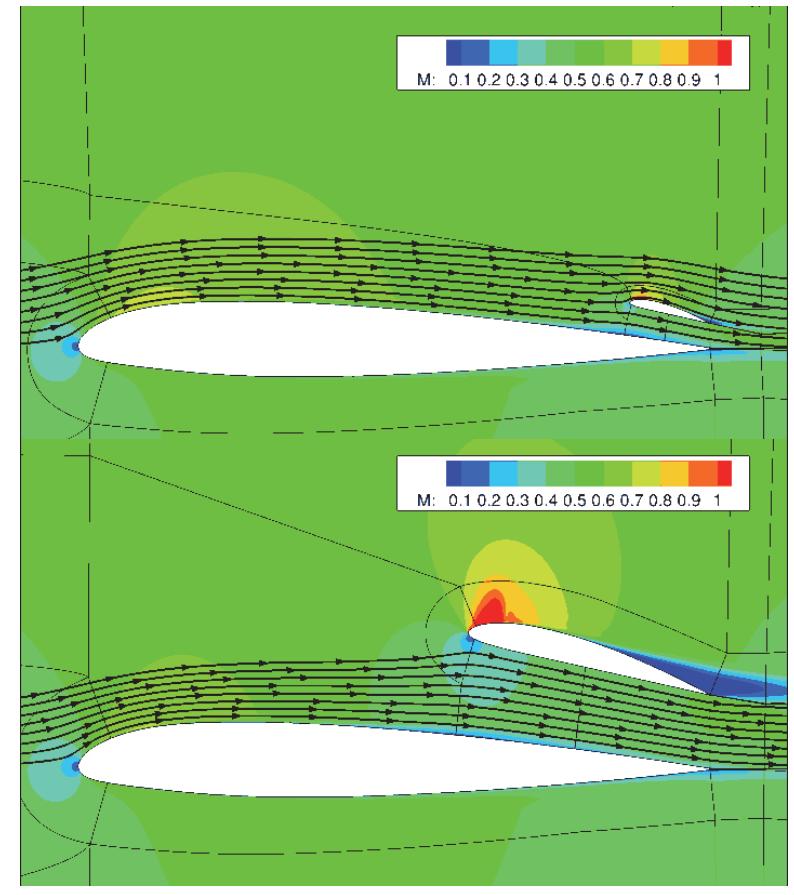

Figure 14. Mach number distributions for small $(D / c=0.04)$ and large $(D / c=0.13)$ engine for thrust/drag balanced condition; $c=$ wing chord at wing station ${ }^{(15)}$.

used within the aero-propulsion experimentation to assess the different benefits and drawbacks delivered by distributed propulsion associated with BLI.

\subsection{Power supply and transmission}

A primary goal of the DMFC is to make provision for BLI via a distributed propulsion system layout and provide significant improvements in propulsive efficiency even when turbo-machinery operate in the presence of highly distorted flow. When BLI is introduced, e.g. for a morphology like a HWB, the airframe and propulsion system are much more closely coupled. Drag produced by the airframe is manifested in the form of lower momentum fluid in the boundary layer, which is ingested by the propulsion system. The propulsion system no longer takes clean and uniform free stream flow even at the design point, and as such the inlet flow distortion is at least an orderof-magnitude higher than what is typically the case at cruise operation for conventional propulsion system installations. Furthermore, with the configuration under investigation the engine exhaust mixes directly with the aircraft wake, whereas, in a conventional configuration the engine exhaust and the aircraft wake generally mix in a separate fashion. All of these effects increase the degree of coupling between the airframe and the fans/engines, requiring new approaches for analyzing and designing BLI propulsion systems. The impact of inlet flow circumferential distortion on stability can be suitably represented by a $\mathrm{PCT}^{(32)}$ based model. The intensity of the flow non-uniformity is described with a distortion coefficient, which takes into account the distorted sector width and the total pressure difference normalised by the mean dynamic head at the Aerodynamic Interface Plane (AIP), as indicated in Fig. 15. 


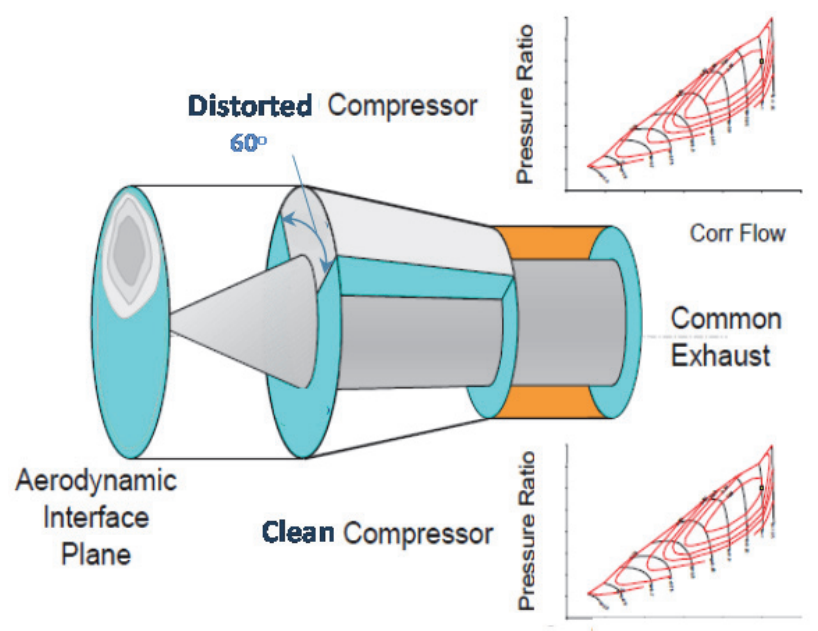

Figure 15. Parallel compressor theory modelling; modified from Kurzke ${ }^{(32)}$.

An indication of how influential circumferential distortion could be was established by inspecting the so-called DC60 on the Fan Surge Margin $\left(S M_{\text {fan }}\right)$ for cruise (M0·80, FL350, ISA) and takeoff (static, sea level, ISA) conditions. It was observed that $S M_{\text {fan }}$ decreased significantly by $30-34 \%$ assuming a circumferential distortion with DC60 $=0 \cdot 35$. Modelling of engine performance in the presence of inlet distortion due to BLI has to take into account this significant impact of inlet distortion on fan surge margin. Early analysis of operating points on standard fan maps with different levels of inlet distortion characterising by DC60 $=0.35$ for takeoff conditions were undertaken and an unacceptable $S M_{f a n}=-20 \%$ was discovered. There are different ways to improve fan stability, including nozzle area variation or fan air blowing. Figure 16 shows the location of a rational operating point at Top-Of-Climb (TOC) design conditions, selected on a special fan map, which provides minimal

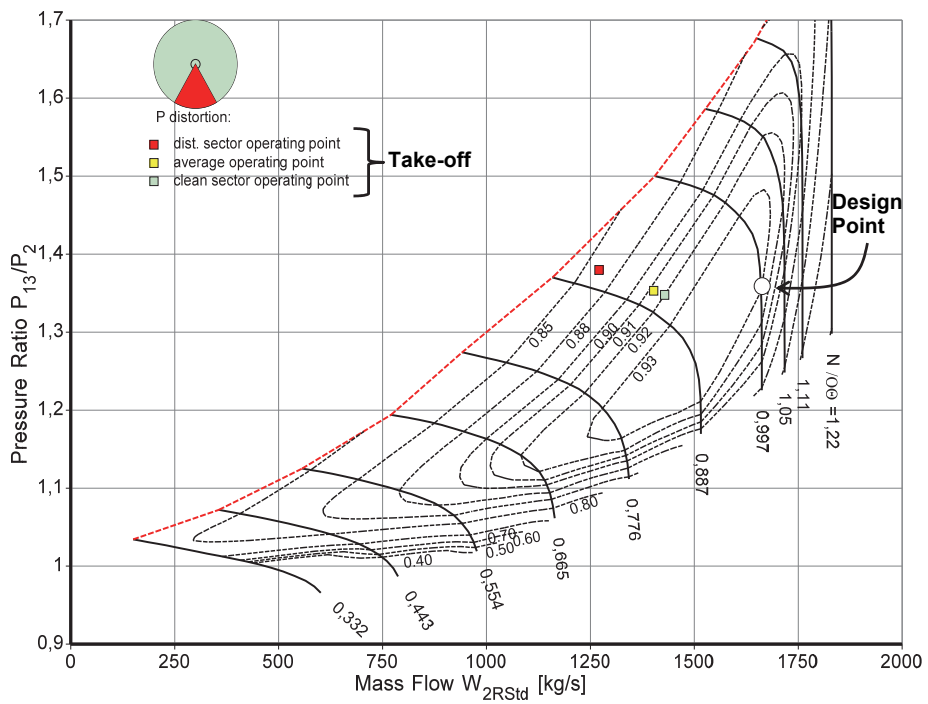

Figure 16. Distributed multiple-fans concept takeoff fan operating point for distorted fan (DC60 $=0 \cdot 35)$ assuming rational selection of design point at top-of-climb generated using GasTurb ${ }^{\mathbb{(}(33)}$. 

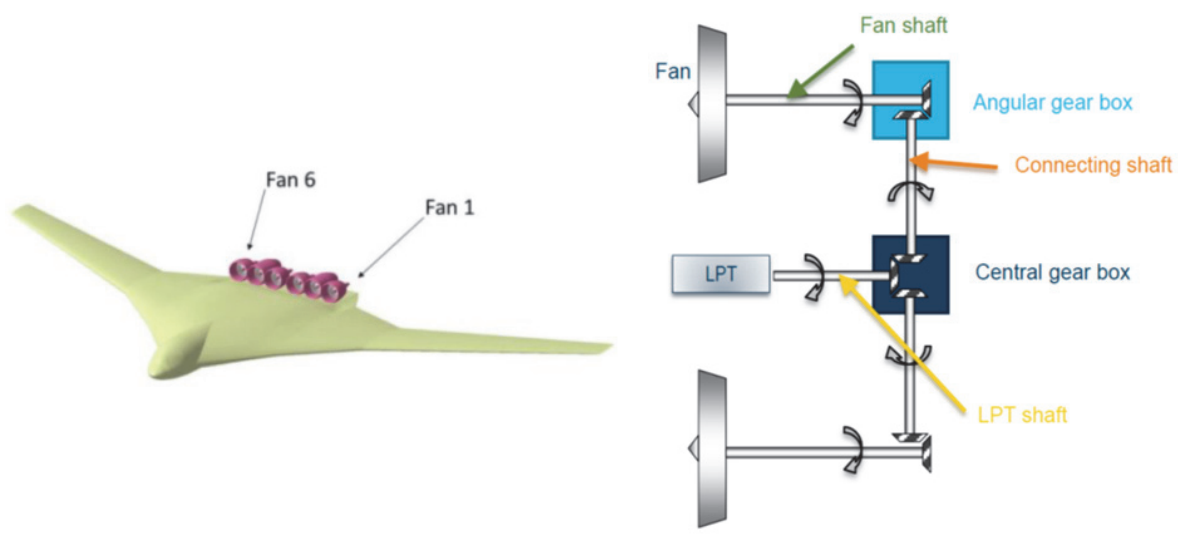

Figure 17. Schematic of power transmission layout of the distributed multiple-fans concept for a given side from aircraft centre-line.

$S M_{f a n} \approx+15 \%$ for the distorted fan (DC60 $\left.=0.35\right)$ in take-off conditions. This shows the importance of taking provision of an acceptable fan surge margin for the distorted fan in all flight conditions.

From the perspective of power transmission and the chosen architecture to support it, similar to the approached presented by Tong et $a l^{(38)}$, a propulsion system package located on each side of the aircraft centre-line, comprising an engine core straddled by mechanically-driven fans on either side off-taking free power from a turbine installed on the core exit with transmission facilitated by shafts and gearboxes was deemed as the appropriate choice (see Fig. 17). This particular arrangement would ensure keeping shaft lengths to a minimum, thereby ensuring the penalising impact of deformations generated by the airframe structure under load are kept at manageable levels. It should be noted that this type of propulsion system integration approach will require bearings fitted to the fans and free-power turbine such that relatively large axial loadings can be absorbed, which tends to increase the overall propulsion system weight. Also, one of the disadvantages of mechanical transmission are losses due to gearing - something like 1-2\% and it was estimated, amounting to $200-400 \mathrm{~kW}$. This necessitates the installation of a dedicated oil cooling system comprising pumps, heat-exchangers and oil tanks.

A synopsis of important propulsion system related parametres associated with the selected design is given in Table 3. As can be seen, important design settings such as engine BPR, i.e. specific thrust level, and fan diameter are noticeably different for the DMFC core compared to the datum 2035R.

Table 3 Synopsis of propulsion system design parametres for DMFC
sized according to an operating condition of M0-80, FL350, ISA

\begin{tabular}{lcccc} 
& & 2035R & DMFC & $\Delta \mathbf{2 0 3 5 R}$ \\
Design Mach number at TOC & {$[-]$} & $0 \cdot 80$ & $0 \cdot 80$ & $0 \%$ \\
Podded Engines & & & & \\
MCL Net Thrust per Engine & {$[\mathrm{kN}]$} & $57 \cdot 5$ & $46 \cdot 4$ & $-19 \cdot 3 \%$ \\
Design Bypass Ratio & {$[-]$} & $18 \cdot 1$ & $20 \cdot 0$ & $+10 \cdot 5 \%$ \\
Fan Diameter & {$[\mathrm{m}]$} & $3 \cdot 30$ & $1 \cdot 88$ & $-43 \cdot 0 \%$ \\
Intake Pressure Ratio & {$[-]$} & $0 \cdot 997$ & 0.975 & $-2 \cdot 2 \%$ \\
& \multicolumn{5}{c}{$\mathbf{M C L}=$ Maximum Climb; TOC = Top-of-Climb }
\end{tabular}




\subsection{General arrangement and attributes}

As a result of the formalised down-selection reviewed in Section 3.1.1, the final sized DMFC aircraft, as visualised in Fig. 18, accommodates 340PAX, provides the same passenger comfort standards as afforded by the 2035R, and adopts similar main systems/sub-systems architecture employed on the 2035R and PFC designs. Based upon the calculation methods and sensitivity studies described in Sections 3.2, 3.3 and 4.1-4.2, assuming the fan inlets being located at $75 \%$ of the total HWB length an ingested drag ratio, $\beta$, of around $11 \%$ resulted. Associated with this is a relative loss in combined overall power plant system efficiency of $10 \%$ due to BLI, which includes the effects of viscous wake flow with reduced momentum, strong non-uniformities in the flow entering the cores and mechanically-driven fans and associated circumferential distortion. Despite the aforementioned detrimental effects on the performance of the DMFC propulsion system, a nominal (engineering target within worst-nominal-best interval) reduction in block fuel burn of up to $8 \%$ relative to $2035 \mathrm{R}$ and $37 \%$ relative to SoAR was established. The overall positive net outcome can be explained by the trade-off between $L / D$ and overall power plant efficiency: when comparing the sizing outcome of almost parity in gross weight, compared to the 2035R using the Specific Air Range (SAR) equation as a basis, the $10 \%$ degradation in overall power plant efficiency is off-set by an almost $18 \%$ improvement in aircraft $L / D$. The complete $L / D$ improvement is broken down as $7 \%$ attributable to morphological change from tube-and-wing to HWB with the remaining $+11 \%$ being a product of ingested drag. A synopsis of important aircraft characteristics, dimensions as well as performance of the selected DMFC design can be found in Section 6.1.2.

\subsection{PROPULSIVE FUSELAGE CONCEPT DESIGN}

Salient results/insights associated with aero-airframe numerical experimentation, as well as the outcomes, findings and technical insights of the completed multi-disciplinary design effort that constituted the PFC design is presented here. As an extension to the original PFC sizing instead of matching aerodynamics/propulsion/airframe according to a typical Long Range Cruise (LRC) speed of M0.80, an alternative 'PFC', was also studied based upon an 'optimal speed matched' LRC of M0.78 for the 4,800nm MAX PAX design range. The PFC* version, primarily a product of wing unsweep yielded significant further improvement in block fuel due to drag, gross weight and required thrust reduction cascade effect for only a minor penalty in flight time. Although not formally declared as a third datum for comparison purposes, notional information that provides

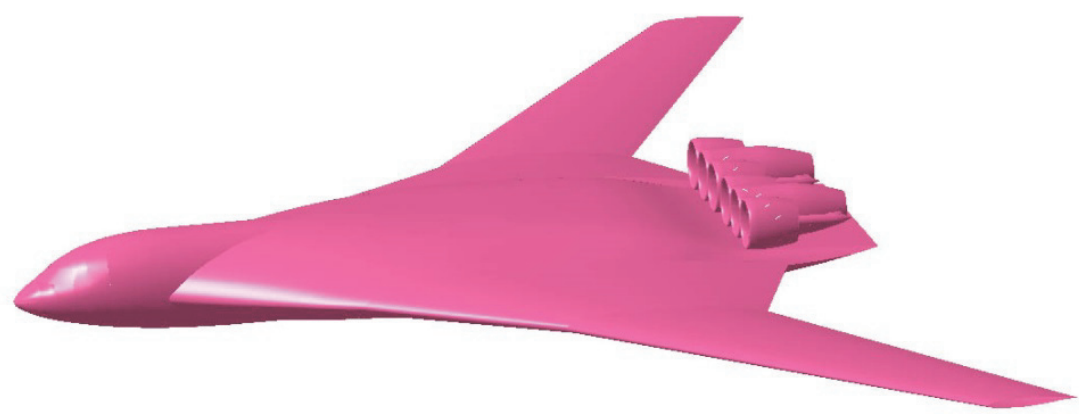

Figure 18. Isometric rendered image of the distributed multiple-fans concept design. 
$\mathrm{PFC}^{*}$ relative merits against a $2035 \mathrm{R}^{*}$ aircraft, the latter being one that constitutes a $\mathrm{M} 0 \cdot 78$ sized version of the 2035R, is briefly discussed within Section 6.1.2.

\subsection{Aero-airframe numerical experimentation}

From an aerodynamics perspective, the goal is to ensure the FF device exhibits qualities where benign internal flow within the inlet without supersonic flow is achieved, and, average and maximum Mach numbers upstream of each disk are kept reasonably low. As a first step design activity, the rear fuselage and the nacelle were modified only in order to obtain a reference geometry reaching the desired thrust and engine mass-flow at cruise. This activity was followed by a sensitivity study with regards to aerodynamic and engine operating conditions. In a second step, the influence of geometric parametres such as the engine fan diameter was assessed.

Due to the fuselage length and rear engine installation, a thick boundary layer (approx $1.0 \mathrm{~m}$ ) immerses the FF device intake, as shown in Fig. 19 (left), where local total pressure/freestream static pressure $<1.52$. It clearly illustrates the increase of total pressure generated by the fan, as well as the low direct influence of the fan on the local Mach number, mainly driven by the engine mass-flow and the cross-section streamwise evolution. Fig. 19 (right), provides a notional understanding of friction lines at the surface of the fuselage (and friction modulus), pressures at the surface of the nacelle and flow streamlines.

The influence of geometrical parametres, such as engine diameter was also assessed. Fig. 20 clearly illustrates for a similar net thrust there existed the risk of 'blockage' in the nozzle with reduced diameter. A nozzle redesign was recommended for such conditions. First, the internal supersonic area in the nacelle nozzle ending with a shock wave at the trailing-edge (see Fig. 21(a)) had to be removed. This was rectified by moving the nacelle forward or extending downstream the straight part of the fuselage in order to get the minimum internal duct section exactly at the nacelle trailing edge, so that the Mach number at full thrust would remain subsonic in the internal duct and would reach its maximum value of $\mathrm{M} 1 \cdot 0$ at the trailing-edge section (choked nozzle). Then, the nacelle leading edge had to be reshaped to avoid the small supersonic area on the internal side (Fig. 21(a)). The leading edge was moved outward by reducing the air intake lip camber, such that the stagnation point moves toward the internal side.

Engine power necessary to generate a target net thrust is shown in Fig. 22 for different power settings or flight Mach number. It should be noted that net thrust is defined as the resulting axial force on the configuration model investigated using CFD methods: disks thrust, less fuselage drag, and less nacelle drag. At typical cruise (M0·80, FL350, ISA), based upon the geometric sensitivities/best practise discussed above a suitably fashioned reference shape surmised to reach
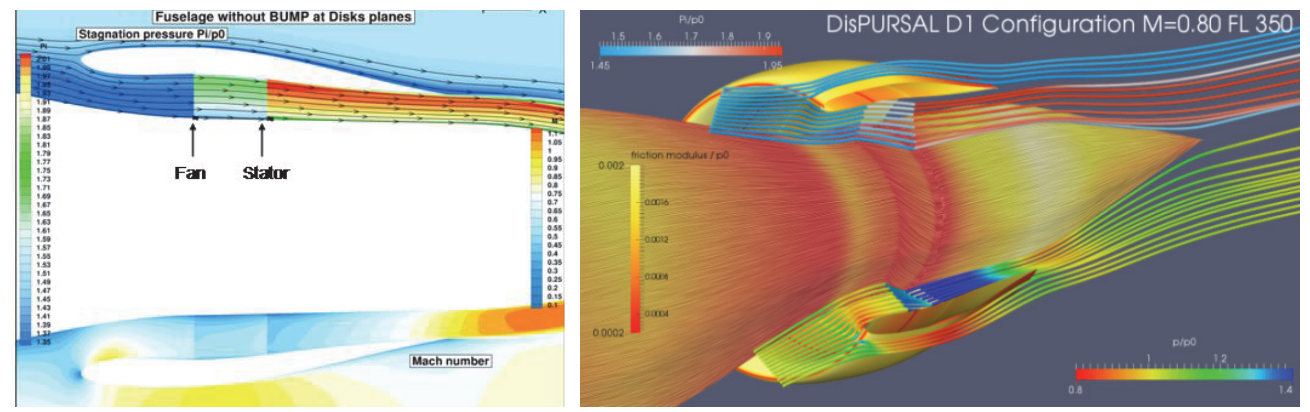

Figure 19. Stagnation pressure (left, upper) and Mach number (left, lower) for a given Fuselage Fan device reference configuration at cruise condition, and, (right) corresponding friction lines, pressures and flow streamlines ${ }^{(15)}$. 


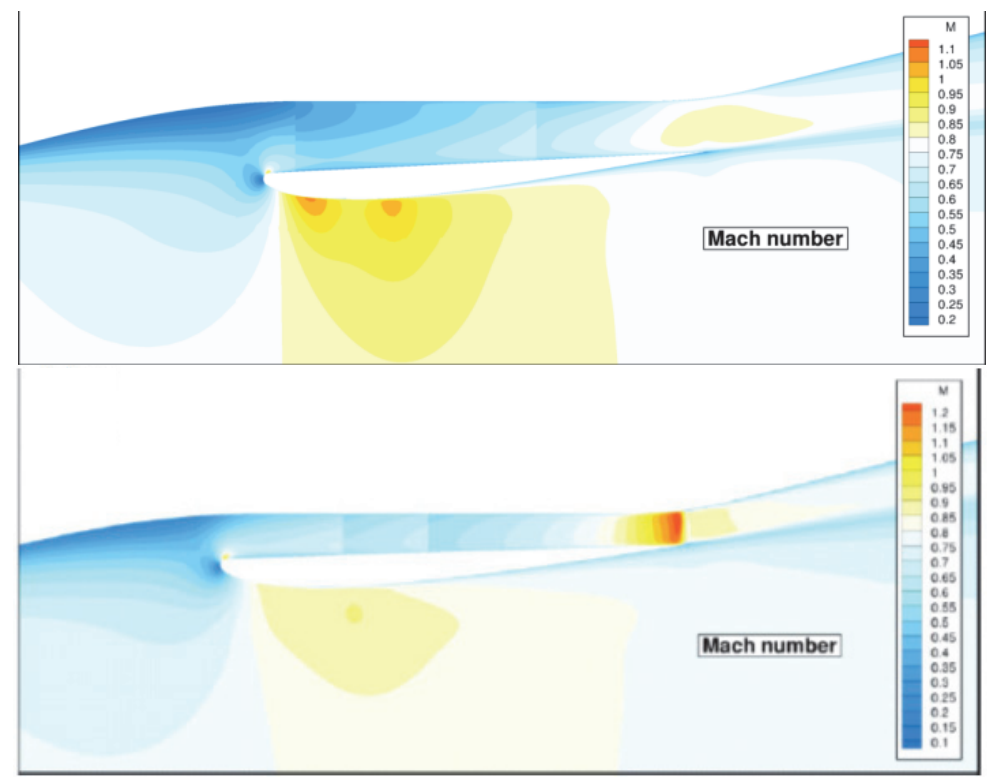

Figure 20. Intermediary results of Fuselage Fan nacelle Mach number evolutions for a reference (top) and a reduced (bottom) engine diameter at cruise ${ }^{(15)}$.

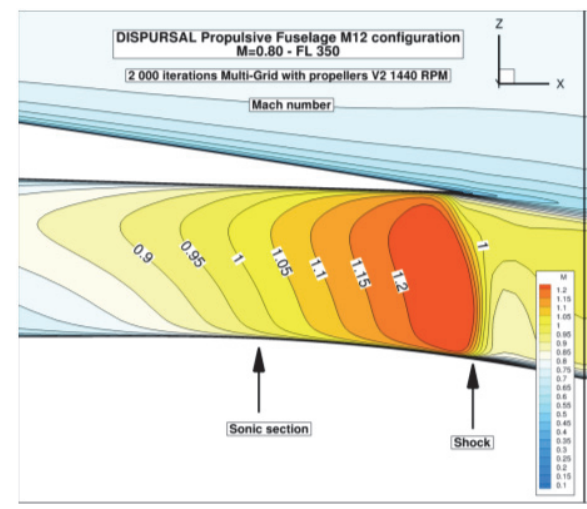

(a)

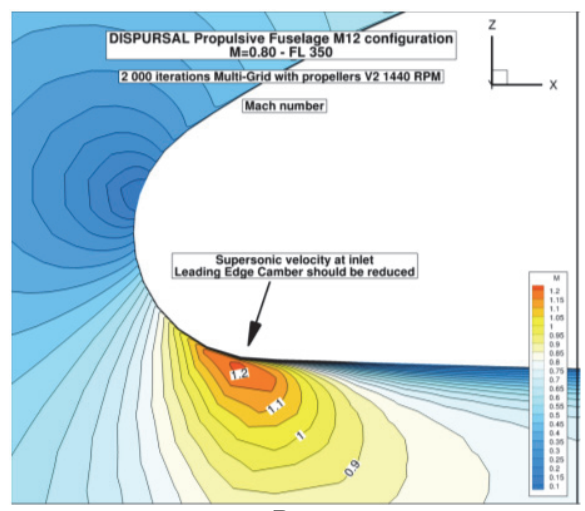

(b)

Figure 21. Intermediary results of Fuselage Fan nacelle internal flow Mach number distributions during typical cruise at (A) nozzle and (B) leading edge.

initial objectives of $12.0 \mathrm{MW}$ in power and $21.0 \mathrm{kN}$ of net thrust was produced. As expected, an increase of engine power was necessary to increase the net thrust for a given Mach number. Similarly, an increase in power is required to get the same net thrust if Mach number is increased, due to drag increase.

Analysis covering the sensitivity of free stream Mach numbers, ranging from M0.75 to M0.85 was also investigated, and results assuming the optimised nacelle shape plus localised fuselage body contouring is given in Fig. 23. Plots of total pressure and local Mach number distributions at 1,450RPM show when the nacelle and body contouring are defined in a thoughtful manner 


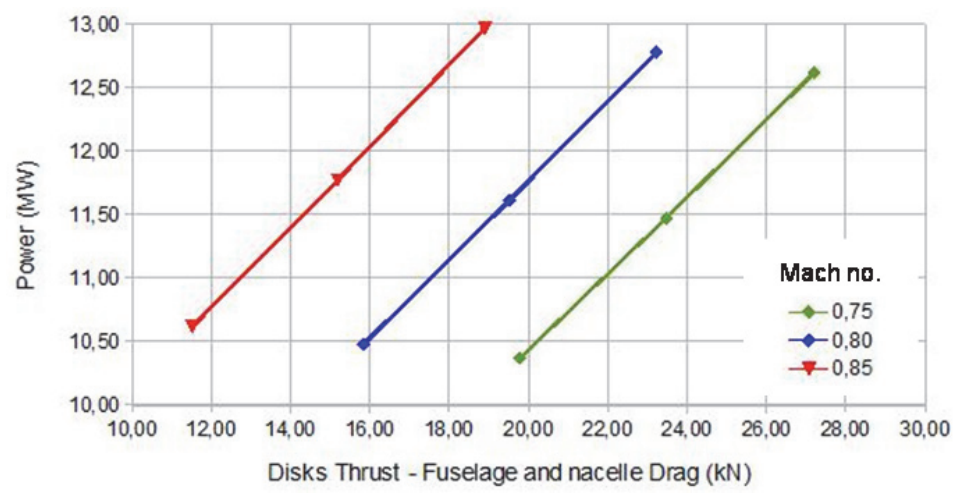

Figure 22. Engine power versus net thrust for various power settings and Mach numbers ${ }^{(15)}$.

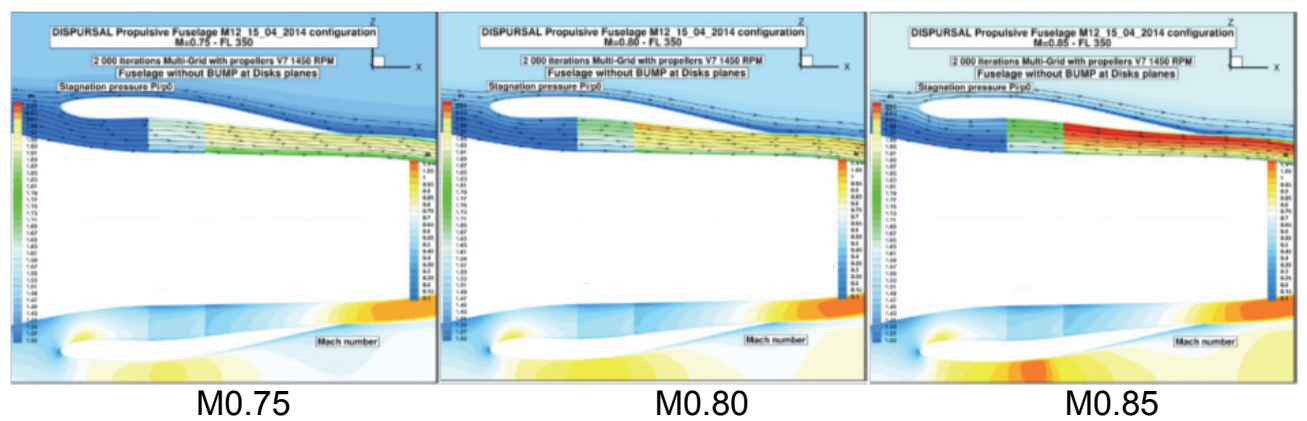

Figure 23. Total pressure and local Mach number contours for the Fuselage Fan device considering variation in free stream Mach number.

the internal flow can remain benign up to a free stream M0.85. There is no supersonic area and no separation in the internal duct, but a supersonic area begins to grow at the upper side of the nacelle for free stream $\mathrm{M} 0 \cdot 85$.

A breakdown of constituent drag coefficients as well as the respective shares of each component associated with each finally sized 2035R and PFC aircraft is given in Table 4. It can be discerned that $C_{D}$ due to skin friction of the PFC in relation to its total $C_{D}$ is significantly lower compared to the proportion observed for the 2035R aircraft. Upon comparison of equivalent adiabatic flat plate areas (based upon skin friction drag) between the PFC and 2035R, the significantly lower value of the PFC is explained primarily by the book-keeping scheme outlined in Section 3.2.1, namely, the fuselage borne skin friction drag of the PFC being completely removed. In conjunction with a further equivalent adiabatic flat plate area reduction due to smaller nacelles sizing, around $-10 \%$, a minor-to-moderate penalising offset due to slight larger wing (same wing loading, but higher MTOW) and empennage resulted in a net equivalent adiabatic flat plate area reduction of $39 \%$ compared to the $2035 \mathrm{R}$. Although slight variations in operating lift coefficient occur (comparison made at M0.80, FL350, ISA, MTOW at brakes release) due to an incrementally lower amount of fuel burn-off of the PFC at initial cruise, comparison of $L / D$ shows approximately $34 \%$ improvement over the 2035R. 


\begin{tabular}{lcccc}
\multicolumn{4}{c}{ Table 4} \\
$\begin{array}{l}\text { Drag breakdown of 2035R and propulsive fuselage concept at } \\
\text { initial cruise (M0-80, FL350, ISA, MTOW at brakes release) } \\
\end{array}$ & \multicolumn{2}{c}{ 2035R } & \multicolumn{2}{c}{ PFC } \\
& C $_{\mathbf{D}}$ [cts] & Ratio [\%] & C $_{\mathbf{D}}$ [cts] & Ratio [\%] \\
CD Skin Friction & 167 & $66 \cdot 3$ & 100 & $54 \cdot 5$ \\
CD Wave & 2 & $0 \cdot 8$ & 2 & $1 \cdot 0$ \\
CD Vortex Induced & 83 & $32 \cdot 9$ & 82 & $44 \cdot 5$ \\
CD Total & 252 & 100 & 184 & 100
\end{tabular}

\subsection{Power supply and transmission}

According to the results obtained from the down-selection process, a single rotating FF device was chosen because of reduced complexity regarding mechanical and structural integration compared to other qualitatively rated alternatives. A shrouded FF was preferred over an open rotor arrangement for noise reasons, and, superior robustness against tail strike.

While in principle one could envision a hybrid-electric drive-train solution for the FF device entering service in year 2035, the main objective of the project was set on the evaluation of a mechanical power-train concept. It was decided a single swan-neck intake could have potential for synergy by being integrated with the empennage attachment structure in some fashion. Moreover, an aft-mounted core engine yields minimum inflow distortion as it does not necessitate a disruption of the fuselage contour in proximity to the forward mounted scoop intakes. In addition, this arrangement benefits from the pressurisation through the FF device. It also features an advantageous utilisation of the volume available within the fuselage aft-cone, and does not reduce the space available upstream of the FF device.

A cutaway view of the FF propulsion system showing important components and design features is given in Fig. 24. The FF is driven by the Low Pressure Turbine (LPT) of a turboengine position in the aft-cone of the aircraft. A planetary reduction gear system decouples both the FF and LPT rotational speeds. The core nozzle is installed at the very aft end of the symmetrically contracting fuselage aft-cone. The FF nacelle incorporates an annular structure required for load transmission between the aft and centre fuselage sections, and, to provide containment in case of fan blade-off scenarios (see Fig. 25). Several axial struts arranged in the FF intake zone serve as load transmitting structures and provide the required space for installing fuel supply lines and electric wiring. In order to avoid ice formation, the nacelle leading edge is equipped with an electrically powered anti-icing system. As outlined above, air supply to the core engine is provided by an eccentrical swan neck intake installed downstream of the FF stator featuring transformation from a smoothed rectangular shape at the inlet to a circular cross section at the attachment to the core engine. In order to reduce pressure losses in the swan-neck S-duct, the contour of the fuselage upstream of the duct inlet necessitates a symmetrical contraction yielding an increasing flow area and hence a reduction of the axial flow Mach number. The axial positioning of the core inlet is tailored to provide sufficient space for straightening any remaining non-uniformities of the FF stator outflow.

A synopsis of important propulsion system related parametres associated with the selected design is given in Table 5. As can be seen, important design settings such as engine BPR, i.e. specific thrust levels, were retained constant for the underwing podded power plants of the PFC. Due to the resulting thrust split, the thrust of the podded engines is reduced yielding a decrease in fan diameter. 


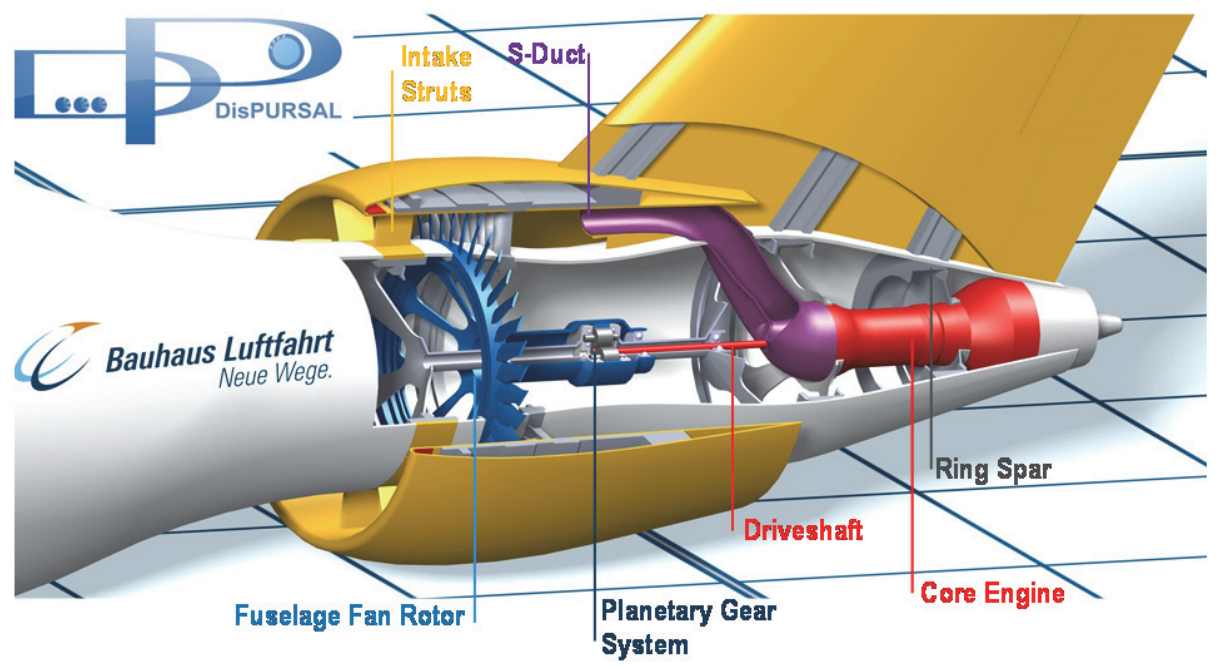

Figure 24. Cutaway view of the Fuselage Fan propulsion system indicating important components and design features ${ }^{(15)}$.

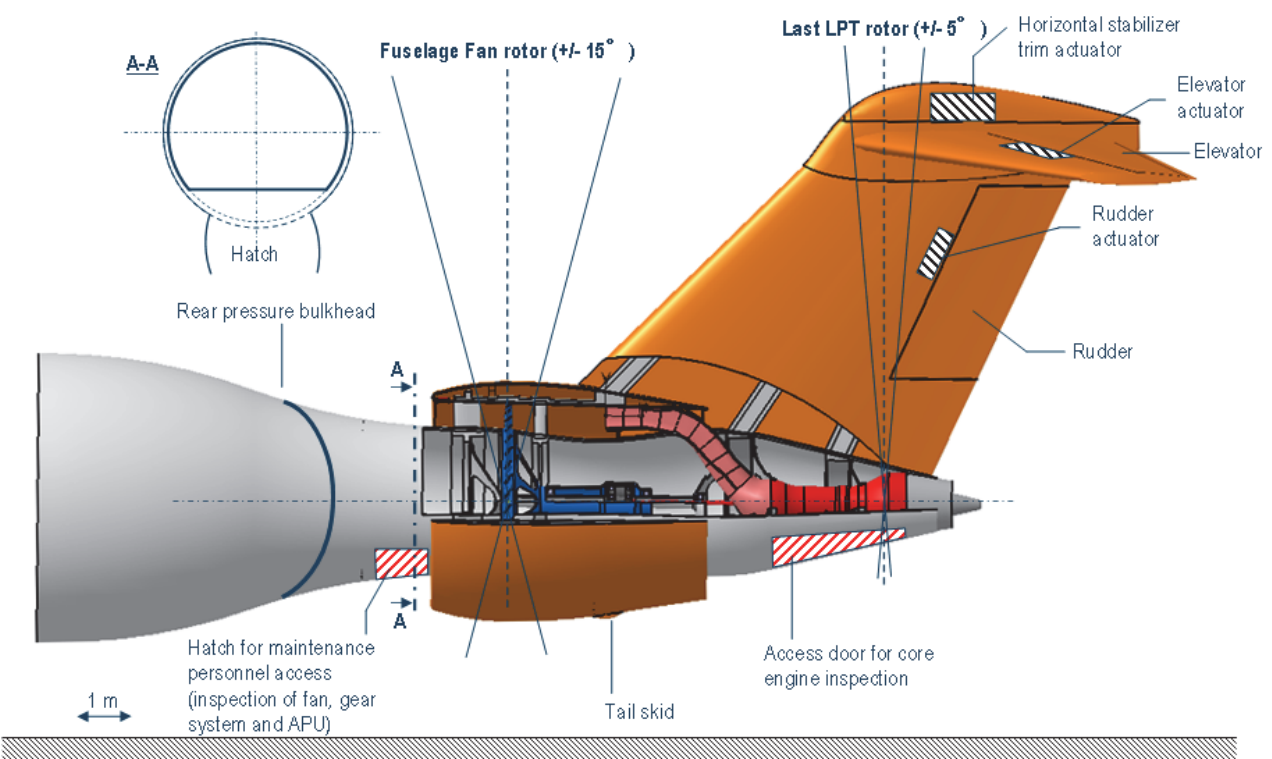

Figure 25. Disk burst corridors of the Fuselage Fan propulsion system; ancillary structures, cabin outfitting as well as APU and associated fuel tank omitted for clarity. 
Table 5

\section{Synopsis of propulsion system design parametres for Propulsive Fuselage Concept sized according to LRC $=$ M0.80 (PFC) and LRC $=0.78\left(\mathrm{PFC}^{\star}\right)$}

$\begin{array}{lcccccc} & & \text { 2035R } & \text { PFC } & \Delta \mathbf{2 0 3 5 R} & \text { PFC* } & \Delta \mathbf{2 0 3 5 R} \\ \text { Design Mach number at TOC } & {[-]} & 0 \cdot 80 & 0 \cdot 80 & 0 & 0 \cdot 78 & -2 \cdot 5 \% \\ \text { Underwing-podded Engines } & & & & & & \\ \text { MCL Net Thrust per Engine } & {[\mathrm{kN}]} & 57 \cdot 5 & 41 \cdot 5 & -27 \cdot 8 \% & 39 \cdot 8 & -30 \cdot 8 \\ \text { Design Bypass Ratio } & {[-]} & 18 \cdot 1 & 18 \cdot 1 & 0 & 18 \cdot 4 & +1 \cdot 7 \\ \text { Fan Diameter } & {[\mathrm{m}]} & 3 \cdot 30 & 2 \cdot 77 & -16 \cdot 1 \% & 2 \cdot 73 & -17 \cdot 3 \\ \text { Intake Pressure Ratio } & {[-]} & 0 \cdot 997 & 0 \cdot 997 & 0 & 0 \cdot 997 & 0 \\ \text { Fuselage Fan Propulsion System } & & & & & & \Delta \mathbf{P F C} \\ \text { MCL Net Thrust } & {[\mathrm{kN}]} & \mathrm{n} / \mathrm{a} & 24 \cdot 4 & \mathrm{n} / \mathrm{a} & 23 \cdot 7 & -2 \cdot 9 \% \\ \text { Design Bypass Ratio } & {[-]} & & 17 \cdot 9 & & 18 \cdot 6 & +3 \cdot 9 \% \\ \text { Design Specific Thrust } & {\left[\mathrm{ms}{ }^{-1}\right]} & & 55 \cdot 0 & & 55 \cdot 0 & 0 \\ \text { Fan Diameter } & {[\mathrm{m}]} & & 4 \cdot 13 & & 4 \cdot 11 & -0 \cdot 1 \% \\ \text { Intake Duct Height at AIP } & {[\mathrm{m}]} & & 0 \cdot 575 & & 0 \cdot 562 & -2 \cdot 3 \% \\ \text { Design Fan Pressure Ratio } & {[-]} & & 1 \cdot 389 & & 1 \cdot 379 & -0 \cdot 1 \% \\ \text { Intake Pressure Ratio } & {[\mathrm{v}]} & & 0 \cdot 867 & & 0 \cdot 872 & +0 \cdot 5 \% \\ \text { Core Intake Pressure Ratio } & {[-]} & & 0 \cdot 975 & & 0 \cdot 975 & 0 \\ \text { FFDGS Gear Ratio } & {[-]} & & 5 \cdot 5 & & 5 \cdot 7 & +3 \cdot 6 \% \\ \text { Design FF Rotational Speed } & \mathrm{RPM} & & 1,380 & & 1,377 & \pm 0\end{array}$

AIP = Aerodynamic Interface Plane; FFDGS = Fuselage Fan Drive Gear System; MCL $=$ Maximum Climb; TOC $=$ Top-Of-Climb

\subsection{General arrangement and attributes}

As a result of a sufficiently exhaustive morphological exploration and down-selection process as intimated in Section 3.1.2, the general configuration of the PFC was conceptually defined. A key feature is the FF device encircling the aft fuselage section, which is primarily intended to ingest the viscous fuselage boundary layer, and, hence to serve the purpose of fuselage WaF. Residual thrust required for the aircraft operation is supplied by two conventionally installed, i.e. under-wing podded turbofans. This configuration complies with propulsion system redundancy and fail-safe requirements stipulated by commercial aircraft certification.

Generally, it was assumed that the same fuselage cross-section, cabin dimensions and advanced technology standard as for the 2035R aircraft applies to the PFC, thus the design of the fuselage forward and centre sections is similar as for the 2035R and the aft section was replaced by specificities associated with installation of an FF device. Apart from the beneficial effects the FF propulsion system affords, the PFC posed a number of significant implications to be carefully addressed during conceptualisation studies. This concerns in particular the aero-thermodynamic integration of the aft-fuselage propulsion system as well as structural aspects including appropriate empennage integration. A major challenge associated with the PFC was associated with the transmission of loads across the FF plane as the load path between the aft and centre section of the fuselage is disrupted by the FF rotor. Mechanical loads 


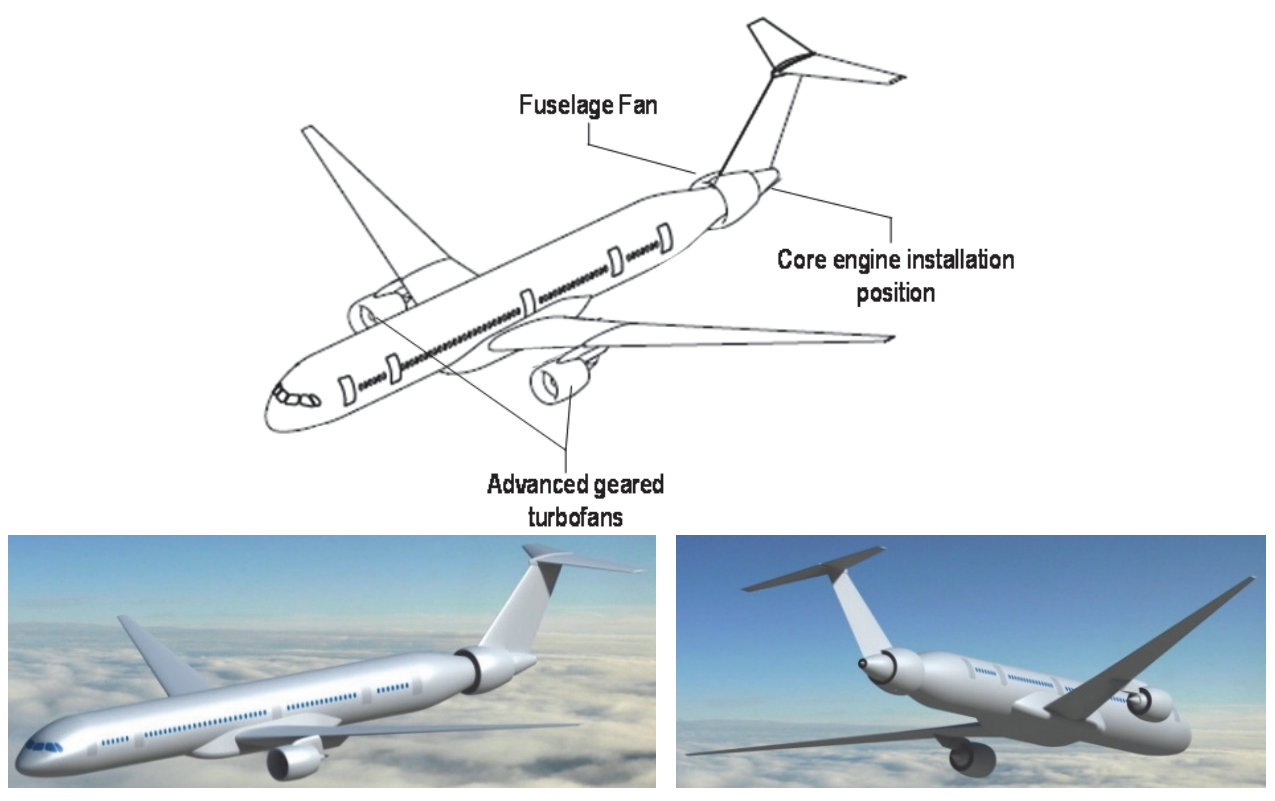

Figure 26. Isometric view and rendered images of the propulsive fuselage concept design.

introduced at the aft-end of the fuselage include inertial and tailplane aerodynamic as well as gyroscopic loads. Fig. 26 provides an isometric view and rendered images of the PFC design.

Based upon the down-selected general layout of the PFC morphology initial sizing and subsequent performance evaluation was conducted. The FF device encircling the aft fuselage was positioned behind the rear pressure bulkhead at $85 \%$ relative fuselage length in order to avoid exposure of the cabin pressure vessel to rotor-burst and to avoid cabin layout and passenger arrangement complexities associated with a non-uniform cabin cross-section (avoid the zone requiring fuselage body contouring). In addition, relative axial positioning between the FF device and empennage was driven by the intent of maximising fuselage drag ingestion while providing appropriate fan disk burst corridors not interfering with critical tail functions. In order to accommodate identical cabin capacity as the 2035R, the fuselage length was increased by $2.0 \mathrm{~m}$ relative to the reference in order to account for the axisymmetrical contraction of the aft fuselage towards the FF inlet. For the horizontal tail, a $5^{\circ}$ anhedral was selected. The tail scrape angle was calculated with $12^{\circ}$ with the main landing gear extended, thus also accounting for a suitable margin regarding any potential stretch version of the aircraft.

The design net thrust between both power plant types installed in the aircraft was iteratively determined in order to allow for parts commonality between engine cores (compressor, combustor and turbine). As a result, the thrust required for the podded power plants is reduced by almost one third relative to the reference yielding a decrease in fan diameter. The final net thrust split for this iteration of sizing was approximately $77 \%$ for the underwing podded and $23 \%$ for the FF device. The selected FF inlet duct height resulted from an optimisation study that included account of sensitivities in FF device weight and power plant performance explicit linked to propulsor size. Based upon the calculation methods presented by Bijewitz et $a l^{(35)}$, Seitz et $a l^{(34)}$ ) and Seitz and Gologan ${ }^{(29)}$, an ingested drag ratio, $\beta$, of around $23 \%$ resulted. Associated with this is a relative loss in combined overall power plant 
system efficiency of $15-20 \%$ due to BLI (mainly because of viscous wake flow with reduced momentum and strong non-uniformities in the flow entering the FF device) for both $\mathrm{PFC} /$ $\mathrm{PFC}^{*}$. Despite the aforementioned detrimental effects on the performance of the FF propulsion system, a nominal (engineering target within worst-nominal-best interval) reduction in block fuel burn of $9-14 \%$ relative to $2035 \mathrm{R}$ and $38-42 \%$ relative to SoAR with the upper bound of improvement synonymous with the PFC* was obtained. A synopsis of important aircraft characteristics, dimensions as well as performance of the selected $\mathrm{PFC} / \mathrm{PFC}^{*}$ designs can be found in Section 6.1.2.

Regarding an explanation as to why the PFC/PFC* nominal outcome is 9-14\% block fuel improvement over the $2035 \mathrm{R}$ even with a sizable degradation in the overall power plant efficiency of the FF device it can be argued thus:

If one observes overall power plant efficiency for a podded gas-turbine, propulsive efficiency generally improves with lower specific thrust. There will be a peak in overall power plant efficiency versus specific thrust because decreasing levels of transmission efficiency (relates the power in the propulsive jet to USble power to drive the propulsor) is associated with it because of the ever increasing impact of pressure losses in the transmission system. This means, generally, transmission efficiency scales inversely with specific thrust. With decreasing specific thrust (increasing duct height) the propulsive efficiency of the FF device improves significantly ${ }^{(29)}$. However, for the FF device, markedly increased stream-tube losses leads to an overall power plant efficiency degradation with decreasing specific thrust levels (as more of the boundary layer velocity profile is ingested) because the transmission efficiency is penalised more compared to a traditional podded engine. With regards to drag book-keeping, since the viscous wake and a portion of boundary layer effects developed by the fuselage body are now considered to be inside the stream tube volume that belongs to the FF propulsion system, this quantity of drag can be removed from the overall aircraft drag accounting, thus leading to a significant improvement in apparent aircraft $L / D$. Since the overall aircraft efficiency, i.e. the SAR, is a product of $L / D$ and overall power plant efficiency (for fixed aircraft gross-weight), the significant improvement in the apparent $L / D$ overcomes the large degradation in overall power plant efficiency of the FF device. Also recall, the PFC has two under-wing podded engines, and the power split between under-wing podded engines to that of the FF device is 2:1 (assuming same core engines), which means the penalising impact of the FF device to the aircraft-level overall power plant efficiency is diminished.

\subsection{EVALUATION AND BENCHMARKING RESULTS}

A sufficiently thorough review of integrated operational performance requires the analysis of block fuel outcomes for a variety of stage lengths. In this interval of stage lengths, the most important cases were taken to be ones that serve as an analogue for a maximum utilisation scenario (basis of defining the Design Service Goal of an aircraft) and the design MAX PAX range. Also, it is important to consider the impact of flight technique (speed schedule and flight profile) to the integrated performance outcome, and so the definition of operationally

permissible speed schedules needed to be fashioned for each studied aircraft and comparisons made on that basis. The integrated operational performance outcomes served as primary input for subsequent prediction of $\mathrm{CO}_{2}$-emissions, $\mathrm{NO}_{X}$-emissions, external noise and operating economics assessment. 

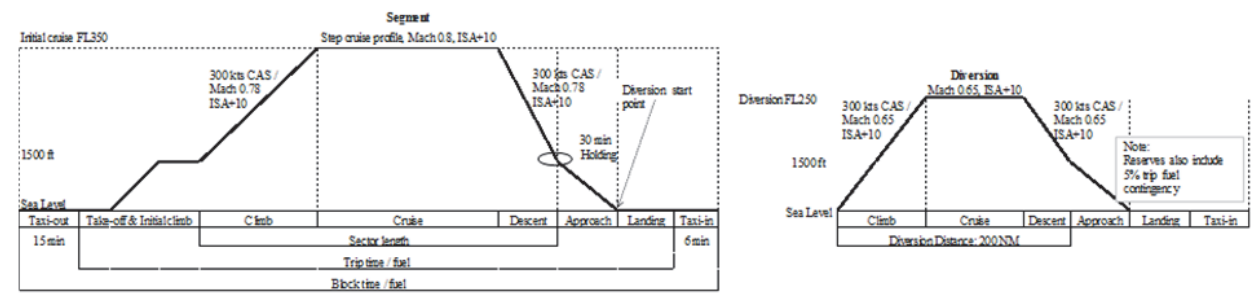

Figure 27. Integrated en route operational flight profile including reserves and contingency fuel policy.

\subsection{En route integrated operational performance}

A complete mission flight profile trajectory as depicted in Fig. 27 consists of three consecutive segments: climb, cruise and descent. Flight time and flight fuel include allowances required for takeoff, initial climb, approach and landing. The block time and block fuel includes additional allowances for start-up, taxi-out and taxi-in. The notion of flight and block definitions does not include any distance credit. Each stage length analysis had with it an associated reserve fuel carried to destination. The set of results to follow are based on aircraft covering stage lengths between $1,500 \mathrm{~nm}(2,778 \mathrm{~km})$ and $4,800 \mathrm{~nm}(8,890 \mathrm{~km})$ with generic international rules in effect. The stage length mission comprises reserves and contingency fuel policy consisting of $30 \mathrm{~min}$. hold at 1,500 $\mathrm{ft}$ pressure altitude, $200 \mathrm{~nm}(370 \mathrm{~km})$ diversion and includes $5 \%$ trip fuel. A passenger payload complement of $100 \%$ load factor at $102 \mathrm{~kg}$ each per PAX was also considered. Speed schedules were deemed open to optimisation and/or judicious selection in relation to each reference and concept aircraft.

\subsubsection{Identification of operationally permissible speed schedules}

For sake of emulating original performance standards during the design sizing and optimisation process, the DMFC and PFC proposals matched the SoAR and 2035R typical/standard LRC speed of M0.80 when fulfilling a MAX PAX, 4800nm range, which subsequently defined the design weights of each. Prudence dictates seeing how the typical array of operational speed definitions, namely, Maximum Range Cruise (MRC), LRC, Economical Long Range Cruise (ELRC) and High-Speed Cruise (HSC) intrinsic to the DMFC and PFC compare against the SoAR and 2035R aircraft. Recalling standard operational practise, traditionally, the LRC speed is taken to be $99 \%$ of the MRC Specific Air Range (SAR) at the faster end of the curve ${ }^{(39,40)}$. This is employed in order to trade increased speed capability for what is considered to be a relatively small penalty in fuel consumption rate. The typical operational speeds of each the SoAR, 2035R, DMFC and PFC were derived to be:

$\begin{array}{lllll}\text { - SoAR and 2035R:MRC }=\text { M0.78 } & \text { ELRC }=\text { M0.79 } & \text { LRC }=\text { M0.80 } & \text { HSC }=0.85 \\ \text { - DMFC: } & \text { MRC }=\text { M0.78 } & \text { ELRC }=\text { M0.79 } & \text { LRC }=\text { M0.80 } & \text { HSC }=0.85 \\ \text { PFC: } & \text { MRC }=\text { M0.75 } & \text { ELRC }=\text { M0.78 } & \text { LRC }=\text { M0.80 } & \text { HSC }=0.85 \\ \text { PFC*: } & \text { MRC }=\text { M0.75 } & \text { ELRC }=\text { M0.78 } & \text { LRC }=\text { M0.78 } & \text { HSC }=0.85\end{array}$

\# as discussed in Section 5, contrived standard LRC to facilitate a like-for-like comparison

\subsubsection{Comparative Analysis of Reference and Concept Aircraft}

Table 6 compares and contrasts the relative merits of 2035R, DMFC, and the PFC together with PFC* against the year 2000 datum of SoAR. 


\section{Table 6}

\section{Leading (nominal data) particulars of the reference and concept aircraft studied}

\begin{tabular}{|c|c|c|c|c|c|c|}
\hline Design Range & {$[\mathrm{nm}]$} & $\begin{array}{c}\text { SoAR } \\
4,800\end{array}$ & $\begin{array}{c}2035 R \\
4,800\end{array}$ & $\begin{array}{c}\text { DMFC } \\
4,800\end{array}$ & $\begin{array}{c}\text { PFC } \\
4,800\end{array}$ & $\begin{array}{l}\text { PFC* } \\
4,800\end{array}$ \\
\hline Accommodation & {$[\mathrm{PAX}]$} & 340 & 340 & 340 & 340 & 340 \\
\hline MTOW & {$[\mathrm{kg}]$} & 229,000 & 206,270 & 206,540 & 208,970 & 203,335 \\
\hline OEW & {$[\mathrm{kg}]$} & 123,638 & 123,462 & 127,240 & 130,585 & 127,235 \\
\hline OEW/MTOW & {$[-]$} & $0 \cdot 54$ & $0 \cdot 599$ & $0 \cdot 616$ & 0.625 & 0.626 \\
\hline MZFW & {$[\mathrm{kg}]$} & 169,039 & 170,345 & not given & 177,465 & 174,120 \\
\hline MLW & {$[\mathrm{kg}]$} & 179,000 & 182,265 & not given & 189,890 & 186,305 \\
\hline Ref Area, Airbus Gross (SW) & {$[\mathrm{m} 2]$} & $363 \cdot 1$ & $335 \cdot 4$ & 614 & $339 \cdot 8$ & $330 \cdot 7$ \\
\hline Wing Aspect Ratio, Airbus Gross & {$[-]$} & $9 \cdot 3$ & $12 \cdot 6$ & $6 \cdot 9$ & $12 \cdot 4$ & $12 \cdot 6$ \\
\hline Wing Span & {$[\mathrm{m}]$} & 58 & 65 & 65 & 65 & $64 \cdot 7$ \\
\hline Fuselage Length & {$[\mathrm{m}]$} & $63 \cdot 7$ & $67 \cdot 0$ & $37 \cdot 0$ & $69 \cdot 0$ & $69 \cdot 0$ \\
\hline Wing Loading (MTOW/SW) & {$[\mathrm{kg} / \mathrm{m} 2]$} & $630 \cdot 7$ & 615 & 336 & 615 & 615 \\
\hline Total Max $\cdot$ Static Thrust (SLS) & {$[\mathrm{kN}]$} & $632 \cdot 6$ & $627 \cdot 2$ & 603 & $635 \cdot 4$ & $618 \cdot 1$ \\
\hline Thrust-to-Weight (SLS, MTOW) & {$[-]$} & $0 \cdot 282$ & $0 \cdot 31$ & $0 \cdot 298$ & $0 \cdot 31$ & $0 \cdot 31$ \\
\hline TOFL (MTOW b.r., ISA, SL) & {$[\mathrm{m}]$} & 2,346 & 2,225 & 2,300 & 2,300 & 2,300 \\
\hline VREF (MLW, ISA, SL) & [KCAS] & 131 & 133 & not given & 138 & 137 \\
\hline Ingested Drag Ratio, $\beta$ & {$[\%]$} & $\mathrm{n} / \mathrm{a}$ & $\mathrm{n} / \mathrm{a}$ & $10 \cdot 5$ & $23 \cdot 7$ & $23 \cdot 2$ \\
\hline$L / D$ (Typ $\cdot$ CRZ, FL350, ISA) & {$[-]$} & $20 \cdot 7$ & $22 \cdot 5$ & $26 \cdot 5$ & $30 \cdot 2$ & $30 \cdot 7$ \\
\hline Total cruise TSFC & & & & & & \\
\hline (Typ· CRZ, FL350, ISA) & {$[\mathrm{g} / \mathrm{kN} \cdot \mathrm{s}]$} & $16 \cdot 2$ & $13 \cdot 1$ & $14 \cdot 5$ & $15 \cdot 7$ & $15 \cdot 3$ \\
\hline Typical LRC/MRC & {$[-]$} & $\begin{array}{l}\text { M0.80/ } \\
\text { M0.78 }\end{array}$ & $\begin{array}{l}\text { M0.80/ } \\
\text { M0.78 }\end{array}$ & $\begin{array}{l}\text { M0.80/ } \\
\text { M0.78 }\end{array}$ & $\begin{array}{l}\text { M0.80/ } \\
\text { M0.75 }\end{array}$ & $\begin{array}{l}\text { M0.78/ } \\
\text { M0.75 }\end{array}$ \\
\hline Design Payload, Max PAX & {$[\mathrm{kg}]$} & 34,680 & 34,680 & 34,680 & 34,680 & 34,680 \\
\hline $\begin{array}{l}\text { Block Fuel, Max PAX, 4,800nm, } \\
\text { Typ· CRZ, FL350, ISA }\end{array}$ & {$[\mathrm{kg}]$} & 62,166 & 42,257 & 38,960 & 38,380 & 36,295 \\
\hline $\begin{array}{l}\Delta \text { Block Fuel, Max PAX, 4,800nm, } \\
\text { Typ. CRZ, FL350, ISA }\end{array}$ & {$[-]$} & datum & $-32 \cdot 0 \%$ & $-37 \cdot 3 \%$ & $-38 \cdot 3 \%$ & $-41 \cdot 6 \%$ \\
\hline
\end{tabular}

Regarding design weights, the 2035R indicates a reduction of 9.9\% in Maximum Take-Off Weight (MTOW) and almost parity Operating Empty Weight (OEW) due to installation of very high BPR GTF propulsion system and larger, more spacious cabin due to projected passenger anthropometrics. The DMFC was found to have an almost parity outcome in terms of MTOW with the 2035R, but with a penalty of $+3 \cdot 1 \%$ OEW due to the installation of the distributed multiple-fans propulsion system. The PFC aircraft is seen to be heavier with regards to both MTOW $(+1 \cdot 3 \%)$ and OEW $(+5 \cdot 8 \%)$, whereas, the 'optimal speed matched' PFC* sizing yielded an outcome of a leaner $-1 \cdot 4 \%$ MTOW, but again, due to the presence of the FF device the OWE ended up being $+3 \cdot 1 \%$ versus the 2035R. The 2035R, DMFC and PFC/PFC* show comparatively much higher OEW/MTOW in relation to the SoAR and this is also indicative of the significantly lower fuel useful load needed in completing the same MAX PAX design range of $4,800 \mathrm{~nm}(8,890 \mathrm{~km})$.

Owing to the ICAO Annex 14 Code E limitation ${ }^{(19)}$ the 2035R and PFC/PFC* aircraft are span limited and due to the adoption of a slender, very flexible in-plane planform (aspect ratio of circa 
$12+$ ) exhibit a modest reduction in wing loading compared to the SoAR. As expected, the DMFC with HBW aircraft morphology has a very low wing loading and wing aspect ratio compared to the other aircraft even when span limited according to ICAO Annex 14 Code $\mathrm{E}^{(19)}$.

The 2035R* aircraft, which embodies a M0.78 sized version of 2035R for the same accommodation and design range although not formally presented in Tab. 6 above does necessitate a brief review. In relation to $2035 \mathrm{R}$, the $2035 \mathrm{R}^{*}$ is characterised by deltas of around $-2 \%$ in MTOW, OEW and maximum sea level static thrust, and, $-3 \%$ in design range block fuel. Upon comparison against SoAR in terms of design range block fuel, the 2035R* outcome was established to be $-34 \%$ as opposed to $-32 \%$ when considering $2035 \mathrm{R}$ versus SoAR. If one now compares PFC* to that of 2035R*, firstly, differences in terms of relative MTOW, OEW and maximum sea level static thrust were found to be similar to comparisons made between PFC and 2035R. Regarding block fuel for the 4,800nm design range, differences were found to be distinct, namely, $-11 \cdot 5 \%$ for PFC* versus $2035 \mathrm{R} *$ in contrast to $-9 \%$ for PFC versus $2035 \mathrm{R}$. To finalise the synopsis, it is highlighted to the reader that $2035 \mathrm{R}^{*}$ does suffer from one problem from an operational perspective: MRC/ ELRC/LRC schedules all collapse to M0.78 synonymously, which is detrimental in terms of speed flexibility. Subsequently, for the sections to follow a conscious decision was made to not have more than two datum, i.e. SoAR (principal comparison basis) and 2035R, in order to simplify an already complex array of data presentations within this technical article.

\subsubsection{Comparison of block fuel for given stage length}

Block fuel results for a selected number of stage lengths assuming MRC, LRC and HSC speeds for the 2035R, PFC and DMFC aircraft is provided in Fig. 28. Regarding MAX PAX maximum range capability at $\mathrm{HSC}$, the SoAR aircraft has the largest with $4,280 \mathrm{~nm}(7,926 \mathrm{~km})$, the PFC with $4,240 \mathrm{~nm}(7,852 \mathrm{~km})$, the $2035 \mathrm{R}$ with $4,180 \mathrm{~nm}(7,741 \mathrm{~km})$ and the DMFC was predicted to yield $4,010 \mathrm{~nm}(7,426 \mathrm{~km})$. The $2035 \mathrm{R}$ aircraft indicates a relative block fuel improvement of $30 \cdot 0-32 \cdot 0 \%$ versus the SoAR covering MRC/LRC speed stage lengths from $1,500 \mathrm{~nm}(2,778 \mathrm{~km})$ to $4,800 \mathrm{~nm}(8,890 \mathrm{~km})$, and, $29 \cdot 0-30 \cdot 5 \%$ reduction in block fuel at HSC for a similar stage length interval. Upon perusal of the chart, it can also be seen that the rate change in block fuel reduction is very similar between 2035R and PFC for all stage lengths using MRC/LRC and HSC speed schedules. The DMFC shows similar behavior, but from around 3,500nm $(6,482 \mathrm{~km})$ onwards. For stage lengths less than $3,500 \mathrm{~nm}$, the DMFC shows attributes of tending to converge towards the 2035R aircraft level of relative block fuel reduction narrowing the gap from $-37 \%$ to $-32.5 \%$ for MRC/LRC speed stage lengths of 4,800nm and 2,000nm respectively, and from $-33.5 \%$ to $-30 \cdot 0 \%$ for HSC stage lengths of 4,000nm $(7,408 \mathrm{~km})$ and $2,000 \mathrm{~nm}(3,704 \mathrm{~km})$ respectively. Relative to SoAR, the PFC demonstrates a relative block fuel improvement of $39 \cdot 5 \%$ at $4,800 \mathrm{~nm}$ and $37 \cdot 0 \%$ at $2,000 \mathrm{~nm}$ compared to the $2035 \mathrm{R}$. A further $2 \cdot 0 \%$ improvement to the PFC outcome could be generated with adoption of the $\mathrm{PFC}^{*}$ sizing approach.

For purposes of comparing and contrasting PFC and DMFC performance against the 2035R, analysis of the results yielded the same qualitative conclusions as the PFC and DMFC versus SoAR aircraft discussed above. Nominally (engineering target within worst-nominal-best interval), it was observed the DMFC produces $7 \cdot 5 \%$ lower block fuel outcome and the PFC over $11 \%$ reduction when examining 4,800nm range at ELRC/LRC speed schedules. For the same type of operation, the PFC* generated a result towards $-14 \%$ block fuel.

\subsection{Emissions and external noise}

The environmental impact of transport aircraft is also taken into consideration when evaluating value of the equipment type. Restrictions dealing with external noise, and, $\mathrm{CO}_{2}$-emissions and 


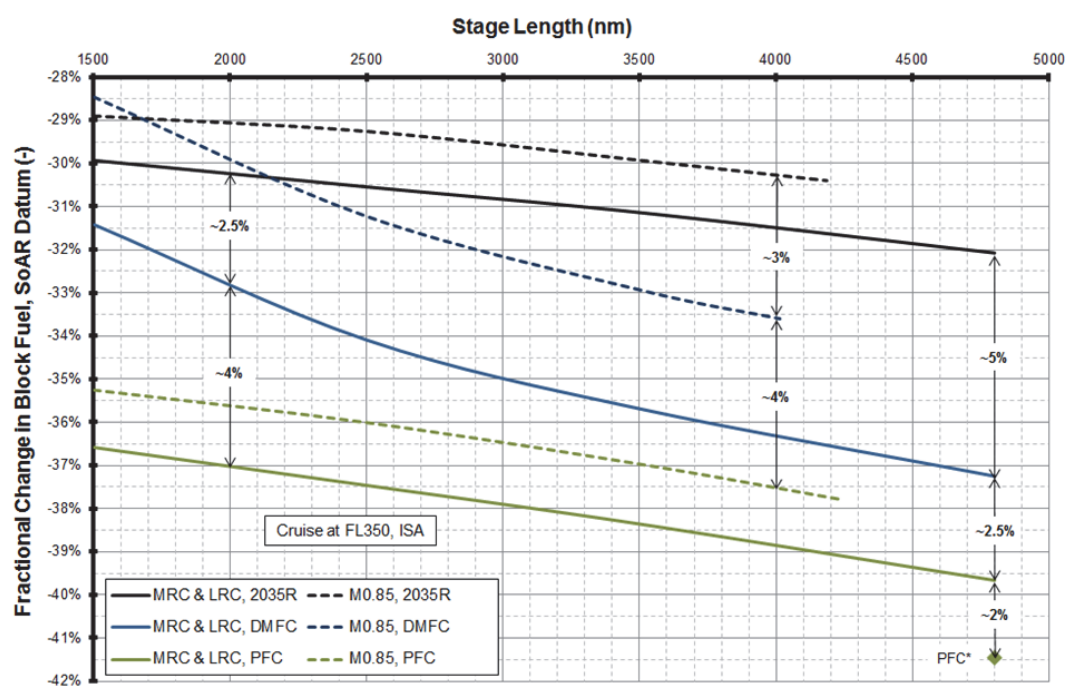

Figure 28. Fractional change in block fuel for 2035R, DMFC and PFC assuming various operational speed schedules; SoAR taken as datum.

$\mathrm{NO}_{x}$-emissions are directly attributable to standards set by ICAO. International standards of ICAO regarding the impact of environmental performance of civil aviation were published in terms of Volume I 'Aircraft Noise' and Volume II 'Aircraft Engine Emissions' of Annex 16 to the international convention ${ }^{(41,42)}$.

\subsubsection{Comparison of the $\mathrm{CO}_{2}$-emissions evaluation metric}

In keeping with the procedures given by Ref. 43, the so-called Metric Value of $\mathrm{CO}_{2}$-emissions, $\mathrm{MVCO}_{2}$, is a figure-of-merit espoused by ICAO as a future means of establishing $\mathrm{CO}_{2}$-emissions certification requirements. At this moment in time, ICAO is still under discussions about the applicability of $\mathrm{MVCO}_{2}$ methods to novel and unconventional aircraft configurations. Notwithstanding this aspect, since it shall constitute the basis for a new Volume III of ICAO Annex 16 Environmental Protection ${ }^{(43)}$ and shall be applied to all subsonic jets and propeller-driven aeroplanes receiving Type Certificates under Part 25 rules, it was deemed appropriate that the $\mathrm{CO}_{2}$-emissions analysis to be presented here reflects this method.

Figure 29 displays the relative merits of the $2035 \mathrm{R}$ versus SoAR, DMFC versus SoAR, DMFC versus 2035R, PFC versus SoAR and PFC versus 2035R. In order to facilitate interpretation of results according to operational performance conventions, MRC, ELRC and LRC have been shown for the 2035R, DMFC and PFC. It is evident that the 2035R aircraft produces a $\mathrm{CO}_{2}$-emissions reduction of around $33 \%$ compared to SoAR. This difference is approximately the same for the entire speed interval of $\mathrm{M} 0 \cdot 75-0 \cdot 80$. This level of $\mathrm{CO}_{2}$-emissions reduction represents approximately an $18 \%$ shortfall against the SRIA 2035 goal of $-51 \%$ for combined Airframe and PPS. In contrast, DMFC, at an $\mathrm{LRC}=\mathrm{M} 0.80$ the amount of $\mathrm{CO}_{2}$-emissions reduction was found to be just over $40 \%$ compared to SoAR, thus producing a deficit of $11 \%$ compared to the SRIA 2035 goal. For a cruise speed at MRC, this level of $\mathrm{CO}_{2}$-emissions reduction degrades slightly to $-40 \%$, however, at HSC the amount of reduction was found to 


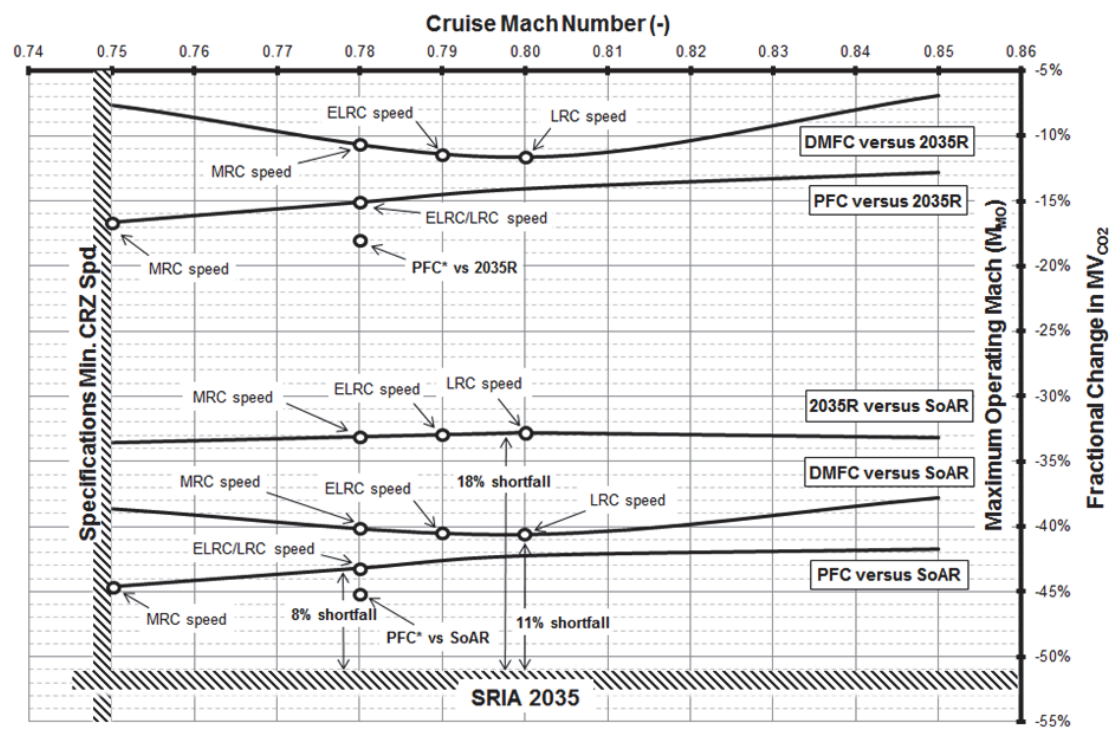

Figure 29. $\mathrm{CO}_{2}$-emissions evaluation metric, $\mathrm{MVCO}_{2}$, results for 2035R, DMFC and PFC aircraft.

be around $38 \%$, which indicates a heightened level of speed sensitivity if DMFC operational requirements emphasise on-time dependability. The $\mathrm{PFC} \mathrm{CO}_{2}$-emissions reduction potential varies between over $44 \%$ at $\mathrm{MRC}=\mathrm{M} 0.75$ and almost $42 \%$ at $\mathrm{HSC}=\mathrm{M} 0 \cdot 85$. Assuming the common speed comparison standard of $\mathrm{M} 0 \cdot 80, \mathrm{MVCO}_{2}$ was found to be $-42 \%$ compared to the SoAR datum. At an LRC speed of $\mathrm{M} 0 \cdot 78$, the $\mathrm{CO}_{2}$-emissions reduction was found to be over $43 \%$, which narrows the shortfall to the SRIA 2035 target at approximately $8 \%$. If instead the $\mathrm{PFC}^{*}$ is considered the deficit to SRIA 2035 narrows to around $6 \%$.

\subsubsection{Comparison of $\mathrm{NO}_{x}$-emissions}

In order to improve the environmental conditions surrounding airports ICAO regularly declare more stringent emissions $\left(\mathrm{NO}_{x}\right.$, unburnt hydrocarbons, carbon monoxide and smoke) standards ${ }^{(42)}$. Since 2008, by way of the Committee on Aviation Environmental Protection (CAEP) the ICAO Standard on $\mathrm{NO}_{x}$-emissions (CAEP/6) was enforced, and in contrast to CAEP/2 (introduced in 1996) and CAEP/4 (introduced in 2004) it is approximately $30 \%$ and $12 \%$ more stringent, respectively. In 2010 ICAO through CAEP accepted new requirements to $\mathrm{NO}_{x}$-emissions (CAEP/8). According to the DisPURSAL Project ATLeRs (see Section 2.1) the EIS 2035 goal for $\mathrm{NO}_{x}$-emissions is at $84 \%$ reduction relative to a year 2000 typical level. The SRIA 2035 subsidiary $\mathrm{NO}_{x}$ goal for local air quality (Landing-Take-Off cycle, LTO) is a $65 \%$ reduction margin from $\mathrm{CAEP} / 6^{(3)}$. As a result an estimation of $\mathrm{NO}_{x}$-emissions levels for SoAR, 2035R, DMFC and PFC aircraft were performed in the project.

$\mathrm{NO}_{x}$-emissions prediction for all aircraft were performed using GasTurb $12^{\mathrm{TM}^{(33)}}$ and was based on the Universal Combustor Model ${ }^{(44)}$. The approach considers $\mathrm{NO}_{x}$-emissions from combustors is of the diffusion flame type, and in this 1D approach the combustors are represented by a series of reactors, each characterised by averaged values of residence time and fuel-air-ratio, according to the assumed geometry and the corresponding mass flow distribution inside the combustor. The $\mathrm{NO}_{x}$ formation process is modeled by a simplified Zeldovich mechanism, reflecting the thermal $\mathrm{NO}_{x}$ pathway. 


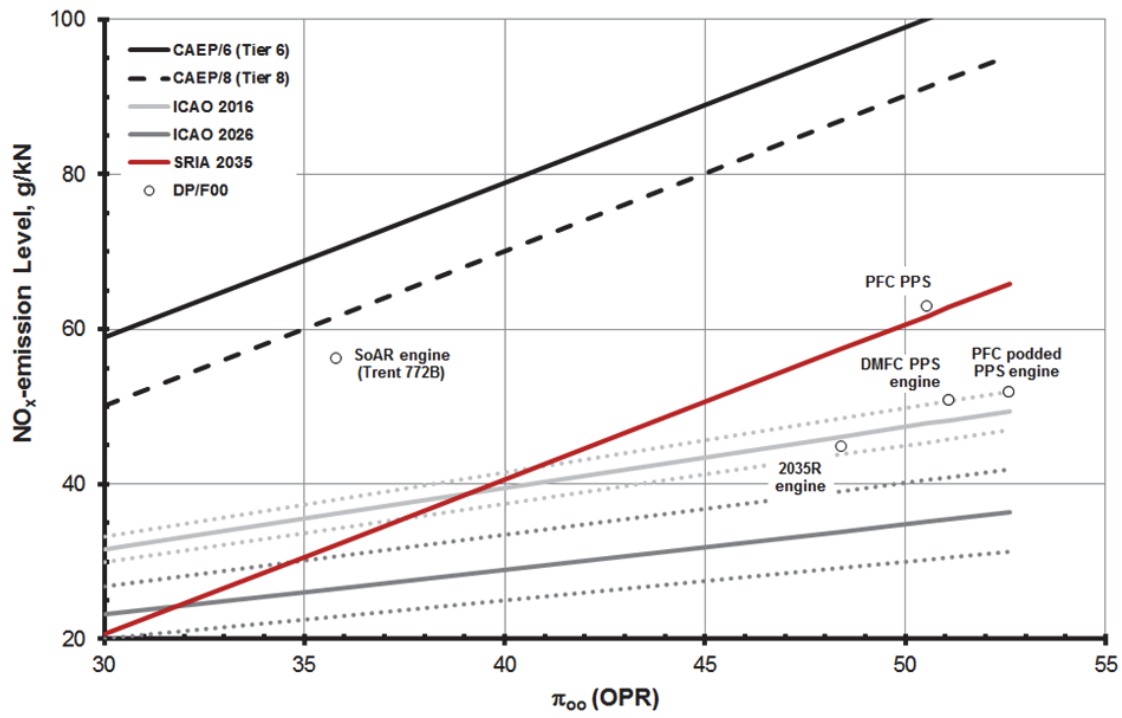

Figure 30. Results of LTO NO

Figure 30 displays the level of $\mathrm{NO}_{x}$-emissions, or $D_{P} / F_{\text {oo }}$ expressed in units of $\mathrm{g} / \mathrm{kN}(1 \mathrm{~g}$ of $\mathrm{NO}_{x}$-emissions per $1 \mathrm{kN}$ of takeoff thrust), for the complete propulsion system of SoAR, 2035R, DMFC and PFC. Inspection of the chart highlights two separate points plotted for the PFC: one indicating $D_{P} / F_{o o}$ for the twin underwing podded engines, and the other marking the entire propulsion collectively representing the two underwing podded engines and the FF device. The reason for delineating between podded engines only and the entire PFC propulsion systems is the fact that, irrespective of the common part-numbers, the propulsion system of the PFC design comprises two types of engines in terms of Overall Pressure Ratio $\left(\mathrm{OPR}, \pi_{o o}\right)$ working parametres. ICAO Standards do not take into account propulsion systems with two different types of engines and correspondingly different OPR, and as such, a calculation according to ICAO Standards currently poses a problem of consistency.

To continue, Fig. 30 above indicates the 2035R, DMFC engines and the podded engines of the PFC have a margin to SRIA $2035 \mathrm{NO}_{x}$-emissions of $19-22 \%$. The SoAR fails to meet SRIA 2035 requirements by a considerable amount, namely, $75 \%$. For the PFC design, as the podded and FF engines have different OPR working parametres, excessive $\mathrm{NO}_{x}$-emissions of the FF device is connected to the detrimental effects of BLI (penalties imposed on transmission efficiency) and the low level of thrust. Even with this taken into account, the entire propulsion system of the PFC aircraft produces a $D_{P} / F_{\mathrm{oo}}$ result close to the SRIA 2035 threshold. Although a prediction for PFC was not generated in this particular investigation, in view of the almost $3 \%$ reduction in TOC design thrust compared to the PFC aircraft means there is circumstantial evidence to indicate the $D_{P} / F_{\text {oo }}$ result will tend towards meeting SRIA 2035.

\subsubsection{Comparison of external noise}

Cumulative noise levels are defined as the arithmetic sum of the noise levels at each of three certification points. According to ICAO Noise Standards noise certification limits depend upon $\mathrm{MTOW}^{(45)}$. Regulations for future aircraft designs are required to meet the following guidelines: 


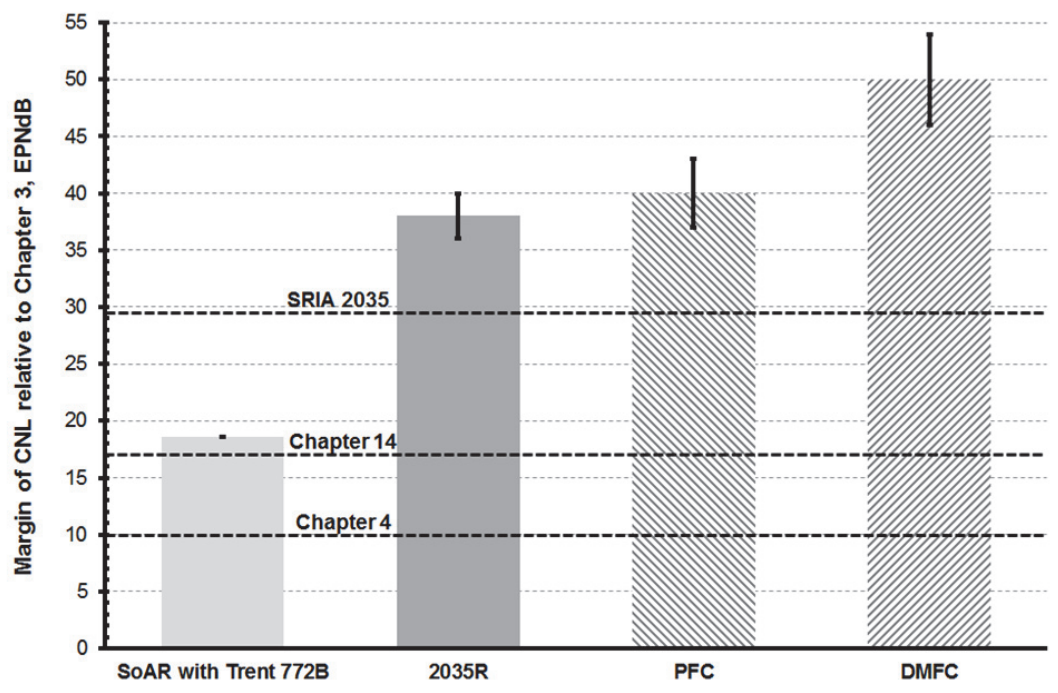

Figure 31. Results of external noise assessments for SoAR, 2035R, DMFC and PFC aircraft based upon CIAM-TsAGI in-house CNPP predictions.

- ICAO Annex 16 Chapter 14 (for all CAEP countries)

- Chapter 3 limits corresponding to each measurement location must be established

- Trades not allowed on individual margins

- The sum of all three margins relative to Chapter 14 must be greater than $17 \mathrm{EPNdB}$

- The sum of any two margins relative to Chapter 14 must be greater than 2 EPNdB

For this study, external noise was mostly assessed in a qualitative manner by DisPURSAL Project subject matter experts with the assistance of calculations produced by in-house software. Calculations of source fan and jet noise, airframe noise and acoustic liner efficiency were based upon the CIAM in-house developed Community Noise Prediction Program (CNPP), which uses state-of-the-art semi-empirical techniques corrected according to internal CIAM-TsAGI (Central Aero-hydro-gasdynamic Institute) acoustic test data. Shielding effects for the DMFC configuration were estimated based upon publications made by $\mathrm{NASA}^{(46)}, \mathrm{ICAO}^{(47)}$, and various CIAM internal reports. According to the ICAO Independent Experts Report uncertainties of noise predictions of advanced aircraft configurations strongly depend upon morphology type and $\operatorname{EIS}^{(47)}$.

In the assessment of the Cumulative Noise Level (CNL) aircraft concepts including 2035R, DMFC and PFC have been carried out taking into account majority features of the advanced aircraft morphology in question as well as configuration specific items such as using novel acoustic liners, ultra-high BPR engines, additional gearbox noise sources and noise shielding. The external noise level of the SoAR aircraft with Trent 772B engine corresponds to certification data from NoiseDB database ${ }^{(48)}$. CNL results together with their corresponding uncertainties are presented in the bar chart of Fig. 31 above; and, uncertainties related to the nominal CNL predictions are presented as plus-or-minus values. As it can be seen in the posted results the 2035R and PFC are likely to meet stated external noise requirements espoused by the ATLeRs, i.e. a CNL margin relative to the typical 2000 level (declared here as the SoAR aircraft noise level) of 11 EPNdB. Taking into account a probable additional noise reduction due to using advanced low noise takeoff 
procedures it may be proposed that 2035R and PFC aircraft will have additional margin relative to the noise requirement given by the ATLeRs. Although a prediction for $\mathrm{PFC}^{*}$ was not produced in this particular investigation, there is strong circumstantial evidence (almost $3 \%$ reduction in maximum static thrust compared to the PFC aircraft) to indicate the ensuing external noise result will meet, if not exceed, the SRIA 2035 requirement. The DMFC configuration appears to be more effective than the other aircraft due to noise shielding and has about 20-22 EPNdB improvement relative to SoAR. On other hand, it should be noted that the configuration has the largest level of uncertainties (about $\pm 4 \mathrm{EPNdB}$ ) due to insufficient experimental information on efficiency of noise shielding for HWB configurations.

\subsection{Operating economics evaluation}

Upon reflection about the very preliminary nature of these initial technical assessments, only Cash Operating Cost (COC) plus Additional Operating Cost (AOC) analysis is presented in this technical article. For purposes of undertaking a Direct Operating Cost analysis, Cost of Ownership (which includes depreciation, interest and insurance costs) requires a suitably robust prediction of aircraft list price. In the context of the DMFC and PFC designs Cost of Ownership constitutes approximately $25-50 \%$ of the Direct Operating Cost (increasing proportion with increasing stage length). In a simplified sense, this means a condition of Direct Operating Cost parity with 2035R would occur if, relative to the 2035R, the DMFC or PFC Cost of Ownership increases by around $3 \%$ for every percentage point of $\mathrm{COC}+\mathrm{AOC}$ reduction generated by such advanced concepts. Echoing recommendations espoused by Isikveren et $a l^{(49)}$ and Isikveren ${ }^{(50)}$, the extent of subjectivity involved in gauging the relative value of product offerings, thence leading to an estimation of aircraft list price, makes for an uncertain basis of comparison. In view of the potential for inconsistency Direct Operating Cost is intentionally not presented here; however, provided a coherent and consistent method is established in the future follow-on investigations should account for this economics sub-space as well.

The COC is defined to be a tally of expenditures related to fuel, crew, maintenance, airport and en route charges. A crew cost model was based on the Association of European Airlines (AEA) methodology where crew hourly rates are expressed as a function of aircraft MTOW and number of passengers $^{(51,52)}$. En route charges for ATM reflects US/European charge levels ${ }^{(53)}$. Airport charges vary between airports, region and time of day, and these charges typically cover expenditures such as landing or ground handling fees. They are determined using parametric cost functions based on MTOW and number of passengers ${ }^{(54)}$. The Direct Maintenance Cost (DMC) covers labour and material cost associated with airframe and engine. Operational dependencies, such as flight cycle and flight time were considered, as well as any de-rating of the engines. The airframe DMC was calculated with an analogous costing method $^{(55)}$ and the engine DMC were determined using parametric cost functions ${ }^{(56)}$.

The AOC covers external noise, and, $\mathrm{NO}_{x}$-emissions and $\mathrm{CO}_{2}$-emissions related charges. $\mathrm{NO}_{x}$ calculations are based on the pollutants of engine emissions defined by the ICAO engine database ${ }^{(57)}$ or computed using specialised prediction methods (see Section 6.2.2 for results of 2035R, DMFC and PFC designs). The noise charge model uses aircraft specific standardised noise values for arrival and departure ${ }^{(58)}$.

A combined COC plus AOC set of calculations was conducted for stage lengths spanning $1,500 \mathrm{~nm}$ to 4,800nm in accordance with operational rules defined in Section 6.1 and assuming a load factor of 100\% (340 PAX). In view of the minimal difference in ELRC speed schedules between each of the pool of aircraft that constitute this study, optimal economic outcomes were compared and contrasted between aircraft. All analysis results reflected a year 2012 standard and the working 
currency was assumed to be in US dollars (USD). Based upon information downloaded from the US Energy Information Administration ${ }^{(59)}$ fuel price was nominally assumed to be USD 3.30 per US gallon (USG), and with intent to gauge sensitivities, a lower value of USD $2 \cdot 00$ per USG and an upper limit of USD 6.00 per USG were declared. By using this min-nominal-max bandwidth of values, it provided a means of treating the operating economics analysis in a non-deterministic manner.

Regarding appropriate account of the airframe and propulsion DMC cost constituents, adjustments were made from the datum SoAR in order to capture alterations in bill-of-material and type of integrated technology associated with the 2035R, DMFC and PFC/PFC* aircraft. These modifications, according to the Air Transport Association (ATA) chapters ${ }^{(60)}$ are qualitatively listed as:

- ATA 24 Electric Power - more complex electrical system for 2035R, DMFC and PFC

- ATA 26 Fire Protection - additional fire protection for PFC with third engine

- ATA 27 Flight Controls - difficulty with empennage access for PFC

- ATA 29 Hydraulic Power - removal of hydraulics for 2035R, DMFC and PFC

- ATA 30 Ice and Rain Protection - much larger surfaces for DMFC

- ATA 32 Landing Gear - variation in certified design weights for 2035R, DMFC and PFC

- ATA 36 Pneumatics - removal of pneumatics for 2035R, DMFC and PFC

- ATA 53 Fuselage - made of mostly CFRP for 2035R, DMFC and PFC; FF structure for PFC

- ATA 54 Nacelles and Pylons - CFRP nacelles for 2035R, and, DMFC and PFC with additional nacelles

- ATA 57 Wings - made mostly of CFRP for 2035R, DMFC and PFC

- ATA 71 Power Plant - additional power transmission bill-of-material items for DMFC and PFC

- ATA 72 Engine - adjusted according to engine working parametres for 2035R, DMFC and PFC Figure 32 presents the variation of $\mathrm{COC}+\mathrm{AOC}$ for the 2,035R, DMFC and PFC aircraft each relative to the SoAR datum. Curves representing speed schedules of combined ELRC/LRC and M0.85 are provided in order to appreciate the effect of speed to the operating economics outcome. It should be noted that at $\mathrm{HSC}=\mathrm{M} 0.85$ maximum range capability of each aircraft is limited to: $4,280 \mathrm{~nm}(7,926 \mathrm{~km})$ for the SoAR, 4,180nm $(7,741 \mathrm{~km})$ for the 2,035R, 4,010nm $(7,426 \mathrm{~km})$ for the DMFC and 4,240nm $(7,852 \mathrm{~km})$ for the PFC. The chart indicates a constraint line denoting $\mathrm{COC}+\mathrm{AOC}$ minus $20 \%$ in keeping with the ATLeRs definition presented in Section 2.1. It has been observed that the 2035R did not meet the ATLeRs for stage lengths less than 4,000nm $(7,408 \mathrm{~km})$ assuming an ELRC/LRC speed schedule and less than $3,300 \mathrm{~nm}(6,112 \mathrm{~km})$ for HSC. The same requirement is violated for stage lengths of $2,100 \mathrm{~nm}(3,889 \mathrm{~km})$ and $2,400 \mathrm{~nm}(4,445 \mathrm{~km})$ for the DMFC when cruising at ELRC/LRC and HSC respectively.

Synonymous with speed variation the best outcome for DMFC is $-22 \cdot 5 \%$ to $-23.5 \%$ at maximum range, and, irrespective of speed schedule, the best result for $2035 \mathrm{R}$ is $-20.5 \%$ at maximum permissible range. When adopting ELRC/LRC speeds for the PFC the COC+AOC outcome was found to be approximately $-20 \cdot 5 \%$ to $-24 \cdot 5 \%$ compared to the SoAR for a stage length interval covering $1,500 \mathrm{~nm}(2,778 \mathrm{~km})$ through $4,800 \mathrm{~nm}$.

Upon comparison of differences at the maximum utilisation analogue, i.e. 2,000nm stage lengths, with SoAR as the datum and assuming a ELRC/LRC speed schedule the DMFC was found to be over $1 \%$ lower and the PFC $3.0 \%$ better than the $2035 \mathrm{R}$. For the maximum range case of $4,800 \mathrm{~nm}$ DMFC was observed to be $3 \%$ lower than the $2035 \mathrm{R} \mathrm{COC}+\mathrm{AOC}$, and the PFC was found to $7 \cdot 0 \%$ better. 


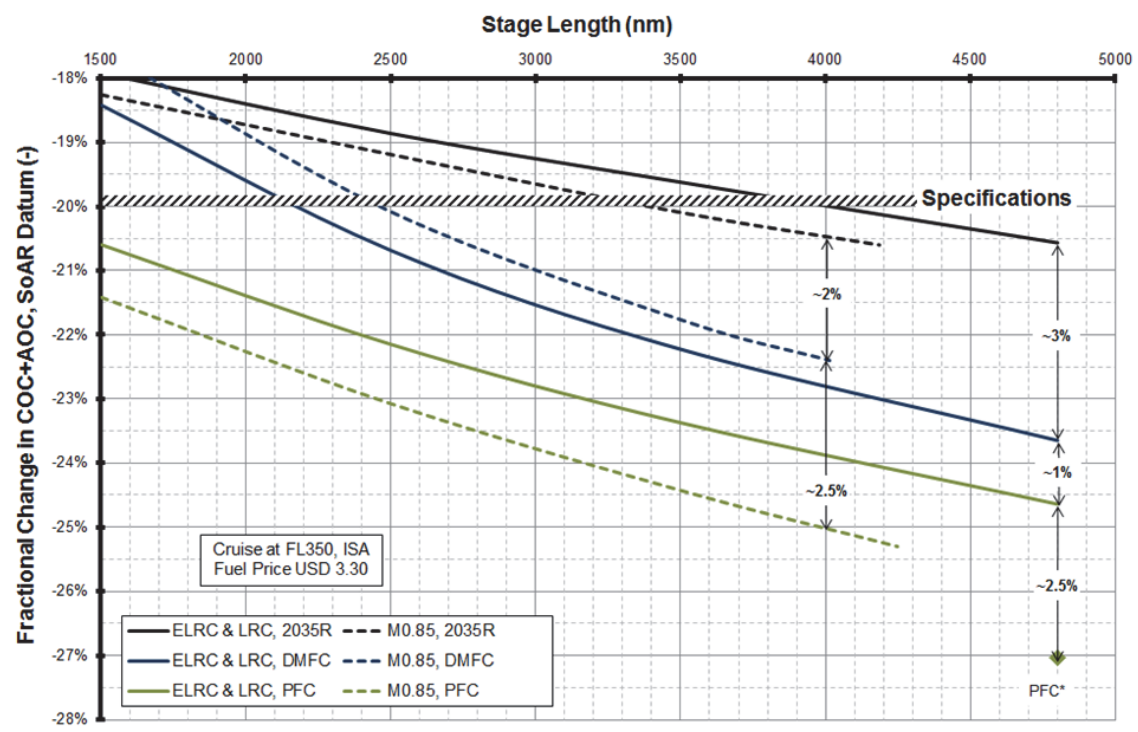

Figure 32. Fractional change in COC+AOC for 2035R, DMFC and PFC assuming various operational speed schedules, SoAR taken as datum.

When 2035R is taken to be the datum, the DMFC and PFC appear to show a $4 \cdot 0 \%$ and $5 \cdot 0 \%$ improvement in $\mathrm{COC}+\mathrm{AOC}$ respectively when adopting a speed schedule of ELRC/LRC and completing the maximum range of $4,800 \mathrm{~nm}$. The same flight technique for a $2,000 \mathrm{~nm}$ stage length produced an outcome of $-1 \cdot 5 \%$ for the DMFC and $-3 \cdot 5 \%$ for the PFC. At M0 85 , the greatest reduction (at maximum permissible range) in relative $\mathrm{COC}+\mathrm{AOC}$ was $2.5 \%$ for the DMFC and $5 \cdot 5 \%$ with respect to the PFC.

Instead of varying stage length, it would be of interest to examine variation in fuel price for stage lengths corresponding to the maximum utilisation analogue $(2,000 \mathrm{~nm})$ and maximum range $(4,800 \mathrm{~nm})$ assuming typical ELRC and LRC speed schedules. Figure 33 presents the variation of $\mathrm{COC}+\mathrm{AOC}$ for the 2035R, DMFC and $\mathrm{PFC}$ aircraft each relative to the SoAR datum. As with Fig. 32 , this chart also includes the $\mathrm{COC}+\mathrm{AOC}$ minus $20 \%$ constraint line.

Upon perusal of Fig. 33, it can be seen that the DMFC meets the COC + AOC minus 20\% condition for a fuel price of USD 3.50 when undertaking 2,000nm and USD 2.20 for the 4,800nm case. The PFC delivers this constraint for the entire min-nominal-max bandwidth of fuel prices when it concerns the maximum range case; however, manages to cross the constraint at USD 2.60 for the maximum utilisation analogue stage length - which is considered to be encouraging since this value is below the nominal fuel price of USD $3 \cdot 30$. For an arbitrary target of COC + AOC minus $30 \%$, except for the PFC conducting maximum range and assuming a maximum fuel price of USD 6.00, none of the other scenarios comply. Finally, Fig. 33 also contains the locus of $\mathrm{COC}+\mathrm{AOC}$ variation with fuel price for the 'optimal speed matched' $\mathrm{PFC}$ * undertaking maximum range only and results show an encouraging $\mathrm{COC}+\mathrm{AOC}$ reduction of $22-32 \%$ for the min-nominal-max fuel price bandwidth. Further scrutiny indicates the PFC* produced COC + AOC minus $30 \%$ at a fuel price of USD 4.90 . 


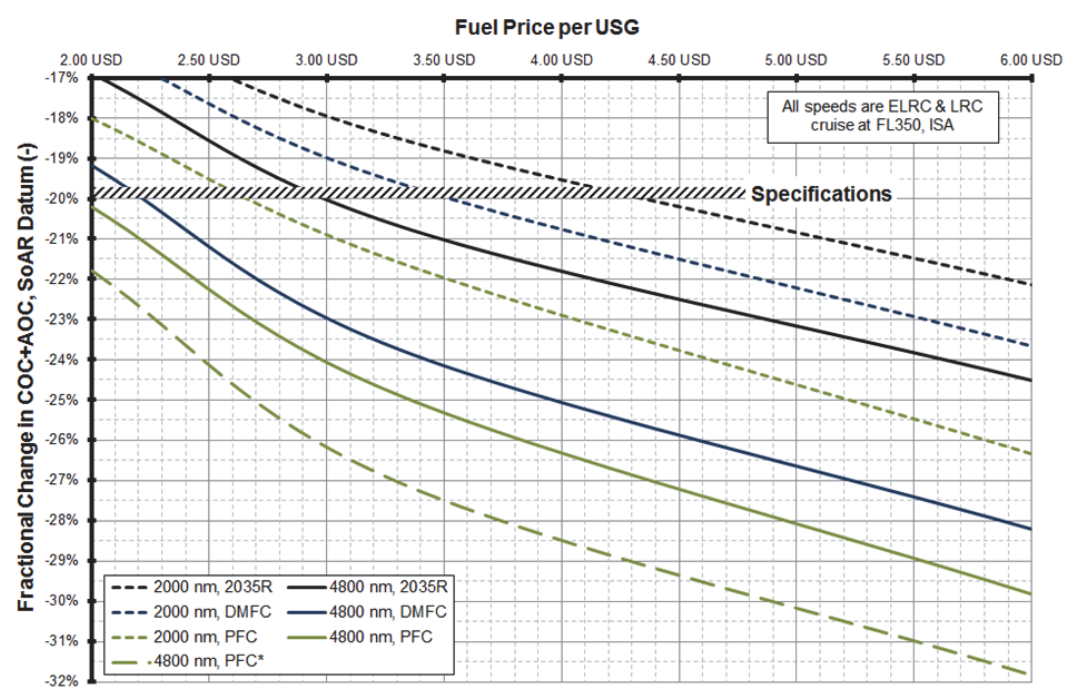

Figure 33. Fractional change in COC+AOC for 2035R, DMFC and PFC assuming variation in fuel price, SoAR taken as datum.

\subsection{INDUSTRIAL ADVISORY BOARD RECOMMENDATIONS AND FUTURE WORK}

On-going critical appraisal as well as recommendations associated with technical and scientific matters were made by a dedicated IAB over the duration of the DisPURSAL Project. Upon completion of the DisPURSAL Project, in consultation with Consortium Partners the IAB itemised a series of key issues as a means of assisting to declare follow-on research activities as published in a publically accessible technology roadmap document ${ }^{(61)}$, which in conjunction with other technical publications is available at the DisPURSAL Project public website ${ }^{(62)}$.

For the DMFC key issues were summarised as:

- Mechanical maturation of a DMFC including power transmission, dynamic load scenarios, and failure cases;

- More detailed 3D RANS-based drag analysis study to further mature the theoretical overall drag reduction potential at flight Reynolds-number, including trimmed aircraft; the IAB considers that quoted block fuel reduction is somewhat small compared to other externally published values without BLI;

- 3D analysis of fan inflow distortions including fan surge for specific key points of the flight envelope (cruise points, take-off/landing, side-wind, at flight Reynolds number respectively);

- More robust analysis of flight mechanics and control aspects regarding yaw stability; yaw stability very likely cannot be achieved for civil aircraft without a vertical tail although the engine are close to the centreline; additional drag has to be taken into account;

- More detailed investigations including load and failure cases are necessary when formulating weights targets; and,

- More detailed aero-acoustic assessment required, including noise shielding effects. 
With its central engine installation, the PFC configuration was viewed as taking full advantage of the increased propulsive efficiency linked to fuselage borne BLI, however, the resulting tri-jet layout was seen to be economically penalised by its three propulsion systems and by the complexity of the central engine installation. For the PFC key issues were summarised as:

- Maturation of potential for block fuel reduction when aircraft design speed is reduced, including impact on aircraft operations;

- More detailed 3D drag analysis study to further mature the theoretical overall drag reduction potential of PFC at flight Reynolds number;

- 3D analysis of fan inflow distortions including fan surge for specific key points of the flight envelope (cruise points, take-off/landing, side-wind, at flight Reynolds number respectively);

- 3D flow analysis of S-duct losses; including core engine inflow distortion aspects to possibly mature results towards 'best scenarios';

- More detailed analysis of design/off-design static and dynamic load cases for sizing of the fuselage-engine-tail section to achieve a more robust mass estimation;

- Further aero-acoustic assessment of the configuration, source characteristics; and,

- Aircraft using more than two engines cause high costs and are less efficient. Therefore novel concepts should be considered, for example, a single aft fan driven by two gas-turbines.

\subsection{Preliminary aerodynamic and aero-acoustic wind-tunnel testing and simulations}

A first step in the aerodynamic analysis is definition of a generic (or easily reconfigured) wind-tunnel model, which has the objective to validate the principles of BLI and WaF. This model should be subsequently designed in detail, manufactured and tested. A suitably scaled modular wind-tunnel fuselage/body model is also envisioned. To arrive at an acceptable relative scale of fuselage/body boundary layer the length of the model will be selected and use will be made of Boundary Layer Control (BLC) in the form of added transition devices and boundary layer suction, where needed. As the influence of angle-of-attack changes the symmetry of the fuselage/body boundary layer the fan blades will encounter azimuthal changes in the inflow angles. The effects of this on the overall drag and the propulsive efficiency could be determined with an external 6-component balance and a Rotating Shaft Balance, respectively. Wings-on and wings-off simulations could quantify this impact and conventional measurement techniques like Particle Image Velocimetry (PIV) could be employed in order to obtain a detailed picture of the flow velocity in terms of magnitude and direction.

Tests using a full-3D model for DMFC and PFC designs in a low-speed wind-tunnel would be mainly aimed at the determination of the aircraft stability and control aspects. Lift, drag and pitching moment would be determined using an external 6-component balance. Since for the PFC design it is anticipated that the wake of the wing would influence propulsion system behavior the effects of flap deflection should be investigated as well. A confirmation high-speed drag measurement for the full configuration assuming all discrete surfaces neutral should also be conducted.

Results from wind-tunnel testing would be used to validate the numerical tools. These tools could then be used to analyse the full aircraft design in all relevant flight conditions. Since both the DMFC and PFC are based upon the positive effects of BLI and WaF, therefore, full unsteady CFD simulations of the baseline design would need to be conducted. Concurrent to these simulations, aero-acoustic modelling and analysis would need to be performed. A methodology for the integrated aerodynamic/aero-acoustic design of the fuselage/body aft shape including the impact 
of the propulsion would then be fashioned, thus providing a means to formulate a set of design rules. Numerical simulations should be supported by an extensive experimental analysis of all investigated concepts.

Finally, all experimental results would be integrated into a consistent aircraft design suite, which would facilitate optimised future concepts for a given design mission.

\subsection{Preliminary power-train and housing structural testing and simulations}

The objective here would be to build a test-rig assembly, suitably scaled and comprising the aft portion of the DMFC and PFC anchoring airframe and integrated distributed propulsion system. Loads could then be applied mechanically to the scaled mock-up through a distribution of external actuators. Issues of appropriate similarity and scaling would need to be addressed. The scale of the mock-up should be determined at a future date, and particular emphasis needs to be placed upon selecting scaling laws not only related to the external environment in which the DMFC and PFC operate, but also the loads and associated response of localised interfacing structures. Attention would need to be paid to avoiding overly small scales where it proves to be very difficult in distributing loads without imposing localised stress concentrations. Two types of tests are envisioned:

1. Geometric Performance Testing - test the performance of the structure and power-train combined without external loads

2. Quasi-static Testing and Methods Tuning - apply expected external loads quasi-statically and test performance. The results would then be compared to the predictions from the model and used to validate the design tools, and if necessary improve upon them.

\subsection{Flying test bed}

To complement computational methods, simulation and ground based physical testing, a suitably scaled manned flying test bed amenable to atmospheric experimentation and appropriate data acquisition would be necessary in order to validate the DMFC and PFC distributed propulsion systems integrated with other annexed technologies that either service the artefact or are standalone systems whose performance is ameliorated by virtue of its presence. When undertaking such a design task and subsequently performing tests, risk reduction could be enhanced and so pave the way forward for understanding what constitutes a well-balanced integration approach of identified key technologies for design and development of the first prototype. Beyond the above mentioned primary goals, such a flying test bed will also permit the testing of other stateof-the-art and emerging technologies suitable for future aeronautical application. Furthermore, the test bed should be of sufficient size in order to permit ease of access for installing and removing new component and sub-system technologies including any associated monitoring and data acquisition equipment.

Flight test campaigns should be performed using an appropriate flight test vehicle in order to measure aero-airframe/aero-propulsion properties, to collect data pertaining to performance, handling qualities and assist in formulating operational procedures. Test plans would comprise functionality tests of the distributed propulsion system, divided into iron bird tests, ground tests and validation tests.

The proposed flying test bed would be designed and operated within a 5-10 year time period where efforts would be expended to increase the maturity of TRLs associated with:

- Validating and ratifying the underlying principles of BLI and WaF including the extent of emissions reduction; 
- Aerodynamic, aero-acoustic and structural integration;

- Mechanical power-train development;

- Propulsion system design;

- Thermal regulation and control strategies;

- Development of annexed technologies; and,

- Initial understanding of an alternative hybrid-electric power transmission approach for the mechanicall-driven fan(s)

Although it is surmised a first flying test bed exemplar would perhaps not be able to investigate aero-airframe and aero-propulsion behavior in the low-to-mid-transonic flow regime in any detail, meaningful performance data of the DMFC and PFC distributed propulsion systems could be measured up until the flow regime where onset of transonic effects begin to arise. More importantly, it is postulated that a 1:3 scale would facilitate a reasonable understanding of distributed propulsion system behavior during low-speed operations, i.e. high angle-of-attack and/ or large side-slip angles and/or cross-wind operations, owing to the Reynolds number in which the test bed aircraft would operate.

\subsection{CONCLUSIONS}

Details about outcomes associated with the recently completed European Commission funded Framework 7 project entitled Distributed Propulsion and Ultra-high By-Pass Rotor Study at Aircraft Level, or, DisPURSAL have been presented. The technical work covered design and integration considerations related to a Distributed Multiple-Fans Concept (DMFC) driven by a limited number of engine cores as well as one unique solution that integrates the fuselage with a single propulsor (dubbed Propulsive-Fuselage Concept, PFC) - both targeting entry-in-service year 2035+. The numerical analysis methods for aerodynamic-airframe interaction include high-end, low-fidelity and interlaced-fidelity methods. Work undertaken for both the DMFC and PFC have provided salient insights when it concerns best practise for nacelle overall sizing, nacelle aerofoil section customisation and localised aircraft body contouring.

A synopsis of outcomes and insights for the DMFC were itemised as:

- For a design range of $4,800 \mathrm{~nm}(8,890 \mathrm{~km})$ with 340 passengers at M0.80 cruise speed, block fuel burn reduction compared to $2035 \mathrm{R}$ (projected 2035 reference aircraft with a conventional configuration) was predicted to be $8 \%$ (nominal case - engineering target within worst-nominalbest interval)

- Assuming the same range, speed and passenger accommodation the block fuel difference to a year 2000 datum A330-300 aircraft (SoAR) was found to be nominally $-37 \%$

- Using methods currently being considered by the International Civil Aviation Organization (ICAO) for upcoming issuance of ICAO Annex 16 Environmental Protection Volume III, nominally $40 \%$ lower $\mathrm{CO}_{2}$-emissions versus the SoAR and $12 \%$ better than the $2035 \mathrm{R}$ were observed; this means the shortfall in $\mathrm{CO}_{2}$-emissions reduction with respect to Strategic Research and Innovation Agenda (SRIA) 2035 is $11 \%$ (2035R is $18 \%$ shortfall)

- There appears to be a good likelihood of meeting the SRIA $2035 \mathrm{NO}_{x}$-emissions and external noise targets

- Assuming a nominal fuel price of USD 3.30 per US gallon up to 24\% lower Cash Operating Costs (COC, fees and charges due to emissions and noise inclusive) versus SoAR was 
predicted, equivalently this was found to be approximately $4 \%$ better than the $2035 \mathrm{R}$

A synopsis of outcomes and insights for the PFC were itemised as:

- For a design range of $4,800 \mathrm{~nm}$ with 340 passengers at M0.80 cruise speed, block fuel burn reduction compared to an appropriately projected-technology, gas-turbine only aircraft utilising a conventional morphology $2035 \mathrm{R}$ was predicted to be $9 \%$ (nominal case)

- Assuming the same range, speed and passenger accommodation the block fuel difference to the SoAR was found to be nominally $-38 \%$

- Using methods in accordance with upcoming ICAO Annex 16 Environmental Protection Volume III, nominally $43 \%$ lower $\mathrm{CO}_{2}$-emissions versus the SoAR and $15 \%$ better than the 2035R were observed; this means the shortfall in $\mathrm{CO}_{2}$-emissions reduction with respect to SRIA 2035 is $8 \%$

- There appears to be a good likelihood of meeting the SRIA 2035 external noise targets; however, realisation of the $\mathrm{NO}_{x}$-emissions target will be a challenge that requires close attention

- Assuming a nominal fuel price of USD 3.30 per US gallon up to 25\% lower COC versus SoAR was predicted, equivalently this was found to be approximately $5 \%$ better than the $2035 \mathrm{R}$

- If the PFC is sized according to an appropriate 'optimal speed matching' philosophy, i.e. Long Range Cruise speed of M0.78 instead of M0.80 (so-called PFC*) the reduction in block fuel and $\mathrm{CO}_{2}$-emissions was found to be at least $11 \%$ compared to the $2035 \mathrm{R} *$ (2035R resized for design cruise of M0 78). Whilst reducing design cruise speed only yields a modest level of incremental advantage, it does provide another avenue in realising emissions and external noise environmental targets.

\section{ACKNOWLEDGEMENTS}

Gratitude is conveyed to the following individuals for their contributions to the analysis and work presented in this technical article:

- André-Denis Bord (ONERA, IAB Representative)

- Olaf Brodersen (DLR, IAB Representative)

- Gerald Carrier, ONERA

- Sascha Kaiser, Bauhaus Luftfahrt

- Mario Kalanja, Airbus Group Innovations (consultant)

- Ulrich Kling, Bauhaus Luftfahrt

- Kay O. Plötner, Bauhaus Luftfahrt

- Clément Pornet, Bauhaus Luftfahrt

- Alexander Prendinger, undergraduate Masters thesis student Bauhaus Luftfahrt

- Michael Schmidt, Bauhaus Luftfahrt (consultant)

- Jörg Sieber (MTU, IAB Representative)

- Johannes Stuhlberger (Airbus Group Corporate Technical Office, IAB Representative)

- Jan van Toor (Airbus Group Corporate Technical Office, IAB Representative)

- Patrick C. Vratny, Bauhaus Luftfahrt

- Guido Wortmann, Bauhaus Luftfahrt (consultant) 
The research leading to results presented in this technical article received funding from the European Commission Seventh Framework Programme (FP7) through the DisPURSAL Project under Grant Agreement No. 323013. Details about the project can be found at URL http://www.dispursal.eu.

\section{REFERENCES}

1. European Commission Flightpath 2050 Europe's Vision for Aviation - Report of the High Level Group on Aviation Research, Luxembourg, 2011.

2. Muller, R. (ASD AeroSpace and Defence Industries Association of Europe) ACARE Goals (AGAPE) Progress Evaluation, Project Final Report Publishable Summary, Support Action Funding Scheme, Proposal No. 205768, European Commission Directorate General for Research and Innovation, June 2010.

3. Advisory Council for Aviation Research and Innovation in Europe (ACARE) Strategic Research and Innovation Agenda (SRIA) - Volume 1, Brussels, 2012.

4. IsIKVEREN, A.T. and Schmidt, M. Future Transport Aircraft Ultra-Low Emissions Technology Options, GARS Workshop Air Transport and Climate Change, Worms, Germany, 4 April 2014.

5. IsIKVEREN, A. Parametric Modeling Techniques in Industrial Conceptual Transport Aircraft Design, 2003 World Aviation Congress, Montreal, SAE Paper 2003-01-3052, September 2003.

6. Advisory Council for Aeronautical Research in Europe (ACARE) European Aeronautics: A Vision for 2020, 2001.

7. Green, J.E. Greener by Design, Innovative Configurations and Advanced Concepts for Future Civil Aircraft Lecture Series 2005-06, von Karman Institute for Fluid Dynamics, Brussels, Belgium, 6-10 June 2005.

8. ToRenBEeK, E. Introductory Overview of Innovative Civil Transport Aircraft Configurations, Innovative Configurations and Advanced Concepts for Future Civil Aircraft Lecture Series 2005-06, von Karman Institute for Fluid Dynamics, 6-10 June, 2005.

9. MCMasters, J.H. A US Perspective on Future Commercial Airliner Design, Innovative Configurations and Advanced Concepts for Future Civil Aircraft Lecture Series 2005-06, von Karman Institute for Fluid Dynamics, Brussels, Belgium, 6-10 June 2005.

10. RodRIGUEZ, D.L. Multidisciplinary optimization method for designing boundary-layer-ingesting inlets, J Aircr, May 2009, 46, pp 883-894.

11. Sмiтн Jr, L.H. Wake ingestion propulsion benefit, J Propulsion and Power, 9, January 1993, pp 74-82.

12. Steiner, H.-J., Seitz, A., Wieczorek, K., Plötner, K.O., Isikveren, A.T. and Hornung, M. Multidisciplinary Design and Feasibility Study of Distributed Propulsion Systems, Paper ICAS 2012-1.7.5, 28th International Congress of the Aeronautical Sciences (ICAS), 2012.

13. Uranga, A., Drela, M., Greitzer, E.M., Titchener, N.A., Lieu, M.K., Siu, N.M., HuangK, A.C., Gatlin, G.M. and HAnnon, J.A. Preliminary Experimental Assessment of the Boundary Layer Ingestion Benefit for the D8 Aircraft, AIAA 2014-0906, AIAA SciTech 52nd Aerospace Sciences Meeting. National Harbor, Maryland, US, 2014.

14. IsIKVEREN, A.T. (Bauhaus Luftfahrt e.V.) Distributed Propulsion and Ultra-high By-pass Rotor Study at Aircraft Level (DisPURSAL), FP7-AAT-2012-RTD-L0, Proposal No. 323013, European Commission Directorate General for Research and Innovation, 14 March 2012.

15. Isikveren, A.T., Seitz, A., Bijewitz, J., Hornung, M., Mirzoyan, A., Isyanov, A., Godard, J.-L., Stückl, S. and van Toor, J. Recent Advances in Airframe-Propulsion Concepts with Distributed Propulsion, 29th Congress of the International Council of the Aeronautical Sciences, St. Petersburg, Russia, 7-12 September, 2014.

16. AERO2k. Global Aviation Emissions Inventories for 2002 and 2025, website: http://aero-net.info/ fileadmin/aeronet_files/links/documents/AERO2K_Global_Aviation_Emissions_Inventories_for_2002_ and_2025.pdf, cited June 2013.

17. Official Airline Guide (OAG) Historical Data, 2012.

18. Schmidt M., Plötner, K.O., Pornet C., Isikveren A.T. and Hornung M. Contributions of Cabin Related and Ground Operation Technologies Towards Flightpath 2050, Paper 301299, 62. Deutscher Luft- und Raumfahrtkongress 2013, Stuttgart, Germany, September 2013.

19. International Civil Aviation Organization (ICAO) ICAO Annex 14 to the Convention on International Civil Aviation Aerodromes, Volume 1, Aerodrome Design and Operations, 4th ed, July 2004. 
20. Lee, D.-S., Periaux, J., Gonzalez, L.F., Srinivas, K. and Onate, E. Active Flow Control Bump Design Using Hybrid Nash-Game Coupled to Evolutionary Algorithms, Proceedings of 5th European Conference on Computational Fluid Dynamics, Lisbon, Portugal, 2010.

21. ReneauX, J. Overview on Drag Reduction Technologies for Civil Transport Aircraft, European Congress on Computational Methods in Applied Sciences and Engineering, ECCOMAS 2004.

22. Walsh, M. Riblets, AIAA Viscous Flow Drag Reduction, 123, 1990, pp 203-261.

23. CAmpBell, F. Structural Composite Materials, ASM International, 2010.

24. SiochI, M. Enabling Technologies for Aerospace Missions - The Case for Nanotubes, FEL Users/Laser Processing Consortium Meeting, Jefferson Lab, 11 March, 2004.

25. KéBraU, S. Fracture Mechanics Analysis of Novel Non-Rectangular Stiffening Concepts in Comparison to Conventional Rectangular Stiffened Fuselage Structures, CEAS 2007, Berlin, Germany, 2007.

26. Fuinn, B. Improving Adhesive Bonding of Composites through Surface Characterization, The Joint Advanced Materials and Structures Center of Excellence, 2009.

27. Pornet, C., Gologan, C., Vratny, P.C., Seitz, A., Schmitz, O., Isikveren, A.T. and Hornung, M. Methodology for sizing and performance assessment of hybrid energy aircraft, $J$ Aircraft, 52, (1), pp 341-352, DOI 10.2514/1.C032716.

28. Mistree, F., Lewis, K. and Stonis, L. Selection in the Conceptual Design of Aircraft, AIAA-94-4382-CP, 32nd AIAA Aerospace Sciences Meeting and Exhibit, Reno, Nevada, US, 10-13 January, 1994.

29. Seitz, A. and Gologan, C. Parametric Design Studies for Propulsive Fuselage Aircraft Concepts, CEAS Aeronaut J, 6, (1), pp 69-82, DOI: 10.1007/s13272-014-0130-3.

30. Cambier, L., Heib, S. and Plot, S. The Onera elsA CFD software: input from research and feedback from industry, Mechanics and Industry J, April 2013, 14, (3), pp 159-174.

31. Atinault, O., Carrier, G., Grenon, R., Verbecke, C. and Viscat, P. Numerical and Experimental Aerodynamic Investigations of Boundary Layer Ingestion for Improving Propulsion Efficiency of Future Air Transport, AIAA 2013-2406, 31st AIAA Applied Aerodynamics Conference, San Diego, California, US, 2013.

32. KuRZKe, J. GasTurb 11, compiled with Delphi 2007 on 27 January, 2010.

33. KuRzKe, J. GasTurb 12. Design and Off-Design Performance of Gas Turbines, GasTurb GmbH, 2013.

34. Seitz, A., BiJewitz, J., Kaiser, S. and Wortmann, G. Conceptual Investigation Of A Propulsive Fuselage Aircraft Layout, Aircraft Engineering and Aerospace Technology: An International Journal, 86, (6), pp 464-472, DOI: 10.1108/AEAT-06-2014-0079.

35. BiJewitz, J. and Seitz, A., Hornung M. Multi-Disciplinary Design Investigation of Propulsive Fuselage Aircraft Concepts, 4th EASN Association International Workshop on Flight Physics and Aircraft Design, Aachen, Germany, October 27-29, 2014.

36. Frota, J. (AIRBUS SAS) New Aircraft Concepts Research (NACRe), FP6-2003-AERO-1, Proposal No. 516068, European Commission Directorate General for Research and Innovation, 2005.

37. GodARD, J-L., Semi-Buried Engine Installation: the Nacre Project Experience, 27th International Congress of the Aeronautical Sciences, 2010.

38. Tong, M., Jones, S. and Haller, W. Engine Conceptual Design Studies for a Hybrid Wing Body Aircraft, Proceedings of ASME Turbo Expo 2009, Orlando, US, 2009.

39. The Boeing Co. Jet Transport Performance Methods, Rept. D6-1420, 7th ed, Flight Operations Engineering, Boeing Commercial Airplanes. Seattle, Washington, US, 1989.

40. Pan-Am. Pan-Am Flight Operations Manual, rev. 228. New York, US, 1988.

41. International Civil Aviation Organization (ICAO) ICAO Annex 16 Environmental Protection Vol.I Aircraft Noise, 6th ed, 2011.

42. International Civil Aviation Organization (ICAO) ICAO Annex 16 Environmental Protection Vol.II Aircraft Engine Emission, 3rd ed, 2008.

43. International Civil Aviation Organization (ICAO) Environmental Protection, Annex 16, Volume III, $\mathrm{CO}_{2}$ Certification Requirement, text of proposed new Annex 16, not issued.

44. WulfF, A. and Hourmouziadis, J. A Universal Combustor Model for the Prediction of Aeroengine Pollutant Emissions, ISABE 99-7162, 1999.

45. Dickson, N. Aircraft Noise Technology and International Noise Standards, Environment Branch, ICAO Air Transport Bureau. 2014.

46. Bradley, M., Droney, C., Paisley, D., Roth, B., Gowda, S. and Kirby, M. NASA N+3 Subsonic Ultra Green Aircraft Research. SUGAR, Final Review, April 2010.

47. MongeAu, L. Noise Technology Goals, Summary of the conclusions of the second CAEP Noise Technology 
Independent Expert Panel (IEP2), ICAO Symposium on aviation and climate change, 'Destination Green', May 2013.

48. Noise Certification Database NoisedB, http://www.noisedb.stac.aviation-civile.gouv.fr, accessed December 2014.

49. Istikveren, A.T., Goritschnig, G. and Noel, M. 'Productivity Metrics for Business and Regional Aircraft', Paper 2003-01-3063, 2003 SAE World Aviation Congress, Montréal, Québec, Canada, September 2003.

50. IsIKVEREN, A.T. 'Section 3: Marketing Requirements and Objectives', Industrial Transport Aircraft Design - A Compendium of Principles, Practices and Technqiues, École Polytechnique de Montréal, Dept of Mechanical Engineering, Montréal, Québec, Canada, 2005.

51. Association of European Airlines Operating Economy of AEA Airlines, 2007.

52. Transport Studies Group Aircraft Crewing - Marginal Delay Costs. London, United Kingdom, 2008.

53. International Air Transport Association (IATA) Airport and Air Navigation Charges Manual. Montreal/ Geneva, 2001.

54. Plötner, K.O., Wesseler, P. and Phleps, P. Identification of key aircraft and operational parameters affecting airport charges. Int J Aviation Management, 2013, 2, (1/2), pp 91-115.

55. Khan, K. and Houston, G. Design optimization using life cycle cost analysis for low operating costs, Bombardier Aerospace Downsview. Ontario, Canada, 2000.

56. RuPP, O.C. Vorhersage von Instandhaltungskosten bei der Auslegung ziviler Strahltriebwerke, Dissertation, Technical University of Munich. Munich, Germany, 2000.

57. International Civil Aviation Organization (ICAO) Engine Exhaust Emissions Databank, Doc 9646AN/943, 2014.

58. Plötner, K., Wesseler, P. and Phleps, P. Identification of Key Aircraft Parameters Related to Airport Charge Quantification, 15th Air Transport Research Society (ATRS) World Conference. Sydney, Australia, 2011.

59. United States Energy Information Administration, http://www.eia.gov/dnav/pet/hist/LeafHandler. ashx?n=PET\&s=EER EPJK PF4 RGC DPG\&f=D, accessed September 2014.

60. Air Transport Association of Āmerica (ATA). ATA Specification 100 - Specification for Manufacturers' Technical Data, Revision No. 37, 1999.

61. Stückl, S., Bijewitz, J., Seitz, A., Isikveren, A.T., Godard, J.-L., Mirzoyan, A., Bord, A.-D., Brodersen, O., Sieber, J., Stuhlberger, J. and van Toor, J. DisPURSAL D1.2 - Report on the Technology Roadmap for 2035, Report D1.2, DisPURSAL Project, Grant Agreement No. 323013, European Commission Directorate General for Research and Innovation, 31 January 2015.

62. DisPURSAL Project public website, http://www.dispursal.eu/, accessed April 2015. 